GJBX $--420-81$

DE82 005550

\title{
TRAINING MANUAL FOR WATER AND SEDIMENT GEOCHEMICAL RECONNAISSANCE
}

SAVANNAH RIVER LABORATORY NATIONAL URANIUM RESOURCE EVALUATION PROGRAM

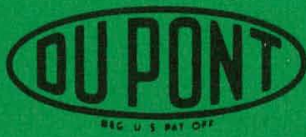

E. I. du Pont de Nemours \& Co. (Inc.) Savannah River Laboratory Aiken, South Carolina 29801 


\section{DISCLAIMER}

This report was prepared as an account of work sponsored by an agency of the United States Government. Neither the United States Government nor any agency Thereof, nor any of their employees, makes any warranty, express or implied, or assumes any legal liability or responsibility for the accuracy, completeness, or usefulness of any information, apparatus, product, or process disclosed, or represents that its use would not infringe privately owned rights. Reference herein to any specific commercial product, process, or service by trade name, trademark, manufacturer, or otherwise does not necessarily constitute or imply its endorsement, recommendation, or favoring by the United States Government or any agency thereof. The views and opinions of authors expressed herein do not necessarily state or reflect those of the United States Government or any agency thereof. 


\section{DISCLAIMER}

Portions of this document may be illegible in electronic image products. Images are produced from the best available original document. 



\title{
TRAINING MANUAL FOR WATER AND SEDIMENT GEOCHEMICAL RECONNAISSANCE
}

\author{
SAVANNAH RIVER LABORATORY \\ NATIONAL URANIUM RESOURCE EVALUATION PROGRAM
}

by

V. Price and P. L. Jones

Approved by:

H. L. Hyder, Research Manager Analytical Chemistry Division - DISCLAIMER This book was prepared os an account of work sponsored by an agency of the United States Government. Neither the United States Government nor any ogency thereor, nor any of their employees, makes any warranty, express ar implied, or assumes any legal liability or responsibility for the accuracy. completeness, ar usefulness of any information, apparatus. product. or process disclosed. Or

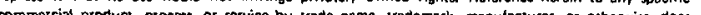

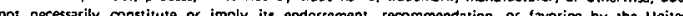
Seles Gover ment or an ore

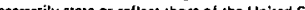

Publication Date: March 1979

Issued by E. I. du Pont de Nemours \& Co. (Inc.) Savannah River Laboratory Aiken, South Carolina 29801

PREPARED FOR THE U. S. DEPARTMENT OF ENERGY UNDER CONTRACT DE-AC09-76SR00001 
This manual is intended to direct and coordinate field operations, site selection, sample collection, and information coding for the Savannah River Laboratory (SRL) contribution to the National Uranium Resource Evaluation (NURE) program. The manual provides technical direction and public relations information for field sampling teams.

The NURE program was begun in 1973 to evaluate domestic liranium resnurces in the rontinental llnited St.ates and th identify areas favorable for commercial exploration in response to the rapidly increasing national demand for uranium. The Grand Junction Office (GJO) of the Department of Energy (DOE) is responsible for administering and coordinating NURE program efforts. Inputs to the NURE program come from DOE prime contractors, DOE-sponsored research and development, the uranium industry, U.S. Geological Survey, U.S. Bureau of Mines, other government agencies, and independent sources.

SRL has accepted responsibility for geochemical reconnaissance surveys in portions of thirty-seven states. Oak Ridge Gaseous Diffusion Plant (ORGDP) and Los Alamos Scientific Laboratory (LASL) have accepted responsibility for similar reconnaissance surveys in the rest of the continental United States including Alaska. Rondix Finid Fnginnoring Conrpnrition (BFFC) is the prime GiIn contractor for the uranium resource assessment. 
I. GENERAL INFORMATION

The NURE Program 5

Contractor's Obligation 8

Field Supervisor's Responsibilities 8

SRL Instruction Program for NURE Samplers 9

Training Sessions 9

Map Reading 11

Qualification 11

Importance of Adhering to Sampling Instructions 11

Meeting the Public 15

Technical Basis for Sample Collection Methods 17

Processing of Water Samples 22

Genera1 22

Filtration 22

Extraction with Ion Exchange Resin 22

Sampling for Dissolved Helium 27

Processing of Sediment Samples 28

General 28

Field-Sieving 28

\section{FIELD OPERATIONS}

A. Logistics and Public Relations 31

B. Sampling Site Selection and Site Operations 35

C. Return of Samples to SRL 35

D. Quality Control 38

APRENDIX $\Lambda$ : Site Selection Procedure 41

APPENDIX B: Sample Collection 45

APPENDIX C: Standard Coding Instructions 79

APPENDIX D; Sampling Kit Inventory Forms 97 


\section{LIST OF · FIGURES}

1. Physiographic Province Map of the United States Showing SRL Areas of Responsibility 7

2. NURE Public Relations Brochure 16

3. Probability of Locating an Anomaly versus Grid Size 20

4. An Heterogenous Area Requiring Supplemental Sampling 21

5. Coefficient of Variation versus Mean Uranium Content In Ground Water 27

6. Invoice to Accompany Samples Sent to SRL 38

7. Sample Transfer History (Form A) 39

8. Sample Transfer History (Form B) 40

\section{LIST OF TABLES}

1. Typical Training Session Schedule 10

2. Review Questions for Training Session 12

3. Comparison of Ion Exchange Conditions 24

4. Elements Removed from Ground Water Samples by İon Exchange Concentration 25

5. Reproducibility of Uranium Analyses by Resin Concentration 26 


\section{GENERAL INFORMATION}

\section{THE NURE PROGRAM}

The Department of Energy (DOE) was created by Congress in October 1977 to consolidate various energy agencies and programs funded by the Federal Government. DOE is conducting or funding research and development work in a number of fields including solar energy, wind energy, geothermal energy, nuclear fission, breeder reactors (including alternate breeder fuels), and nuclear fusion. DOE is also evaluating the United States reserves of fuels for energy sources and methods of containing or disposing of their wastes.

The National Uranium Resource Evaluation (NURE) program was established in the spring of 1973 by the U.S. Atomic Energy Commission, continued under the Energy Research and Development Administration, and is now administered by the DOE. The purpose of the program is to evaluate domestic uranium resources and to identify favorable areas for commercial exploration. The NURE program is expected to increase the activity of commercial exploration for uranium in the United States.

The principal objectives of the NURE program are:

- To prepare, based on existing data, a preliminary evaluation of domestic uranium resources and favorable exploration areas.

- To complete a more comprehensive assessment of the uranium reserves of the Ini.ted States as rapidly as posible.

- To identify areas favorable for uranium resources.

- To develop new and improved technologies for resource assessments.

The Grand Junctinn (Colorado) Office of the Department of Energy. (DOE-GJO) has completed the first objective* and is responsible for administering and coordinating efforts to meet the other objectives. Inputs to the NURE program come from DOE prime contractors, DOE-sponsored research and development, the uranium industry, U.S. Geological Survey, U.S. Bureau of Mines, other government agencies, and independent sources.

* See Documerit GJO-111(76). Available from DOE-GJ, P.0. Box 2567, Grand Junction, CO 81501 . 
The NURE program consists of 5 parts:

1. Hydrogeochemical and Stream Sediment Reconnaissance Survey

2. Aerial Radiometric Survey

3. Surface Geologic Investigations

4. Drilling for Geologic Information

5. Geophysical Technology Development

The Savannah River Laboratory (SRL), Oak Ridge Gaseuus Diffusion Plant (ORGDP), Los Alamos Sccientific Lahnratory (LASL), axe responsihle for hrdrogoochomical and 3tream sediment reconnaissancc of the United States (F1gure 1). SRL is responsible for areas of widely varying geology, topography, and climate. The objestive of this portion of lie pruyram is to accomplish a systematic determination of the distribution of uranium in surface and underground water and in stream sediments in the continental United States, including Alaska. The significance of the distribution of uranium in natural waters and stream sediments will be assessed as an indicator of areas favorable for the discovery of uranium deposits.

To simplify reporting, areas of responsibility are coincident with $1^{\circ} \times 2^{\circ}$ National Topographic Map Series (NTMS) quadrangle boundaries.

Before entering the reconnaissance phase of the NURE program, SRL conducted an extensive development program, * Techniques were developed to obtain greal precision and accuracy for analyzing uranium concentrutions from less than 0.020 parts per billion (ppb) in natural waters to greater than 1000 parts per million (ppm) in rocks and sediments. Field orientation studies were conducted in a variety of geologic and geographic sett.ings to develop technical and operational experience applicable to the reconnaissance prngram. Variability of sampling techniques was studied to ensure that a representative sample can be taken at a given site. Sampling instructions in this manual are derived in part from SRI, experience and in part from standard geochemical sampling practices.

Geocheinical sunples collected systemalically over broàd areas will constitute a significant national resource. SRL will analyze samples for uranium and geochemically related elements. Portions of samples collected in the NURE program will be archived for future study. Every effort will be made to preserve the integrity of these archived samples for possible additional analyses in the future.

* Described in a series of quarterly reports beginning in 1975; designated as DPST-(yr)-138-(no.). Available from DOE-GJ, P.O. Box 2567, Grand Junction, CO 81501. 


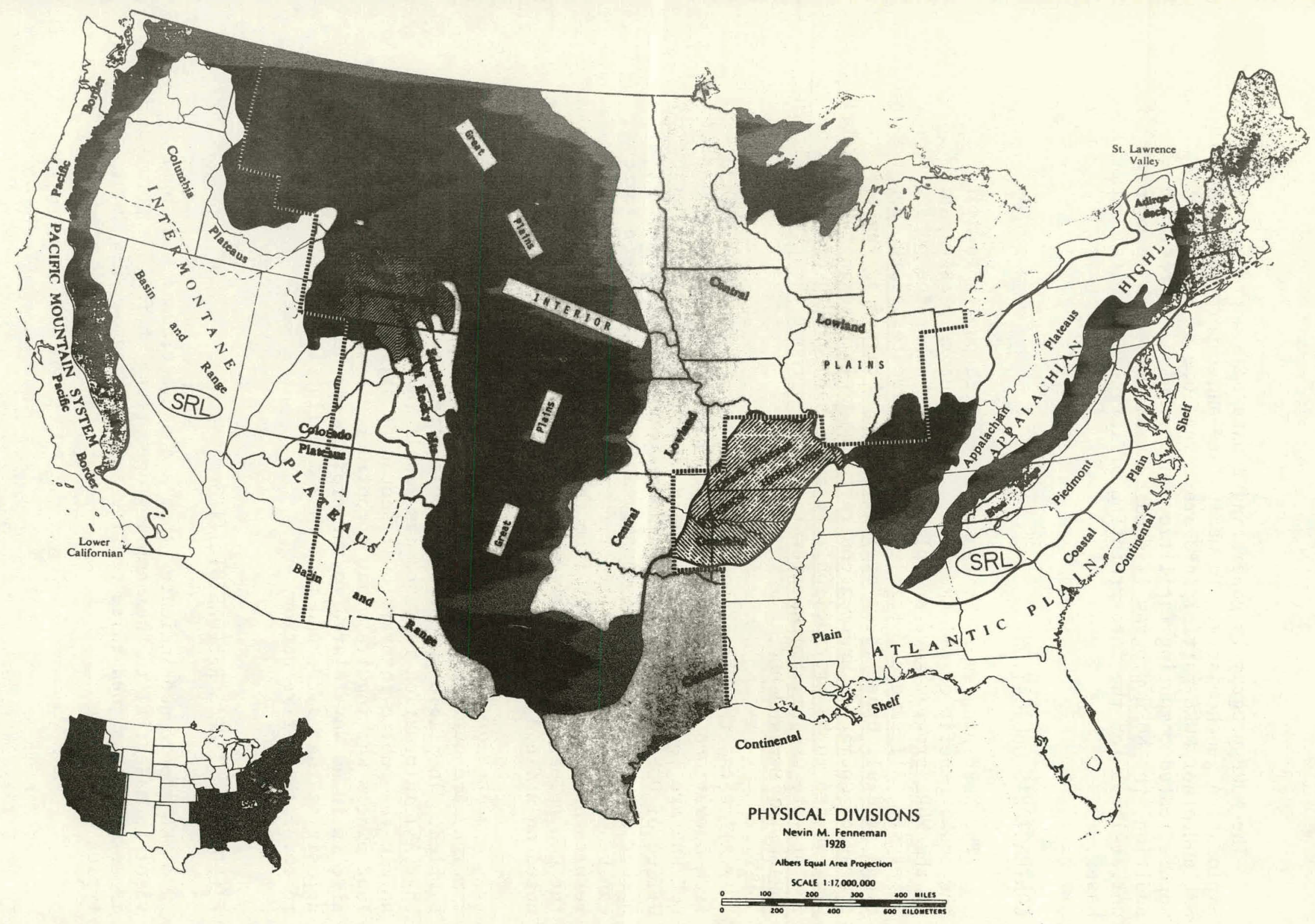

FIGURE 1. Physiographic Province Map of the United States Showing SRL Areas of Responsibility 
The NURE program is generating a data base unprecedented in exploration geochemistry. To manipulate and interpret these data, SRL and other NURE participants are using some of the most sophisticated computing facilities in the United States. In addition, the NURE program is funding basic research in several universities for the interpretation of large geochemical data bases.

\section{CONTRACTOR'S OBLIGATION}

The NURE program is being conducted with public funds for the equal benefit of all Americans. Contractors participating in the NURE program have an ohligation to protect the public interest. All samplos, sample splils, duplicates, data, observations, and all other items of information obtained during the course of nperation under a conlracl to participate in the SRL/NURE program are to be provided only to SRL. None are to be retained for private use or communicated to others without the prior written consent of SRL and DOE.

A11 data, theories, speculations, and conclusions derived from operations under an SRL/NURE contract are the property of DOE and are to be communicated only to SRL. The Grand Junction Office of DOE will release data and reports simultaneously at a number of sites across the country as rapidly as these releases can be processed. SRL will notify individual land owners of results obtained on samples from their property at the time of the DOE release, if their request for such information has been noted on a field data form.

A number of individuals and companies, both domestic and foreign, are currently exploring for uranium in the areas being sampled. The field supervisor should stress to all personnel that ANY information released may result in proprietary benefit not in the public interest. It should bc stressed to individual 1 and owners who inquire, lliat a contractor's presence at a given site is in no way related to the presence or absence of a uranium lepusit at that site, and that this sampling is part of a program to cover the entire nation.

\section{FIELD SUPERVISOR'S RESPONSIBILITIES}

SRL experience indicates that a conscientious field supervisor is essential to the sampling operation. A field supervisor is normally assigned lhree to five sampling teams. His duties typically include: 
1. Planning the work of each team.

2. Contacting land owners, public officials, and news media, and arranging for accommodations before teams arrive in an area.

3. Reviewing team performance. Is productivity adequate? Are field forms neat and complete? Are meter calibrations being maintained? Are all grid units being sampled when possible?

4. Verifying some percentage of site locations. Doing "catchup" sampling when sites are skipped or samples are damaged.

5. Preparing samples for transfer to SRL.

6. Maintaining liaison with SRL - discussing sampling plans, status of field supplies, and any problems which should be called to SRL's attention.

SRL INSTRUCTION PROGRAM FOR NURE SAMPLERS

Training Sessions

It is assumed that samplers are familiar with geologic field methods and principles of sedimentation and stratigraphy. These requirements are implicit in bidding specifications for the SRLNURE sampling program.

The purpose of the SRL-NURE training session is twofold: (1) to acquaint samplers with the objectives of the NURE geochemical reconnaissance; and (2) to provide specific instructions on sampling technique and operating equipment. The sampler will encounter many field situations that will requi re him to make a professional judgment in the context of program objectives. Checklists and detailed instructions are provided to help the sampler develop efficient techniques. Short-cuts or abridgment of procedures in this manual are not approved.

An outline of a typical training session schedule is given in Table 1. Copies of this manual will be distributed to each subcontractor prior to the training session. Each sampler should have studied this manual thoroughly before attending the training session. 


\section{TABLE 1}

Typical Training Session Schedule

Evening Before 1st Day

Orientation and special training for field supervisors

$\underline{1 \text { st Day }}$

Morning

Backgrnund and uljectives of NURE program

Introduction to sampling equipment

Afternoon

Demonstration of sampling techniques

Instruction on completing field forms

2nd Day

Morning

Orienteering

Afternoon

Onsite surface sampling

3rd Day

Mnrning

Onsite ground water sampling

Afternoon

l'esting and review

Issuing NURE ID cards/issuing equipment 
Map Reading

Map reading is fundamental to every field geologic endeavor. It is assumed that samplers are competent in this area. During the training session, each trainee will be required to demonstrate proficiency by doing one or more of the following:

1. Construct a topographic profile with a stated vertical exaggeration.

2. Calculate the gradient of a stream.

3. Describe locations using:

a. bearing and distance from a reference point

b. latitude and longitude

c. township system

d. road $\log$ from a reference point

4. Locate a point in the field from a written description of the location.

5. Locate a point in the field by triangulation from prominent topographical features.

\section{Qualification}

A short-answer test will be administered at the close of the training session. The purpose of the test is to allow trainees to review major points of the training session and to reveal any areas of misunderstanding.

nnly personnel who successfully complete the training session and pass the test will be issued USDOE identification cards and sampling equipment.

Example review questions are given in Table 2 of this manual.

\section{IMPORTANCE OF ADHERING TO SAMPLING INSTRUCTIONS}

In a thesis or research project, each sample can be given individual attention. The NURE geochemical reconnaissance is not a pure research project, but rather is more of a production progran. Sample receiving personnel at SRL may process several thousand samples per week during the peak of the field season. Each sample is visually inspected to see that labels are clear, packages are unbroken, and that each package contains a field data form and map locality. Key-punched field data forms are run through a computer scrub program which checks for missing, improper, or incompatible 


\section{TABLE 2}

Review Questions for Training Session

Q. Is it permissible to choose an alternate sampling site if a preselected site is unsuitable?

A. Yes:

Q. How often should the $\mathrm{pH}$ meter be calibrated?

A. At least once euch morning. If results look "funny" in the field, the pH meter should be recalibrated and then the sample retested.

Q. Why is it necessary to avoid sampling treated water?

A. Some types of water treatments (e.g., flocculation, charcoal filtration, softening, etc.) can remove uranium and other ions or add materials to the sample that would make geochemical interpretation of the results impossible.

Q. Why is contamination so critical in water samples?

A. Because the analysis is carried out to the point of pp billinn and pp trillion and the slightest contamination could seriously affect these results.

Q. The conductivity of a sample reads 700 micromhos per centimeter. How many milliliters of water should be ion exchanged with one resin capsule?

A. $500 \mathrm{~mL}$ of water.

Q. What do you do if you cannot "red-line" the conductivity meter?

A. Change the batteries. If this does not work, consult your supervisor, do not take any more snmples until the meter i.s replaced with a good one.

Q. Why are you not allowed to take a sample from a well less than one year old?

A. Caving from the side of the well and new metal in the form of pumps and pipes may still affect the water. Also grease can seriously affect the sample. After about a year, all this is settled down. 


\section{TABLE 2 (Cont'd)}

Q. The conductivity of a sample reads 450 micromhos per centimeter. How many milliliters of water should be ion exchanged with one resin capsule?

A. $1000 \mathrm{~mL}$ of sample.

Q. You have added 20 drops of sulfuric acid to 50 milliliters of water containing indicator solution. The color has not begun to change. What do you do?

A. Drop back to 10 or $20 \mathrm{~mL}$ of water and try again.

Q. The conductivity of a sample reads 1100 micromhos per centimeter. How many milliliters of water should be ion exchanged with one resin capsule?

A. $200 \mathrm{~mL}$ of water.

Q. What is the normal range of $\mathrm{pH}$ for typical well water?

A. $\approx 5$ to $9 \mathrm{pH}$.

Q. Must $\mathrm{pH}$ electrodes be stored wet?

A. Yes.

Q. You are sampling in a limestone area. Twenty drops of acid are required to titrate $50 \mathrm{~mL}$ of the sample. The $\mathrm{pH}$ of the sample reads 4.1. What do you do?

A. Recalibrate the $\mathrm{pH}$ meter and test it again. The water sample is obviously fairly alkaline and something went wrong with the $\mathrm{pH}$ measurement.

2. Two samples are received with the same site identifier. Will the subcontractur be paid for two samples?

A. No. Both samples are questionable. If the discrepancy is not easily resolved at SRL, the sites must be resampled.

Q. Where is a slash (/) allowed on the field form?

A. (1) When depth of well is unknown.

(2) When age of well is unknown.

(3) Between the names in the address of town, name of person, etc. 
TABLE 2 (Cont'd)

Q. You are sampling and your $\mathrm{pH}$ meter becomes inoperable. What do you do?

A. Cease taking samples until it is replaced and operable again. (Try using your spare pH probe.).

Q. Why is it necessary to sample on the upstream side of a road?

A. Because contamination from the road is more likely on the downstream side.

Q. How many subsamples (or composites) of sediment must be taken at a stream site? What distance of stream channel must be sampled?

A. At least 5 subsamples should be taken from the central portion of the stream along at least 100 feet or more of stream channel:

Q. If no roads cross a sampling grid unit, what do you do?

A. It may only be left unsampled if all surrounding grid units are sampled. Otherwise, you will have ton take an off-theroad sample.

Q. Why is it poor practice to sample only along main roads?

A. Many roads will follow only one of many geolngj.r. units in an area because of weathering or other characteriatiss of that unit. Thus, rost sampling may not give geologically representative coverage.

Q. Which of the following may indicate an error?

a. Conductivity $=1300, \mathrm{nH}=7.2$

b. Conductivity $=25, \mathrm{pH}=6.9$

c. Conductivity $=25$, Alkalinity Titration Requires 25 Drops

d. Conductivity $=100, \mathrm{pH}=10.4$

e. Alkalinity Titration Requires 20 Drops, pH Reads 4.2

f. Alkalinity Titration Requires 2 Drops, $\mathrm{pH}=5.4$

g. Alkalinity Titration Requires 20 Drops, $\mathrm{pH}=8.1$

A. Answers are $c, d$, and e. 
information and other errors. Anything that slows the sample check-in process increases the effective cost of the SRL sampling program and delays payment to the sampling subcontractor. Significant error rates can be grounds for cancelling contracts or at least requiring retraining of personnel who contribute to such error rates.

SRL conducts quality assurance (QA) documentation for all phases of the current sampling and analysis program. OA for field sampling begins with the computer scrub program to detect inconsistencies in the field data. Letters are sent to a significant portion of property owners. Finally, SRL personnel and independent subcontractors revisit selected sites to verify locations and site descriptions. The vast majority of field QA checks indicate careful and accurate work. Unfortunately, some checks have indicated substandard work and resulted in cancellation of sampling contracts and resampling of questionable areas.

MEETING THE PUBLIC

Any survey where door-to-door contacts are made to obtain permission to collect samples will create a great deal of public interest. SRL experience indicates that a significant number of land owners contacted do not fully understand the sampler's purpose, even though the owners may cooperate. If the owners are suspicious about your motives, they typically telephone someone they know at the county health department or sheriff's office. A reassuring word from some official that the sampling is a legitimate effort is normally sufficient to allay any suspicions. However, if you should cause a public official the embarrassment of not being able to respond knowingly to a citizen's inquiry, you may be very sorry. NURE samplers have been detained and questioned by public safety officers. Such delays are time consuming, embarrassing, and expensive.

A public relations brochure (Figure 2) has been prepared for distribution to land owners and public officials. Inquiries from the local press should be welcomed because newspaper, radio, and TV coverage can expedite sampling. A standard release has been approved for distribution to the news media.

Any requests for additional coverage or information should be referred to the USDOE Dffice of Public Affairs at the Savannah River Operations Office for approval. Release of unauthorized information could result in reduction or cancellation of sampling contracts. 


\section{National Uranium Resource Evaluation}

In determining the future energy policy of the United States, nur Foderal yoverhment is studying many natural energy sources. One of thase enorgy sourres is uranium. Tó determine how muoh of this notural resource is potentially available in tle United 3laies, the U.S. Department of Energy (DOE) is conducting the National Uranium Re. source Evaluation (NURE) Program.

In this program, many types of surveys must be made to determine if an area has potential uranium resources; for example, water samples and stream sediment samples must be collected and analyzed. Because the Department of Energy wants to survey the whole United States as efficiently and timely as possible, universities, private companies, and state agencies have been contracted to assist in conducting these surveys.

\section{Program Objective}

The objective of the program is to complete a systematic survey of the nation's surfaoo woters, ground waters, and stream sediments for uranium. This systematic sampling is expected to provide evidence of uranium occurrences not gènerally known

Uranium is ofteli scattered in varying concentrations in rocks surrounding ore deposits. Ground water and streams running through these areas can move some of the uranium outward and down. stream from these ore deposits. By randomly collecting and analyzing semples of ground water, stream sediment, and soil from thousands of sites throughout the nation, maps can be plotted and areos ideitilifloo jo likely to contain uranium ore deposits. The completed maps will be plạced in files onen to tho public.

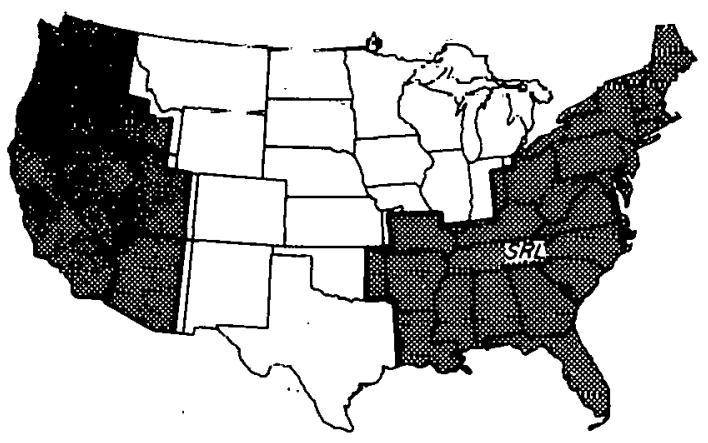

- Location of Sevenneh River Operations Office. $\vdots$

\section{Your Assistance Needed}

A member of a survey team may visit yuur iviuperty. requesting permissiun to collect soil. sediment, rocks, ui water samples. This purson will carry a DOE identification card and will be authorized by the Federal government. You can halp contribute to a very important national effort by giving this person permission to obtain samples.

Questions regarding the NURE sampling program in the areas shaded above should be directed to:

lamóo D. Hellner

Savannah River Laboratory

Aikon, OC 298u1

Tolephone (803) 725-2068

\section{FIGURE 2, NURE Public Relations Brochure}


In general, local public relations is the responsibility of the sampling field supervisor. Public acceptance is essential to the success of a sampling program. To this end, all sampling personnel should conduct themselves in a professional and businesslike manner. Experience indicates that dress and personal appearance are sometimes factors in public acceptance.

\section{TECHNICAL BASIS FOR SAMPLE COLLECTION METHODS}

The instructions for sampling given in this manual are based on standard geochemical practice and on SRL development studies. The goal of any geochemical exploration program is to determine the chemical composition of natural samples and to relate this composition to the presence or absence of an economic mineral deposit. In most cases, one looks for anomalously high concentrations of the particular ore element or mineral of interest and anticipates finding an economic deposit near the anomalous samples. In other cases, however, anomaly recognition may be a subtle art and depend on a more complete geochemical characterization of the samples. Elemental ratios, pathfinder elements, the mineralogical make-up of the sample, and understanding of regional geology/ geochemistry may be very important to interpretation.

A sampling grid is adhered to at all times. The sampler should attempt to sample at sites depicted on the grid without regard for factors which might bias statistical data treatments or invalidate the random sample collection method (e.g., abnormal radioactivity or geological prejudice about uranium favorability criteria). The sampling is not strictly random, but rigidly systematic with a random starting point. The NURE hydrogeochemical and stream sediment reconnaissance (HSSR) is a regional survey and is not intended to yield the same sort of information that a survey at the individual deposit level would yield. Geologic information about the site is taken, but as part of a site description, nol as a site selection criterion.

In addition to randomly gridded samples, a certain number of supplemental samples will be collected as the sampler deems desirable. These samples will be chosen: (1) to represent geologic units which have little areal extent, (2) where radioactivity readings are high, and (3) where, in the sampler's judgment, uranium favorability criteria are met. These supplemental samples will be given special treatment during data interpretation. 
One basic consideration in design of a regional sampling program is to choose a sample medium (soil, rock, plants, stream sediment, stream water, ground water, airborne particulates, etc.) which can be collected more or less uniformly over broad areas. In some cases, it may be necessary to neglect a locally desirable sampling medium in order to get uniform regional coverage. For example, botanical samples will not be taken in the SRL-NURE reconnaissance although these samples may be useful in restricted areas. Follow-up or anomaly verification field studies may be conducted in selected small areas defined in the reconnaissance program. In these studies, careful consideration is given to local. geologic and physiographic factors, and tecllnically conservative and uprlmized sampling programs lallored for each spceific area may be undertaken.

Tn detect a uinlum ore deposit, samples from an anomalous zone or "halo" around the ore deposit must be collected, analyzed, and interpreted. Both primary and secondary halos are found in nature. A primary halo is a zone of weak mineralization produced in the host rocks at the time of ore deposit formation. A secondary halo results from the weathering and redistribution of the ore body and primary halo. A secondary halo may be called a dispersion train when elongated as in a stream.

There is no simple a priori way to determine the size or length of a geochemical halo. Thus, an element of chance exists in designing any sampling grid. Fortunately, uranium and other ore deposits seldom occur singly. An area in which geulogic conditions are favorahle for the accumillation of ore mdy contain a number of sub-economic and economic concentrations yielding many targets for exploration sampling. As the number of targets increases, the probability that sampling will fail to intersect an anomaly decreases.

SRL studies have indicated that adjacent samples takon from a halo arca may not yield anomalous values for the same elements or measurements. For example, a sodiment sample may be anomalous cven when a water sample from the same grid unit is not, or vice versa. Similarly, a ground water sample may contain anomalous holium and background uranium, while a nearby sample contains anomalous uranium and background helium.

. Because SRL's analytical and interpretive techniques are somewhat unique, much of the published geochemical literature cannot be directly applied to program design. For example, one study in the literature, involving known uranium deposits in the Catskill Formation of Pennsylvania, concluded that analysis for uranium in stream water could not be used to detect the deposits. An SRL study in the same area clearly demonstrated the value of 
stream water analyses. The observed anomaly threshold of $0.15 \mathrm{ppb}$ $U$ in the SRL study was much lower than the $0.5 \mathrm{ppb}$ analytical detection limit available in the first study.

SRL studies tend to support sampling based on a grid rather than on consideration of drainage basins and patterns. Canadian studies indicate that, in most areas, grids of up to 10 square miles in area can detect anomalies about as well as $5 \mathrm{sq}$ mi grids. However, in an area of complex geology containing small, isolated, uranium veins, performance probability fell off rapidly as grid size increased (Figure 3 ).

Some areas where the geology within a given grid unit is exceptionally heterogenous will probably require supplemental sampling. Figure 4 illustrates an area where the normal grid sample would not likely indicate a uranium-bearing horizon exposed in a nearby bluff or canyon.

Many analytical techniques are used in exploration geochemistry. These techniques may range from quick field tests to laboratory procedures requiring elaborate equipment. One of the most sensitive and accurate methods for uranium analysis is that of delayed neutron counting (DNC). Other techniques, such as the classical fluorometric method, can be subject to chemical interferences and require extraction or other special sample treatment before an analysis can be performed. The DNC method requires that the samples be irradiated with neutrons. The SRL analytical facility uses one of the Savannah River Plant production reactors to supply neutrons for this activation.

A strong advantage of DNC is that many elements other than uranium may be determined simultaneously by measuring gamma rays emitted by the irradiated samples. SRL personnel have developed an automated neutron activation analysis (NAA) system capable of analyzing as many as 2500 samples per week for uranium, thurium, and about twenty other elements in natural materials without difficult chemical separations or treatments.

* Garrett, R. G., 1977, Scomple Density Investigations in Lake Sediment Geochemical Surveys of Canada's Uranium Reconnaissance Progrom: USDOE Report GJBX-77(77), pp 173-185. Available from DOE-G.J, P.O. Box 2567, Grand Junction, CO 81501 . 


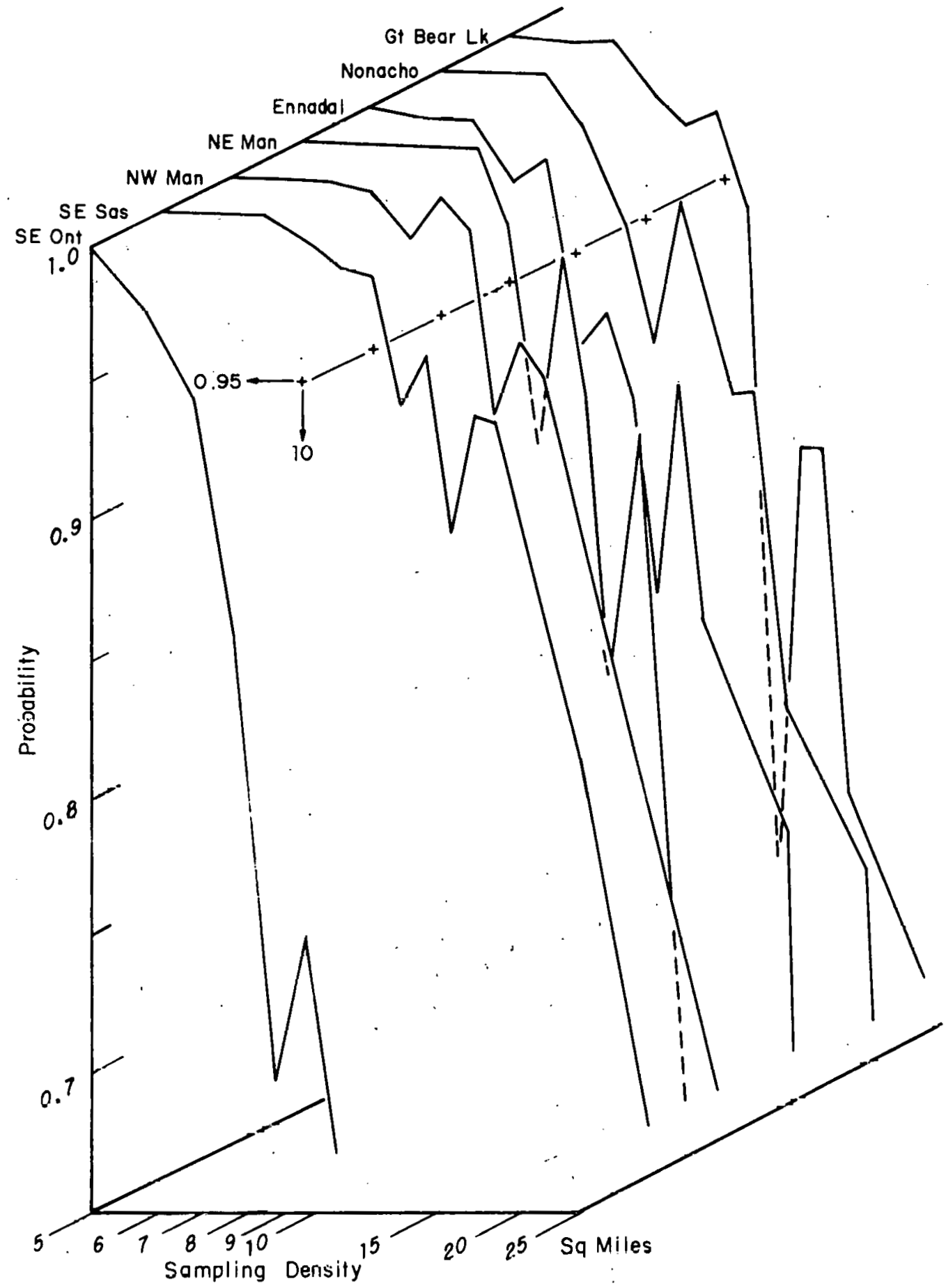

FIGURE 3. Probability of Locating an Anomaly versus Grid Size (after Garrett, R. G.) 


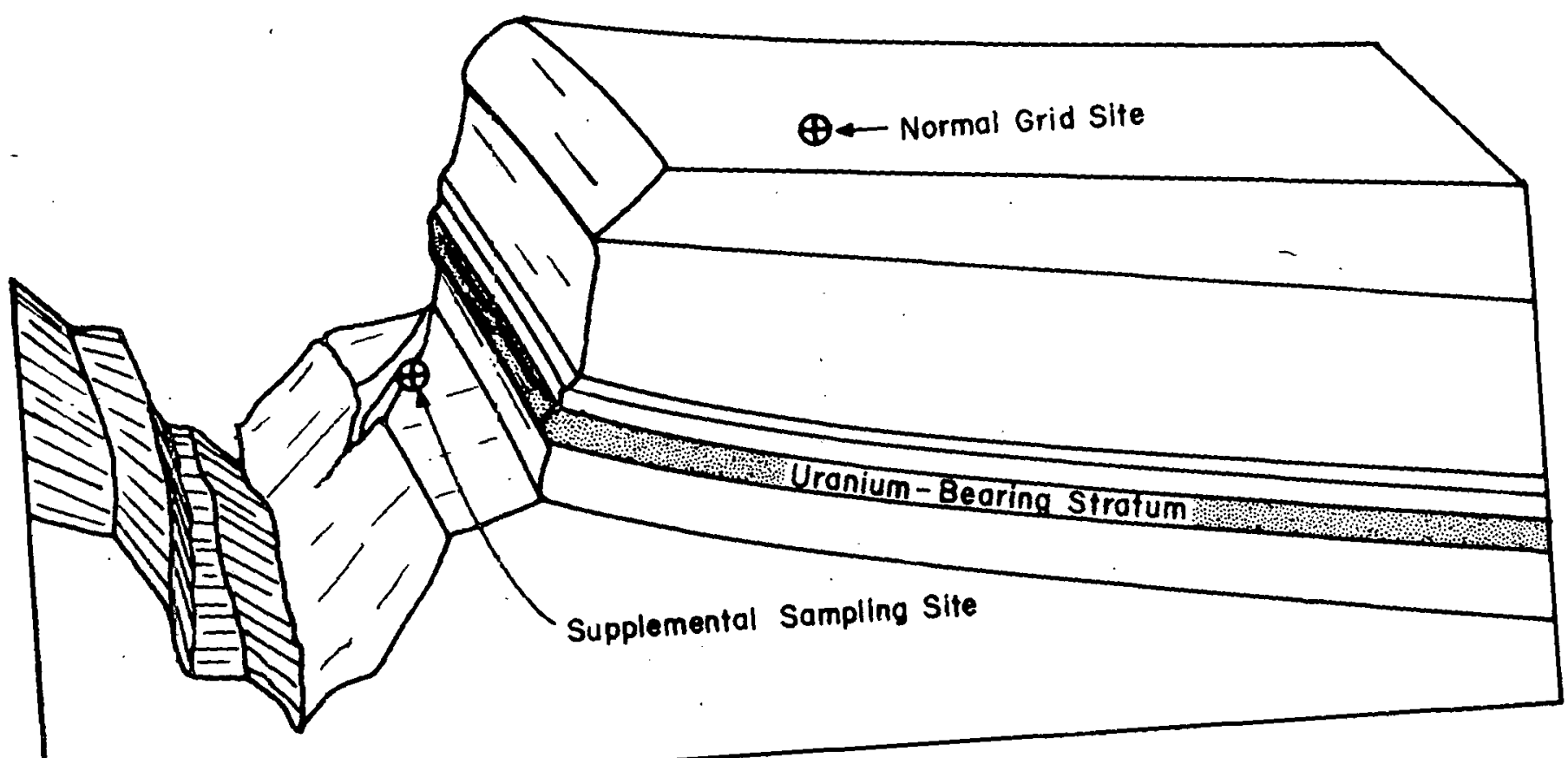

FIGURE 4. An Heterogenous Area Requiring Supplemental Sampling 
PROCESSING OF WATER SAMPLES

\section{Genera1}

In general, uranium minerals with commercial potential such as pitchblende or carnotite are slightly soluble in shallow ground water and surface water. Other minerals, such as monazite and zircon which may contain uranium in virtually insoluble form, are not readily processed and so have limited commercial potential. Thus, anomalous concentrations of dissnlved uranium may uften be a clue lu the presence of ore minerals.

\section{Filtration}

Deciuse suspended particulate matter may contain more uranium than is actually dissolved in solution, water samples must be filtered as part of the sample collection procedure. This is especially true in collecting stream water samples. Without filtration, analysis of a sample might turn out to be more a measure of a stream's turbulence (and hence particulate content) than of any proximity to a uranium deposit.

Pressure filtration is necessary because of clogging of the extremely fine filter. After studying several methnic of prosurization, fluorocarbon gas canisters were chosen primarily for two reasons: safety and portability. When operated as described below, these canisters generate up to about 40 psi. Ry contrast, purtable nitrogen tanks dre pressurized to 2000 psi. A fluorocarbon gas canister is suffirient for procuising 20 to 50 samples, weighs aluut 1 pound, and can be easily transported.

\section{Extraction with Ion Exchange Resin,}

A seriuus problem facing the collector of water samples is preservation of the samplo until dllalysis. Dissolved material can plate out on container walls. Acid added to preserve the sample may attack container walls or suspended matter. To avoid sample preservation problems, SRL-NURF personnel have developed a ficld ion-exchange technique which is very effective in removing any dissolved or suspended material from a water sample.

The ion exchange resin used in this work is a specially prepared, mixed, cation-anion resin which collects all dissolved ions, including uranium. The resin is ultra pure to permit lowlevel analysis for uranium and other elements. Resin of 100 to 200 mesh size is used because coarser sizes require too much field time for complete ion exchange, and finer mesh sizes are difficult to recover completely. 
The novel feature of the cation-anion resin is that it is used in the hydronium and hydroxide forms, respectively. All exchange reactions with the resin yield water, and the chemical driving force for quantitative exchange is very. great. Not only charged uranium species but also neutral complexes can be collected on this resin.

Table 3 summarizes results of a series of tests illustrating that stirring is necessary to react the resin with a water sample. Water conductivity is taken as a measure of the concentration of dissolved material. It can be seen from Table 3 that agitation in a moving vehicle for 6 hours removed only $80 \%$ of dissolved material, whereas 10 minutes of stirring removed $99.9 \%$ of the ions in solution.

Table 4 summarizes the efficiency with which various elements are concentrated by the ion exchange resin. Samples of filtered natural water before and after ion exchange were slowly evaporated to dryness on spark source mass spectrometry electrodes: Greater than $90 \%$ of all elements detected were removed by the resin. Uranium recovery was greater than $99.9 \%$ from natural water containing several parts per billion (ppb) of uranium. Fission-track analyses were made before and after ion exchange. Hundreds of tracks were counted from residues of unexchanged water, while no tracks above background were observed from residues of exchanged water.

In other tests, natural waters doped with trace ${ }^{23} \mathrm{U}$ and $3 \mathrm{meq} / \mathrm{L}$ each of sodium, calcium, chloride, and sulfate ions were exchanged and measured radiometrically. Uranium recovery was greater than $99 \%$, and total ion recovery was $99.9 \%$, despite the fact that the resin was $70 \%$ saturated.

The results of reproducibility tests of uranium concentration and analysis are sumularizcd in Tahle 5. Multiple samples were taken from 10 sites in North Carolina. The filtered water samples (one liter each) were concentrated on ion exchange resin in the field. The dried recovered resins were then activated in the NAA facility and uranium and a number of more abundant elements such as sodium and chlorine were determined by counting the delayed neutrons. A $10-\mathrm{mL}$ sample of filtered water from Site 1 was also analyzed by NAA. Recovery of uraniun was quantitative within experimental error. These data, together with conductivity data, can be used to estimatc the possible maximum concentrations of anions (such as sulfate) that are not specifically measurcd in the field. A plot showing percent variation at different concentration levels is given in Figure 5.

The resin has a certain limited capacity for removal of ions from a water sample. To stay within the capacity of the resin, the volume of the water samplc is reduced for samples with high conductivity (a measure of dissolved solids). 


\section{TABLE 3}

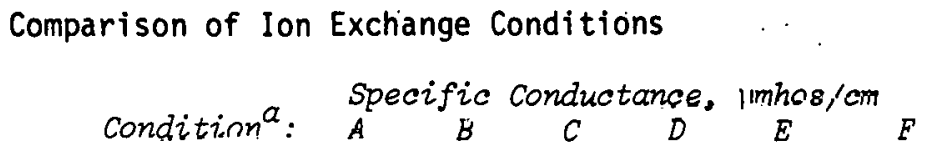

Flapoed Time, hr

0

1

2

3

4

6

$\begin{array}{lllll}61 & 61 & 61 & 61 & 61\end{array}$

Then 5 minutes

Mechanical

Stirring

After 10 minutes

Mechanical

stirring

$\begin{array}{lllll}17 & 37 & 26 & 41 & 41\end{array}$

$\begin{array}{lllll}38 & 26 & 16 & 32 & 30\end{array}$

$\begin{array}{lllll}34 & 21 & 12 & 22 & 26\end{array}$

$\begin{array}{lllll}31 & 15 & 7 & 17 & 19\end{array}$

$\begin{array}{lllll}29 & 12 & 3 & 12 & 14\end{array}$

$\begin{array}{llllll}0.15 & 0.14 & 0.16 & 0.17 & 0.14 & 0.11\end{array}$

a. Condition during measurement:
A - Sitting still on laboratory bench
B - Sitting on laboratory bench, shaken vigurously once each time period
C - Lying on side in moving vehicle
D Gilling upright in moving vehicle
E - Sitting upright in moving vehicle
F - Stirred for 5 minutes with meclianical stirrer and al lowed to sit still on laboratory bench 


\section{TABLE 4}

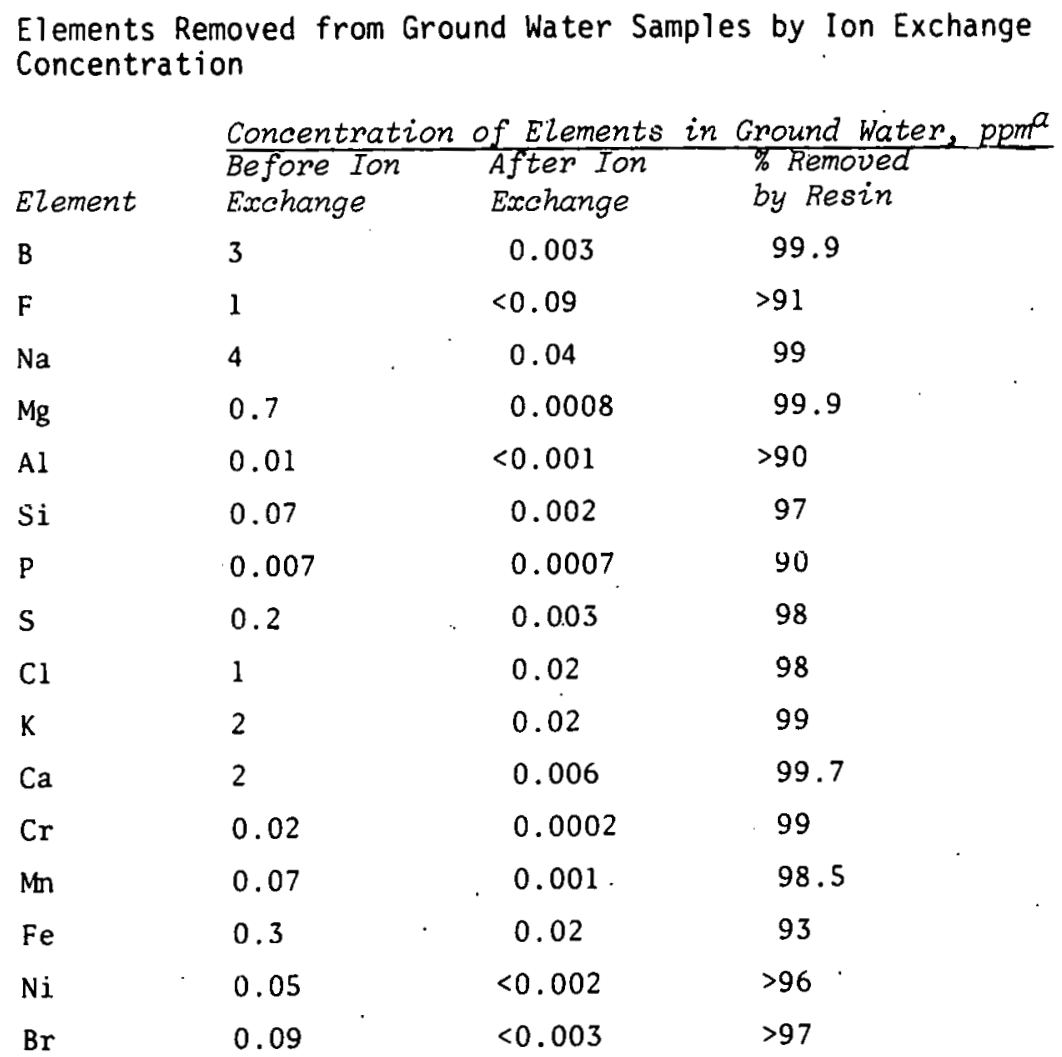

a. Analyses by spark source mass specliometry of residue. 


\section{TABLE 5}

Reproducibility of Uranium Analyses by Resin Concentration

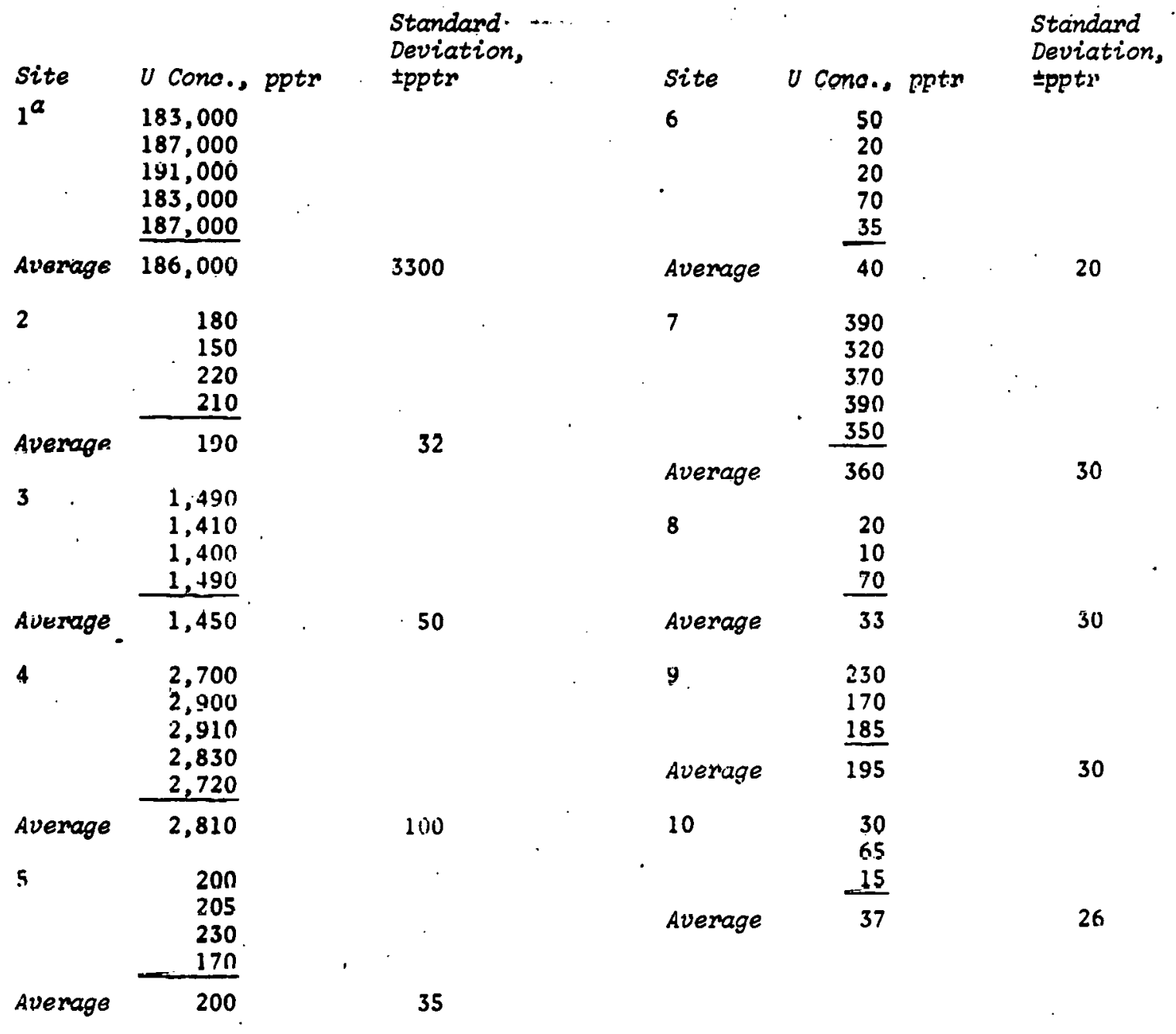

a. niroct dolayed ueutron activation analysis of $10 \mathrm{ml}$ of filtered water (not concentrated on resin) gave values of $184,000 \mathrm{pptr}$ and $189,000 \mathrm{pptr}$. 


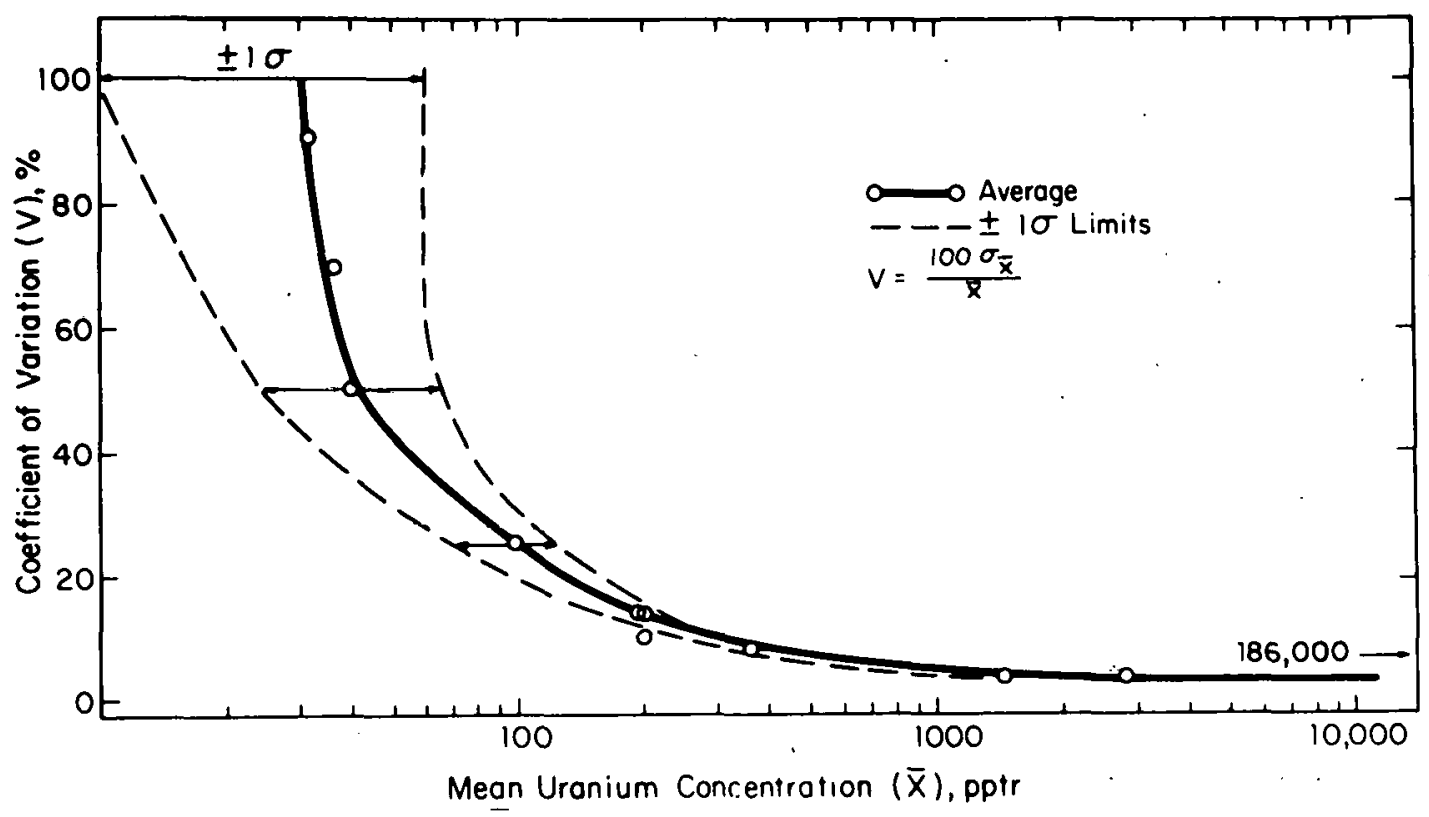

FIGURE 5. Coefficient of Variation versus Mean Uranium Content in Ground Water

Sampling for Dissolved Helium

Helium is a very volatile gas which is produced in rocks by alpha radioactive decay such as exhibited in the thorium and uranium decay series. Because helium is relatively inert, it can diffuse considerable distances in the subsurface and thus can serve as a pathfinder element with a broad dispersion halo for buried uranium and thorium concentrations.

Ground water samples are collected for measuring dissolved helium. The collection technique is modified from one developed by the Geological Survey of Canada. ${ }^{*}$ Samples collected by this technique retain most of their helium and can be analyzed under precise laboratory conditions later. However, rapid capping ( 210 seconds) of the sample bottles in the field and timely transport of the hottles to the analytical facility are imperative to prevent loss of dissolved helium frum the samples before analysis.

* Dyck, W., Pelchat, J. C., and Meilleur, G. A., 1976, Equipment and Procedures for the Collection and Determination of Dissolved Gases in Natural Waters: Canada Geolog. Survey Paper 75-34, $10 \mathrm{pp}$. 


\section{PROCESSING OF SEDIMENT SAMPLES}

Genera 1

Uranium in stream sediment, rock, or soil samples can occur in several forms:

1. As a constituent of minor rock-forming minerals such as zircon, epidote, monazite, and others.

2. As a constituent of unusual minerals such as xenotime $\left(\mathrm{YPO}_{4}\right)$ or samarskite.

3. As loosely adsorben or trapped ions tn oxido coatings on other: millerals.

Because not all of these forms are economically attractive with current technology, it is necessary to estimate the form of any uranium as it exists in a sediment sample to determine the potontial for commercial uraniuin production.

Ideally, to interpret results of uranium analyses in sediments, the distribution of uranium among these various forms should be known. For example, high uranium zircons in granitic terranes havc been linked to epigenetic uraniun deposits in nearby basins. Uranium adsorbed on other mineral grains is most likely ton be related to soluhle uranium and, hence, to conventional ure deposits.

ERL studies have shown that analysis of sediments for uranium alone does not provide enough data for unique interpretation. However, it is not feasible to perform a complete mineral characterization of each sediment sample collected in this program. Therefore, by analyzing samples for elements (e.g., Th, Ce, Y, Hf, and Ta) which are conetituents of uraniumbearing minerals, ratios of uranium to these elements can be calculated. Estimates of the relative poitiuns of a total uranium analysis that can be attributed to the above forms can then be made.

\section{Field-Sieving}

Field-sieving assures that the sample will contain adequate amounts of fine material. Further sieving is done prior to analysis. Normally the fraction passing a.100-mesh sieve is analyzed, although the -18 to. +40 mesh fraction may be analyzed where significant contamination by windblown material is suspected or known. 
Transporting agents (e.g., wind and streams) sort sediments locally into fractions which may be very high in uranium-rich heavy minerals. SRL sampling variability studies indicate that a minimum of five subsamples must be composited to compensate for local sorting and yield a representative stream sediment sample. For sampling of surficial (soil, colluvium, etc.) materials, ten or more subsamples collected over a 25 -yard radius are composited. 
THIS PAGE

\section{WAS INTENTIONALLY \\ LEFT BLANK}




\section{FIELD OPERATIONS}

\section{A. LOGISTICS AND PUBLIC RELATIONS}

1. Notification of Public Officials

Prior to team operation in a given county, the field supervisor is REQUIRED to visit the county seat, present proper idcntification, and notify the county. sheriff's office, health department, and any other officials having responsibility in a given area. of the sampling program in that area. A few minutes spent in a public relations effort in various public offices could prove of immense benefit.

\section{Access to Property}

\section{a. Private Property}

Most NURE samples will be collected on private property. The rights of the property owner must be respected. Care should be taken to avoid any damage to private property; even snakes and brush are private property. Because no one is obligated to give samples, the sampler should take care to be most tactful in his approach.

\section{b. Military Bases}

The commanding officer of each base enjoys a great deal of autonomy in controlling access to the base. The field supervisor should attempt to contact this person well in advance of any planned sampling on the base. Problems in gaining access should be reported promptly to SRL. Sampler ID cards do not imply access rights to restricted areas.

\section{c. Federal Lands}

Several Federal agencies are charged with the responsibility to manage and protect public lands. Among these are the Forest Service, the Bureau of 
Land Management, the Fish and Wildlife Service, and the National Park Service. Each of these agencies has agreed to cooperate with DOE sampling to the extent that such sampling does not damage the values under their protection.

In some cases, acccss beyond that available to the general public may be granted for official DOE sampling. In all cases, field supervisors must secure approval for sampling activities at the local level several days before working in an area.

SRI, wi.11 conperate and provide lijts of as many government agency contact personnel as possible. Ultimately, however, field public relations falls in the area of responsibility of the subcontractor who should be careful to identify and contact all appropriate persons.

1. Forest Service - The Forest Supervisor should be contacted about one week prior to sampling so that he can notify District Rangers of the presence of authorized DOE sampling teams in the area. The field supervisor must contact District Rangers when sampling teams detually arrive and before sampling is bcgun. District. Ranlyer's may be of assistance in arranging contacts with private land owners. DOE samplers are requested to prepare $\therefore$ work plan of sampling operation 3 for approval by Forest Supervisors whenever sampling is to take place in wilderness or primitive areas. Under most conditions, access will be limited to primitive methods. Forest personnel may assist DOE samplers by providing information on availability of commercial outfitter services, camping sites, access routes by foot or horse, various means of primitive access to minimize the need for aircraft use, points for pickup by packstock or helicopter, etc. No fishing or hunting activities using helicopter access will be permitted. No rutting of vegetation for helispots, and no ground vehicular transportation in wilderness/primitive areas will be considered.

2. Bupeau of Land Manciyemert (BLM) - NURE field supervisors must contact BLM field managers for briefing on specific access restrictions before sampling may begin in BLM areas. DOE samplers will be given advice on how to travel through closed and limited areas to reduce the impact on the resources. 
3. Fish and Wildiife Semice - NURE field supervisors must contact National Wildlife Refuge Managers to determine what access restrictions may be necessary. Such restrictions might be: the nonuse of motorized equipment (including helicopter landings) in designated wilderness areas; limited or prohibited use of off-road vehicles to prevent environmental damage, etc. Each refuge will have its own special set of circumstances requiring certain restrictions.

4. National Park Service - NURE field supervisors must contact Park superintendents prior to collection of any samples in a National Park Area. The superintendent will determine any necessary access restrictions: At this time (August 1979) sampling is not permitted in any area under the jurisdiction of the National Park Service.

5. Indian Reservations, State Parks, and Other Public Preserves - The field supervisor must contact the local agent, tribal representative, ranger, or other official-in-charge several days prior to anticipated sampling.: SRL must receive written documentation of refused access. No problems in gaining access are anticipated.

NOTE: SRL must receive copies of all correspondence between the contractor and agencies or individuals contacted.

3. Identification

Numbered DOE identification cards will be issued to all sampling team personnel. A short brochure (Figure 2) giving some highlights of the NURE program has been prepared so that sampling teams will have something tangible to leave with property owners. In no case is false identification or misrepresentation of purpose to be used.

4. Rejection

Most land owners will be more than happy to cooperate and may volunteer much useful information. Some may forbid access to their property and may even be hostile. LEAVE WHEN ASKED! 
5. Team Numbers

Each contractor will assign team codes to his sampling teams and furnish SRL a list of the team members and codes. A team code consists of a letter designating the contractor and a number which is unique for each person or pair on a team. SRL will assign a block of acceptable codes to each contractor.

EXAMPLE: Team KO7

Contractor: King

l'eam Seven: J. Loe, M. Brown

6. Liaison with SRL

The field supervisor must contact SRL at least weekly by telephone or messenger. He will provide a motel or boarding-house address and a telephone number where he can be contacted by SRL personnel during any twenty-four hour period. The supervisor will also apprise SRL during the last week of each month of the area to be sampled during the coming month.

A telephone recording device is available at SRL to record collect calls from field supervisors. It is mointored at least vince daily and should be used for all routine calls.

The field supervisor is expected to be abreast of tcam activities at all times. Under normal circumstances, SRL will communicate with field teams only through their field supervisor.

Routine maintenance of equipment such as changing probes and batteries is also the responsibility of the field supervisor. SRL will perform major repairs or replacements of equipment; but turnaround time may be on the order of several weeks. The field supervisor should try to detect failing instruments and anticipate needed repairs. It is suggested that a daily log of instrument checks be kept to aid in identifying failing meters or probes.

The supervisor should also anticipate the need for resupply far enough in advance to allow time for shipping. SRL will process requests for supplies once per week and turnaround time on such requests can be expected to be two weeks on the average. 


\section{B. SAMPLING SITE SELECTION AND SITE OPERATIONS}

1. Sampling Density

Orientation studies indicate that the average sampling density needed to define most geologic features varies depending upon rock type and geologic complexity. Samples are normally collected in the range of one site per five to twenty square miles ( 10 to $50 \mathrm{~km}^{2}$ ). Densities will be specified by SRL on a county-by-county or map-by-map basis.

\section{Site Selection Procedure}

The procedure suggested for site selection is given in Appendix A.

3. Sample Collection

Detailed instructions for sample collection are given in Appendix B.

4. Coding of Field Data Forms

Detailed instructions for coding of field data forms are given in Appendix C.

C. RETURN OF SAMPLES TO SRL

The contractor is responsible for all samples until these are received by SRL in usable form. Payment will be made only for samples which are clearly labeled and which are accompanied by correctly completed data forms, keypunched data cards, and sampling site maps. Inaccuracies in field forms add considerably to sample processing costs at SRL and will delay payment to contractors.

\section{Maps}

Each sampling contractor will be furnished two or more sets of maps, one of which is to be returned with the samples. Coordinates (Lat.; Long.) of sampling points will be measured by SRL directly from the map returned with each group of samples. 
Maps for measurement of coordinates must be clean, unfolded (rolled in protective tubes), and labcled with sampling sites precisely indicated as points within circles in red ink. If both ground water sampling sites and surface sampling sites are marked on the same map, ground water sites must be highlighted with a colored marker. Each map should be labeled with the contract number (AX number) and with an abbreviated list of the samples taken. Field copies of maps are to be returned also, but these may be folded.

Care must be taken to assure that each site identifier is unique to only one sample. Two samples with the same identifier are both questionable. If the discrepancy is not easily resolved at SRL, the sites must be resampled.

\section{Data Forms}

Data forms and 80-character, İM-compatible, keypunched, and verified data cards suitable for automated processing must accompany samples:" The forms and card should be shipped in a moisture-proof enclosure. Detailed instructions for completing the data forms are given in Appendix l'.

All data forms are to be checked for errors by the field supervisor. If the supervisor is also a sampling team member, his cards should be checked by a different sampling team member.

\section{Samples}

Samples are to be arranged in serial order within each map unit (normally a $15^{\prime}$ rectangle) and packaged by map unit. Neatness in packaging will facilitate sample check-in at SRL and thereby facilitate payment.

Stream sediment samples should be oven-dried (90 to $\left.100^{\circ} \mathrm{C}\right)$ betore shipping to SRL in the prescribed Kraft paper collection bags. 'l'he paper bags may weaken and burst during shipment if samples are damp. Higher drying tompcratures may char and woaken bngs. Heat lamps will damage the hags and are not acceptable for drying. Microwave ovens have not proven satisfactory.

Resin samples should be checked before shipping to assure that labels and lids are securely attached. Labels are to be taped over with transparent tape. Sediments and resins should be packaged in separate containers to reduce possible contamination and water damage to bags in the event of leakage. 
Two analytical blanks each for resin and acid are to be submitted from those $15^{\prime}$ rectangles designated $A A, B B, C C, D D$, $\mathrm{AE}, \mathrm{BF}, \mathrm{CG}$, and $\mathrm{DH}$ (Figure C-2). These blanks should be numbered 499 and 999 and shipped with surface water and ground water samples, respectively. For example, the sample shipment containing Samples KFCG-501 through KFCG-532 should also contain an acid bottle and a resin bottle labeled KFCG-999; the shipment containing Samples KFCG-001 through KFGC-036 should contain an acid bottle and a resin bottle labeled KFCG-499. Deionized water should be used in the place of sample water to fill the bottles. These blanks may be prepared by field supervisors, but acid and resin should be taken from field supplies used in sampling. Payment will be made for 8 blank ground water sites and 8 blank surface sites at the established rates within each $1^{\circ} \times 2^{\circ}$ NTMS quadrangle.

\section{Cartons}

Each shipping carton should contain samples and forms from only one map unit. If multiple map units are shipped together, they must be separated or compartmentalized within cartons. Samples of a given type from a given map unit may be shipped in separate cartons only if the number of samples is too large for one carton. SRL will furnish special shipping containers for acidified water samples.

A packing list must be attached to the exterior of each carton shipped. The packing list. should include:

(a) the total number of samples contained in the carton, (b) any data forms enclosed, (c) any maps accompanying the shipment, and (d) the order number (AX number of the contract). A duplicate packing list, an invoice which must agree with the packing list and sample inventory, and an SRL sample transfer form should be enclosed in the carton. A sample invoice is shown in Figure 6. Sample packing lists are shown as Figures 7 and 8 . Blank forms can be furmished if requested.

\section{Shipping}

Samples are to be delivered or shipped to SRL at approximately two(2)-week intervals. The recommended method of shipping is by motor freight to E. I. du Pont de Nemours and Company, 300/700 Receiving Department, Dunbarton, South Carolina. Air freight to Augusta, Georgia, via Delta Air Line has been satisfactory. Air freight forwarders are not recommended. 
D. QUALITY CONTROL

SRL has instituted a series of quality control checks (QA) to detect problems which compromise the technical validity of samples. One quality control index is reported to the sampling contractor as an "error rate" for each shipment.

In general, most field QA problems result from inattention to detail by the sampler and failure to detect and reprimand errant samplers because of lax field supervision. The field supervisor should visit 5 to $10 \%$ of the sites collected by each sampler to verify location and site data. In this way, samplers who have difficulty navigating ran he identified and retrained before their problems impair the quality of the contractor's performance.

\section{INVOICE}

FOR NURE SAMPLES

DELIVERED ON Auqust 8.1979.

BY John Doe

AX 123756-A ITEM No. 2

$\frac{\text { NO. }}{12} \frac{\text { DESCRIPTION }}{\text { KFAA 001-012 }} \frac{\text { PRICE, \$ }}{12.47} \frac{\text { AMOUNT, \$ }}{149.64}$

$\begin{array}{llll}1 & \text { KFAA } 499 & 12.47 & 12.47\end{array}$

$\begin{array}{llll}1 & \text { KFAA } 999 & 12.47 & 12.47\end{array}$

$9 \quad K F A B$ 001-009 $12.47 \cdot \frac{112.23}{286.81}$

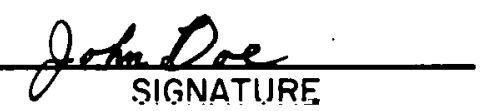

FIGURE 6. Invoice to Accompany Samples Sent to SRL 
SAMPLE TRANSFER HISTORY FORM

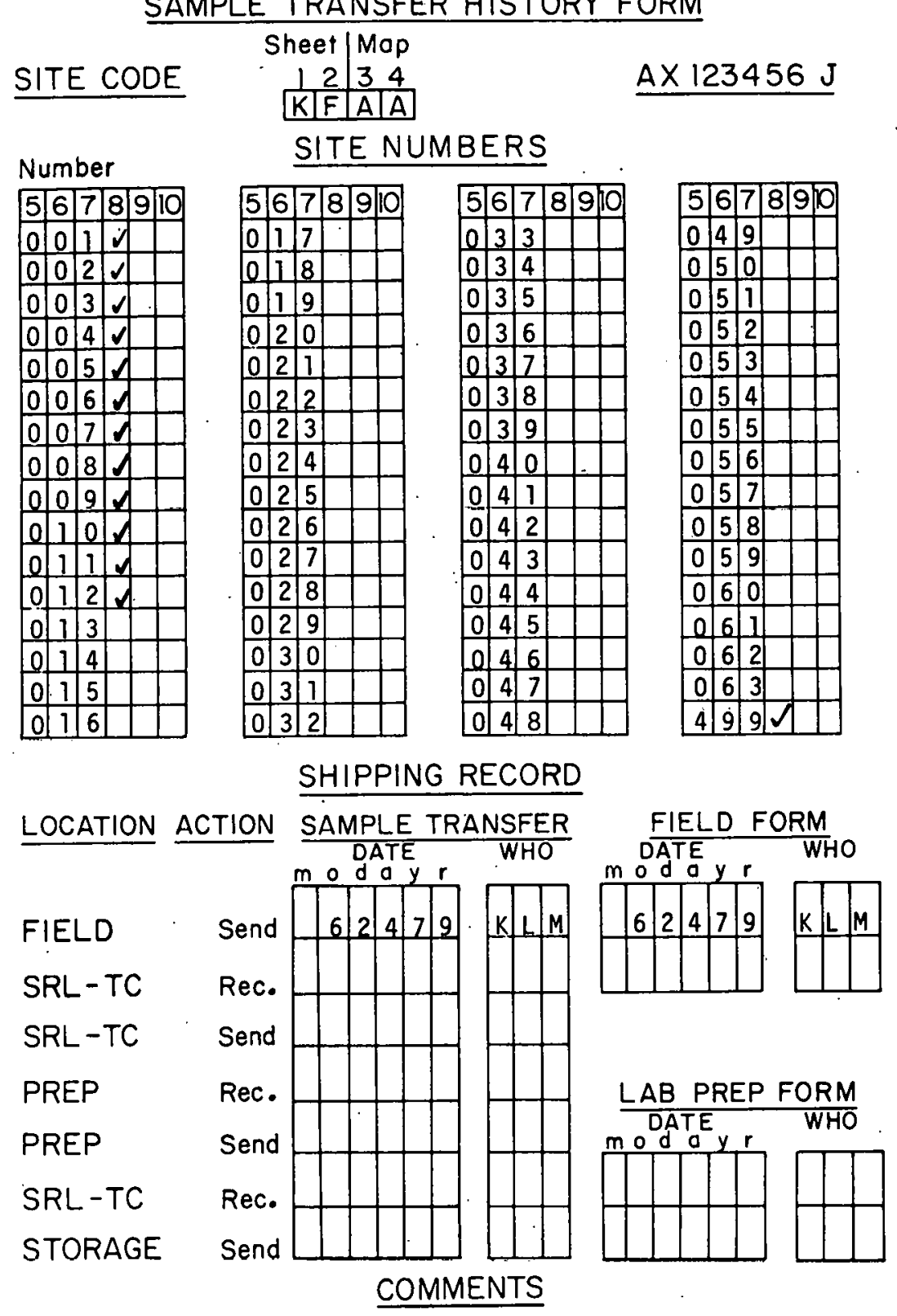

FIGURE 7. Sample Transfer History (Form A)

Example: Twelve surface samples were collected from Klamath Falls sheet, map unit AA. Samples were labeled KFAA001-KFAA012. " The field supervisor initials the transfer form and encloses a copy in the shipping carton. 
SAMPLE TRANSFER HISTORY FORM

Sheet $\mid$ Map

\begin{tabular}{lr|r|r|r}
\hline SITE CODE & 2 & 3 & 4 \\
\hline $\mathrm{K}$ & $\mathrm{F}$ & $\mathrm{A}$ & $\mathrm{A}$ \\
\hline
\end{tabular}

$\underline{A \times 123456 \mathrm{~J}}$

Number

SITE NUMBERS

\begin{tabular}{|l|l|l|l|l|l|}
\hline 5 & 6 & 7 & 8 & 9 & 10 \\
\hline
\end{tabular}

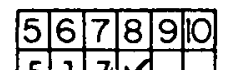

5.001.

\begin{tabular}{l|lll}
5 & 0 & 2 & $V$ \\
\hline
\end{tabular}

\begin{tabular}{lllll}
5 & 0 & 3 & $V$ \\
\hline 5 & 0 & 4 & \\
\hline
\end{tabular}

$\begin{array}{lllll}5 & 0 & 4 & V\end{array}$

\begin{tabular}{llll}
5 & 0 & 5 & $V$ \\
\hline & & 0 & 0
\end{tabular}

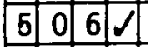

\begin{tabular}{l|l|l|l|}
\hline 5 & 0 & 7 & $V$ \\
\hline 5 & 0 & 8 & 6 \\
\hline
\end{tabular}

\begin{tabular}{ll|ll}
5 & 0 & 8 & 1 \\
\hline & 0 & 9 & 1
\end{tabular}

\begin{tabular}{l|c|c|c|}
\hline 5 & 0 & 9 & $\sqrt{ }$ \\
\hline 5 & 1 & 0 & 1 \\
\hline & & & 1 \\
\hline
\end{tabular}

\begin{tabular}{l|lll|}
5 & 1 & 0 & $\checkmark$ \\
\hline 5 & 1 & 1 & $\sqrt{ }$ \\
\hline & 1 & 2 & 8 \\
\hline
\end{tabular}

\begin{tabular}{lllll}
\hline 5 & 1 & 2 & $\checkmark$ \\
\hline 5 & 1 & 3 & \\
\hline
\end{tabular}

\begin{tabular}{llll}
5 & 1 & 3 & $\checkmark$ \\
\hline 5 & 1 & 4 &
\end{tabular}

\begin{tabular}{l|l|l|l|}
\hline 5 & 1 & 4 & $\checkmark$ \\
\hline 5 & 1 & 5 &
\end{tabular}

\begin{tabular}{lllll}
\hline 5 & 7 & 5 & $V$ \\
\hline & & 6 & \\
\hline
\end{tabular}

\begin{tabular}{llll}
\hline 5 & 1 & 5 & \\
\hline 5 & 1 & 6 & 1 \\
\hline
\end{tabular}

\begin{tabular}{|l|l|l|l|l|}
\hline 5 & 1 & 7 & & \\
\hline 5 & 1 & 8 & & \\
\hline 5 & 1 & 9 & & \\
\hline 5 & 2 & 0 & & \\
\hline 5 & 2 & 1 & & \\
\hline 5 & 2 & 2 & & \\
\hline 5 & 2 & 3 & & \\
\hline 5 & 2 & 4 & & \\
\hline 5 & 2 & 5 & & \\
\hline 5 & 2 & 6 & & \\
\hline 5 & 2 & 7 & & \\
\hline 5 & 2 & 8 & & \\
\hline 5 & 2 & 9 & & \\
\hline 5 & 3 & 0 & & \\
\hline 5 & 3 & 1 & & \\
\hline 5 & 3 & 2 & & \\
\hline
\end{tabular}

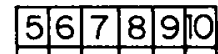

\begin{tabular}{|l|l|l|l}
\hline 5 & 3 & 3 & \\
\hline 5 & 3 & 4 \\
\hline
\end{tabular}

\begin{tabular}{|l|l|l|}
\hline 5 & 3 & 4 \\
\hline 5 & 3 & 5 \\
\hline
\end{tabular}

\begin{tabular}{llll}
\hline 5 & 3 & 5 \\
\hline
\end{tabular}

\begin{tabular}{l|l|l|}
\hline 5 & 3 & 6 \\
\hline
\end{tabular}

\begin{tabular}{|l|l|l|}
\hline 5 & 3 & 7 \\
\hline 6 & 3 & 8 \\
\hline & 3 & \\
\hline
\end{tabular}

\begin{tabular}{|l|l|l|}
\hline 5 & 3 & 8 \\
\hline 5 & 3 & 9 \\
\hline & 4 & 0 \\
\hline
\end{tabular}

\begin{tabular}{|l|l|l|}
\hline 5 & 4 & 0 \\
\hline
\end{tabular}

\begin{tabular}{l|l|l}
5 & 4 & 1 \\
\hline & 4 &
\end{tabular}

\begin{tabular}{l|l|l|}
\hline 5 & 4 & 2 \\
& &
\end{tabular}

\begin{tabular}{|l|l|l|}
\hline 5 & 4 & 3 \\
\hline
\end{tabular}

\begin{tabular}{|l|l|l|}
\hline 5 & 4 & 4 \\
\hline
\end{tabular}

\begin{tabular}{|l|l|l|}
\hline 5 & 4 & 5 \\
\end{tabular}

\begin{tabular}{|l|l|l|}
\hline 5 & 4 & 6 \\
\hline
\end{tabular}

\begin{tabular}{|l|l|l|}
\hline 5 & 4 & 7 \\
\hline 5 & 4 & 8 \\
\hline
\end{tabular}

\begin{tabular}{|l|l|l|}
\hline 5 & 4 & 8 \\
\hline
\end{tabular}

\begin{tabular}{|l|l|l|l|l|l|}
\hline 5 & 6 & 7 & 8 & 9 & 0 \\
\hline 5 & 4 & 9 & & & \\
\hline 5 & 5 & 0 & & & \\
\hline 5 & 5 & 7 & & & \\
\hline 5 & 5 & 2 & & & \\
\hline 5 & 5 & 3 & & & \\
\hline 5 & 5 & 1 & & & \\
\hline 5 & 5 & 5 & & & \\
5 & 5 & 6 & & \\
\hline 5 & 5 & 7 & & \\
\hline 5 & 5 & 8 & & & \\
\hline 5 & 5 & 9 & & \\
\hline 5 & 6 & 0 & & & \\
\hline 5 & 6 & 7 & & \\
\hline 5 & 6 & 2 & & \\
\hline 5 & 6 & 3 & & \\
\hline 9 & 9 & 9 & $\checkmark$ & & \\
\hline
\end{tabular}

SHIPPING RECORD

LOCATION ACTION SAMPLE TRANSFER DATE WHO
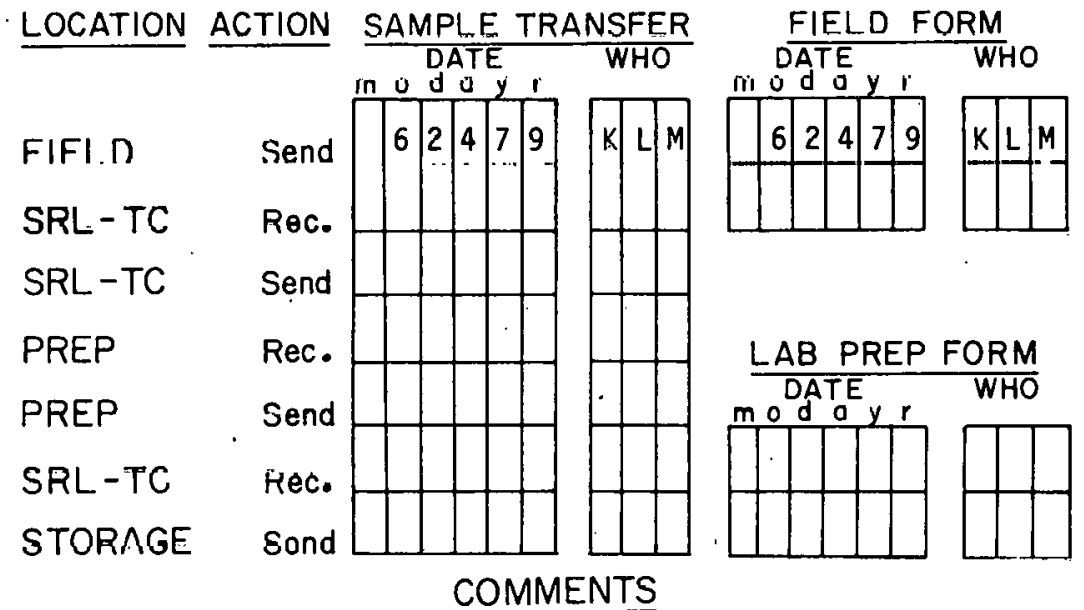

COMMENTS

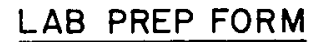

DATE WHO

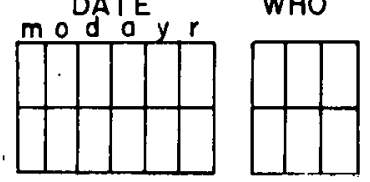

FIGURE 8. Sample Transfer History (Form B)

Example: Seventeen ground water samples were collected from Klamath Falls sheet, map unit AA. Samples were labeled KFAA501-517. Supervisor initials form and encloses a copy in the shipping carton. 


\section{APPENDIX A: Site Selection Procedure}

Site-selection for the three modes of NURE sampling is discussed below. The three modes are:

1. Ground Water Sampling

2. Surface Sampling in Humid Areas

3. Surface Sampling in Arid Areas

This site selection procedure was developed for areas which are being sampled at a nominal density of one site per 5 to 20 square miles. Other areas may be sampled at different densities, but similar logic will apply. The procedure is meant to serve as a guideline to assure uniformity in site selection. It should be kept in mind that the primary objective is to obtain coverage that is (as nearly as possible) uniform, complete, and representative.

Adequate maps are required to pinpoint the sampling sites. County road maintenance maps appear to be the most generally useful maps in the. Eastern U.S. They are current and show all road-stream intersections. In the Western U.S., topographic maps, U.S. Forest Service maps, and other special maps will be useful in most areas and are necessary where counties do not maintain roads. Duplicate maps (a field map and clean copy) must be delivered to SRL.

Every effort should be made to fill in the sampling grid with acceptable samples.

It is not practical to sample within some metropolitan areas; however, many small towns may have pristine sampling sites. Ground water may be available from industries, car washes, subdivisions, and municipal wells. We recognize that city limits bear no set relation to the land-use patterns within them, and the judgment of the sampling team must be relied upon to maximize coverage while minimizing strongly biased samples.

As samples are taken, sites are numbered sequentially, i.e., no valid sample identifiers are to be skipped. Sampling locations and site numbers are to be marked accurately on working maps in the field as the samples are collected. Compilation maps showing completed sites as points within circles are to be prepared and returned to SRL with the samples. Sampling site identifiers on the maps should be listed in the margins. 
Site identifiers consist of four letters and three digits. The first two letters are regional designators and represent a State or a $1^{\circ} \times 2^{\circ}$ NTMS quadrangle. The second two letters are local designators and represent a county or other unit of equivalent size (200 to $500 \mathrm{sq} \mathrm{mi}$ ). When the regional designator is for a $1^{\circ} \times 2^{\circ}$ quadrangle, the local designator will normally be for one of thirty-two $15^{\prime}$ rectangles as illustrated in Figure C- 2 . The numerical portion of the site identifier begins with 001 continuing sequentially for surface sites; and begins with 501 continuing sequentially for ground water sites. (Numbers 499 and 999 are used by SRL for special purposes and are not to be assigned to field samples.)

\section{Ground Water Sampling}

An attempt will be made to collect a ground water sample from each sampling grid unit. Flowing springs may be sampled at the point where they issue from the ground. Wells should be sampled as near the well-head as possible. Water from storage tanks and stock tanks should be avoided but may be sampled if no other ground water source is available for the grid unit. Water which has been softened, chlorinated, or otherwise treated in any way must. not be sampled.

To facilitate the selection of sites for sampling ground water, the field map is ruled with the appropriate sampling grid. In the field, the sampler locates a well or flowing spring as near the grid center as practical. If for some reason the site selected proves unsuitable, a site further from the grid center may be considered. If no suitable site can be sampled, the grid-unit boundary may be crossed and a suitable site sampled in the next adjacent unit. This alternate site should be as near the original site as practical, but must not be within one mile of a regular site in the alternate grid unit.

\section{Surface Sampling in Humid Areas}

In humid arøas, Etreame pursuo continuous coursc3 from their source areas to the sea. Land forms exhibit the classical Davisian stages, and most areas to be sampled will be in early to late maturity.

In humid areas, smaller streams serve to transport materials delivered to them by mass wasting. Larger streams accept sediment from smaller streams and either store it temporarily as part of their flood plains or transport it downstream. Elements which are primarily. present in heavy resistate minerals move downstream as part of a bed-load dispersion train; unusual minerals are normally 
diluted to the point that they do not influence a chemical analysis of the sediment after a relatively short distance. Elements such as zinc and copper may dissolve and either precipitate or equilibrate with bed materials for some considerable distance downstream.

Stream sediment samples will be collected in all humid areas... Where streams are flowing, water quality measurements will be made, and a filtered water sample will be treated with ion exchange resin.

Streams which drain not more than three times the area of a sampling grid unit will be sampled. To select sites, a grid is ruled on the sampling map and the largest stream which begins in the grid unit to be sampled or in the next adjacent unit is selected. If a road/stream intersection or other point of easy access exists on the selected stream, it may be sampled. Otherwise, the stream should be sampled as near to the center of the grid unit as practical. All streams are sampled upstream from roads, ponds, or any recognizable factor which could alter the material being sampled.

A grid unit may not contain a stream or channel suitable for sampling; however; no two adjacent units should go unsampled even if the normal stream-size criteria must be violated. No samples of like kind shall be taken closer than one mile from any other sample.

\section{Surface Sampling in Arid Areas}

For purposes of our sampling, arid areas will be recognized as regions of interior drainage or regions in the very youthful stages of the fluvial erosion cycle. Typical natural vegetation consists of sagebrush, mesquite, cactus, and assorted desert shrubs. In Figure 1, this designation applies to the Basin and Range and much of the Colorado Plateau.

Field examinations by SRL geologists and recourse to the geochemical literature indicate that soil sampling is an effective substitute for stream sediment sampling in arid regions.. Some studies support the use of desert wash sediments to detect mineralization in adjacent mountains.

Sampling in arid regions will follnw a gridded pattern very closely with two general exceptions: (1) ground covered by obviously windblown sands shnuld be avoided; (2) in mountainous areas, a well-defined fluvial channel system may exist and sampling sites may be selected as outlined in the section on humid regions. 
A grid is ruled on the sampling map and a site is selccted as near the center of each unit as practical. Desert washes may be sampled only if they lie at the chosen point; no special effort is to be made to collect from these washes.

Where a grid unit includes both mountain and basin, the normally selected site would be as high up an alluvial fan as necessary to avoid windblown material.

Where much of the area is covered by windblown material, the sampler should exercise care not to take this material. Normally, the aeolian cover will be patchy and a suitable site can be found nearby. Desert washes may be located within the grid unit and can be sampled. Do not sample sand dunes.

Supplemental Sampling Sites

Rigid adherence to a sampling grid may miss significant features which should be sampled. If the sampler, in his best profcssional judgment believes this to be the case, authorization is granted for collection of supplemental samples in addition to grid site samples. Fifty to one hundred such sites are anticipated in the average $1^{\circ} \times 2^{\circ}$ quadrangle.

The primary criterion for a supplemental sampling site is that it is geologically distinct from most of the grid area. Examples are:

- Volcanic necks

- Canyon or cliff cxposures:

- High radioactivity

- Mineral deposit noted

- Hot springs

When a supplemental site is sampled, a reason for site selection must be written on the back of the field data card (in addition to the usual site description). Also an $X$ must be entered in Column 70 of the Field Data Form (Figure C-1). 
This section is divided into two parts:

A. Description of equipment and supplies and instructions for their calibration and use.

B. Checklists of equipment and supplies and an outline of the sampling procedure for:

1. Ground water sites

2. Surface sites in humid areas

3 . Surface sites in arid areas. 


\section{A. EQUIPMENT AND SUPPLIES}

Each item normally included in a sampling kit and its use or purpose are described in the following pages.

1. Filter Unit

The pressure filtration unit is shown fully assembled in Figure B-1. Figure B-2 illustrates the procedure for changing the filter membrane. The filter membrane must be replaced before each sample is taken. The membrane used is normally a very thin plastic shcct. A slluoth-slirfaced plastic frit supports the membrane. Any foreign mattor betweeñ membrane and trit can puncture the membrane during filtration. Special polished tweezers are furnished for handling membranes.

Flgure $\mathrm{B}-3$ illustrates the procedure for placing a sample in the filter unit. 0-rings visible in Figures $B-2$ and $B-3$ assure a good pressure seal with a minimum of tightening. A special plastic wrench is supplied to turn stubborn nuts,

A11 filter components which come into contact with samples are made of polytetrafluoroethylene. These components should be rinsed with deionized water between samples to ensure that no cross contamination occurs.

A pressurized fluorocarbon gas can with the adapter necessary to apply pressure to the filter unit is shown in Figure B-4.

To operatc, the uinil is removed from its case and locked onto the case which then serves as a stand. All componcnts whicll contact samples should be rinsed with distilled or deionized water (not with a portion of the sample which might contain considerable suspended matter). A new membrane is carefully installed. The pressurc vessel.is put in place and serured by hand-tighteninly the three bolts arranged for this purpose. Note: $\Lambda$ n alignment pin prevents twisting which would tear the membrane. A clean 1-1iter hnttle is plaood beneatli llie fllcer to receive the filtrate. 'The interior lining of the pressure vessel is then filled with sample and the lid is secured. Light wrench-pressure on all nuts may be appropriate.

A gas canister and adapter (Figure B-4) are attached via the quick-disconnect fitting and pressure is applied to the filter. The fluorocarbon gas is conserved by applying only sufficient pressure to produce adequate sample flow. Occasional stream samples may contain so much suspended material that it will be expedient to filter one-half liter, change the membrane, and filter a second sample to obtain the required volume of filtrate. 


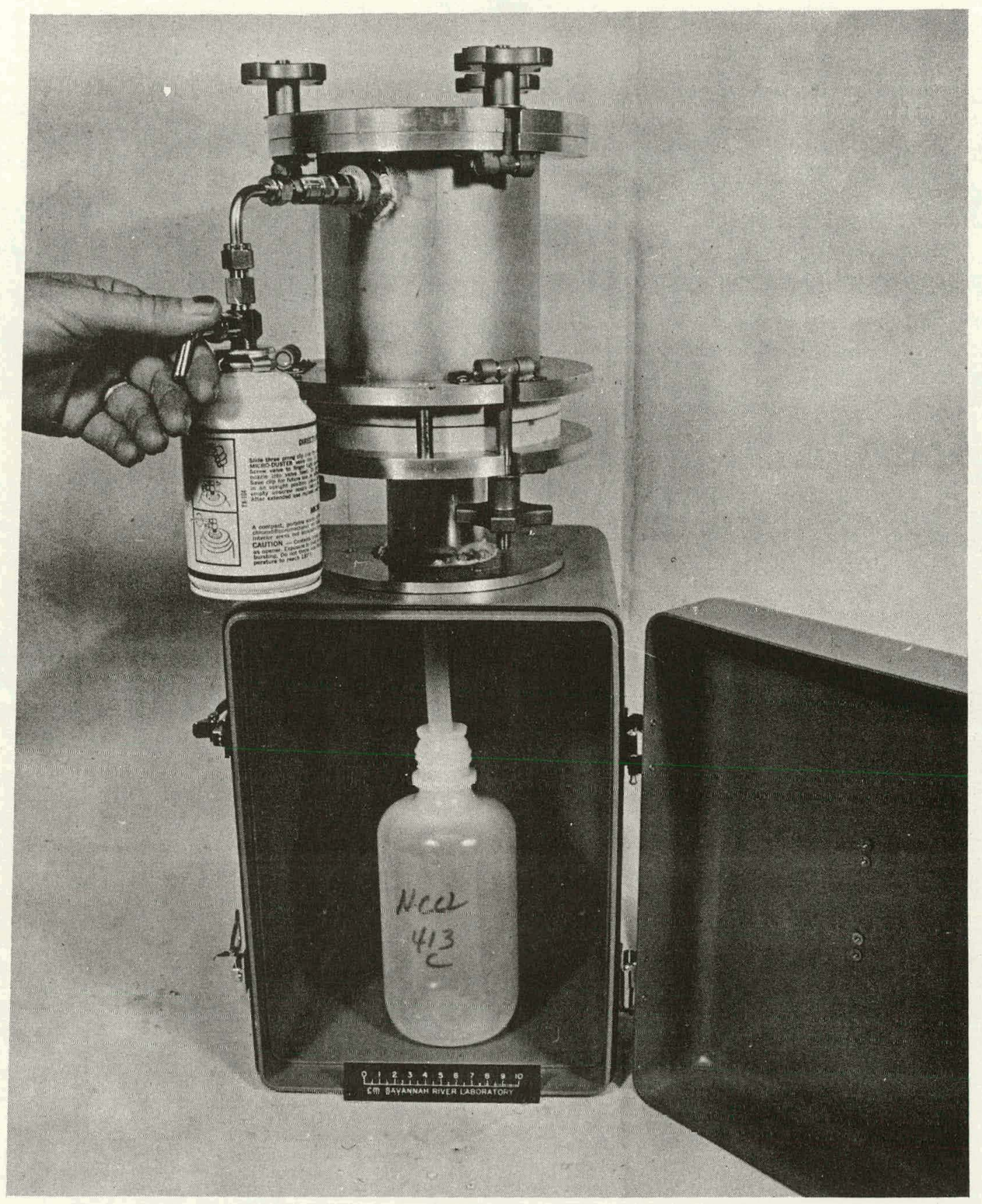

FIGURE B-1. Filtration Apparatus in Operation 


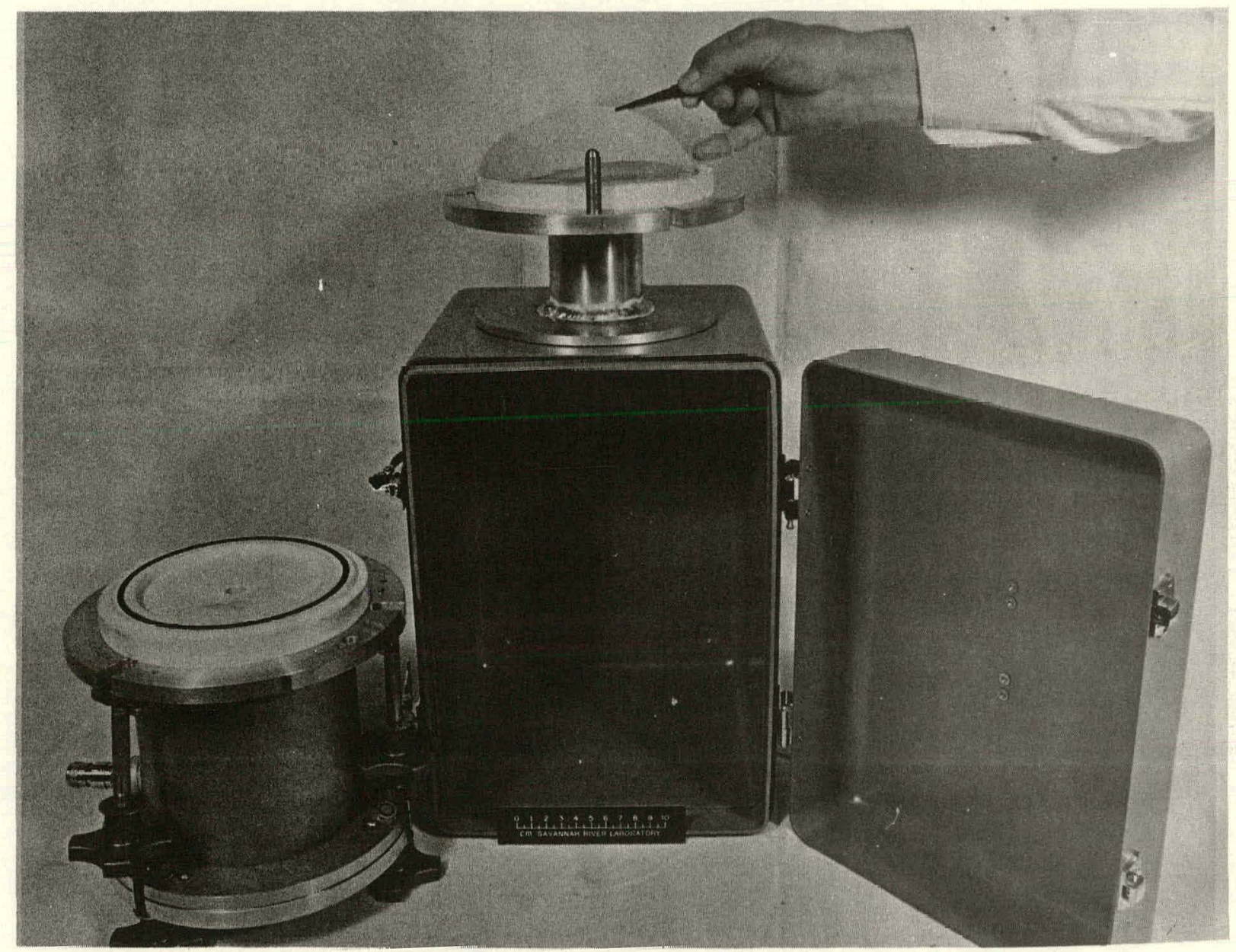

FIGURE B-2. Replacing Filter Membrane in Filter Assemb1y 


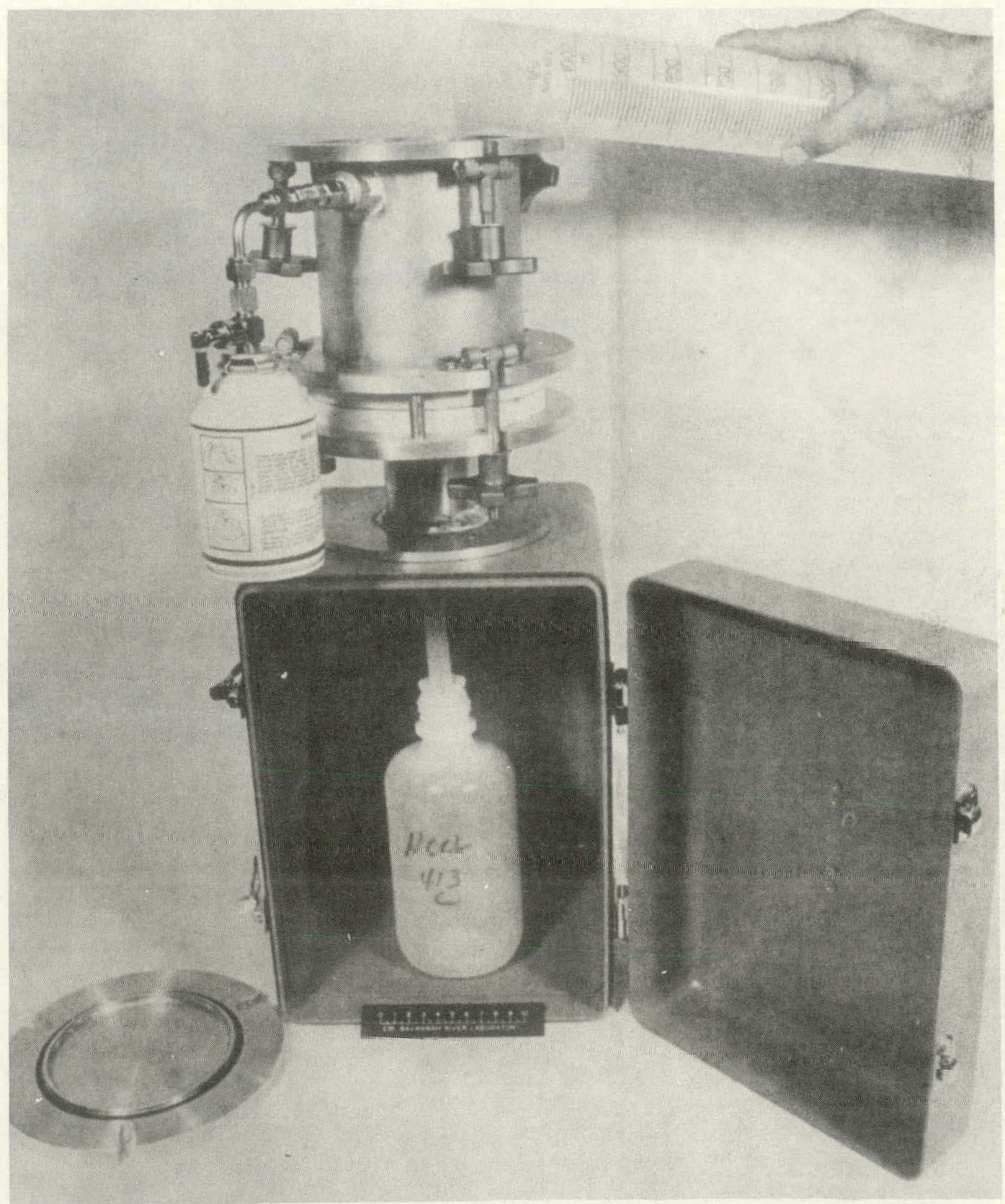

FIGURE B-3. Fround Water Sample Being Poured in Filter Reservoir 


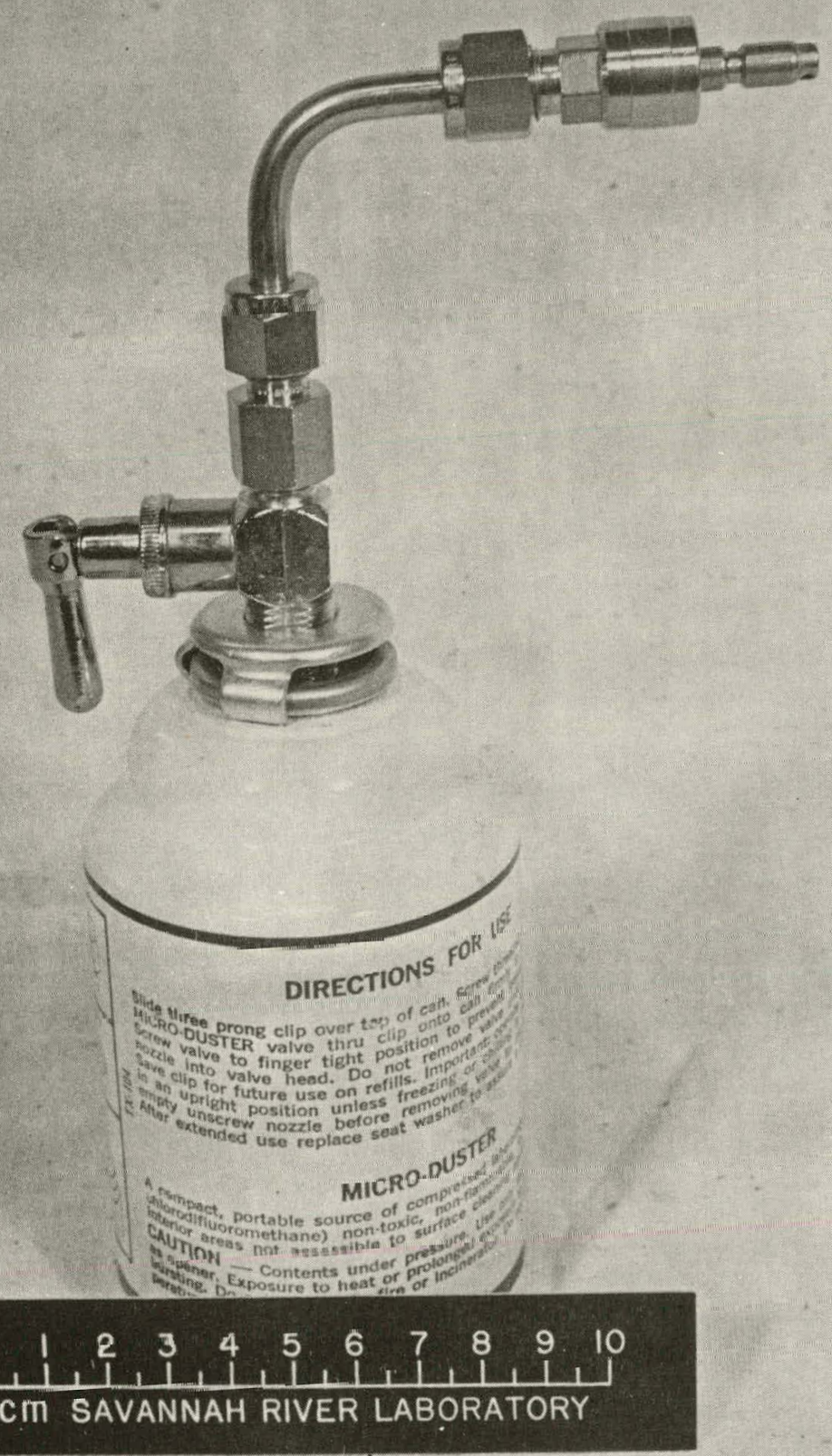

FIGURE B-4. Gas Pressurizing Assembly 
Slightly more than one liter will be needed because $60 \mathrm{~mL}$ (0.06L) of filtered water will be returned to SRL as an acidified water sample as described below.

The field supervisor is supplied with spare 0-rings, tweezers, and other parts or supplies to maintain filter units.

\section{Instrument Case $A$}

Figure B-5 shows the instrument case which contains meters and supplies for measurement of water alkalinity, conductivity, temperature, and $\mathrm{pH}$. The illustrated instruments have proven satisfactory under field conditions, but their inclusion here does not imply that other similar instruments may not also be satisfactory.

Conductivity, temperature, and $\mathrm{pH}$ measurements are made in a water sample as soon as it is taken. Alkalinity should be measured in a filtered water sample because suspended material tends to obscure the subtle color change of an indicator.

\section{Alkalinity}

Alkalinity is a measure of substances in the water which neutralize acid. A simple field titration using dilute sulfuric acid and an indicator which turns pink at a $\mathrm{pH}$ of 4.5 gives very good results. The indicator is a mixture of bromcresol green and methyl red (see Figure B-6). Several drops of indicator (sufficient to impart a decided greenish color) are added to $50 \mathrm{~mL}$ of sample in an Erlenmeyer flask. Using the dropper supplied, drops of $0.01 \mathrm{M}$ sulfuric acid are added to the swirling sample. The number of drops of acid necessary to produce a color change to pink is recorded on the field data form. If no hint of color change is noted after about 20 drops of acid are added, a smaller sample, say $10 \mathrm{~mL}$, should be used and the titration repeated. The volume of sample actually used in the titration should then be recorded on the field form. A calibrated syringe and attachable filter are furnished to filter and dispense an accurately measured sample for titration. The droppers supplied have been selected to deliver similar numbers of drops per $\mathrm{mL}$ of acid. If the $\mathrm{pH}$ of the water sample is 4.5 or less, the indicator will turn pink immediately when added to the samplc. Record the number of drops as zero. Note that a low $\mathrm{pH}(<4.5)$ and a high alkalinity are incompatible. 


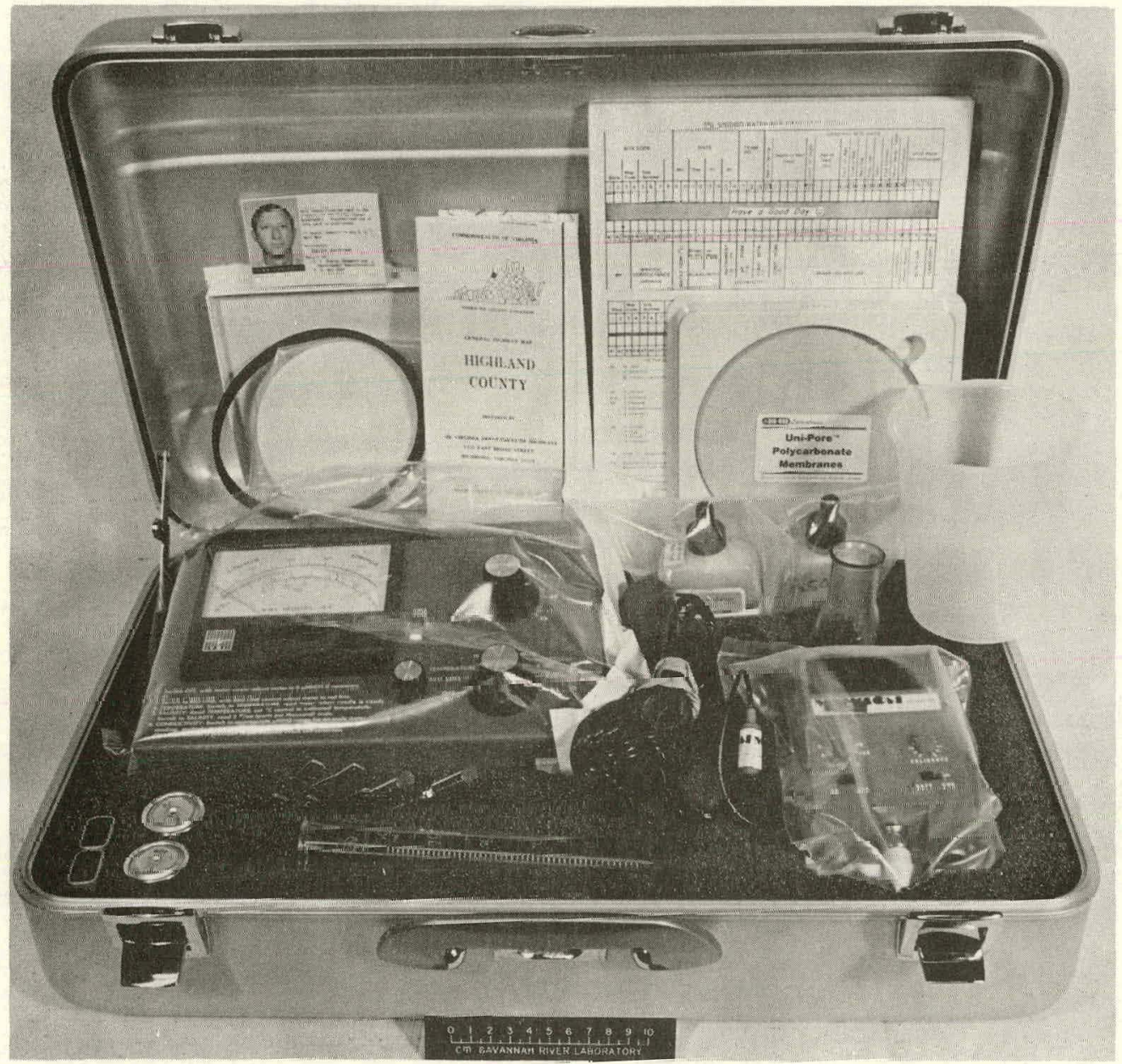

FIGURE B-5. Instrument Case Containing Portable Field Laboratory 


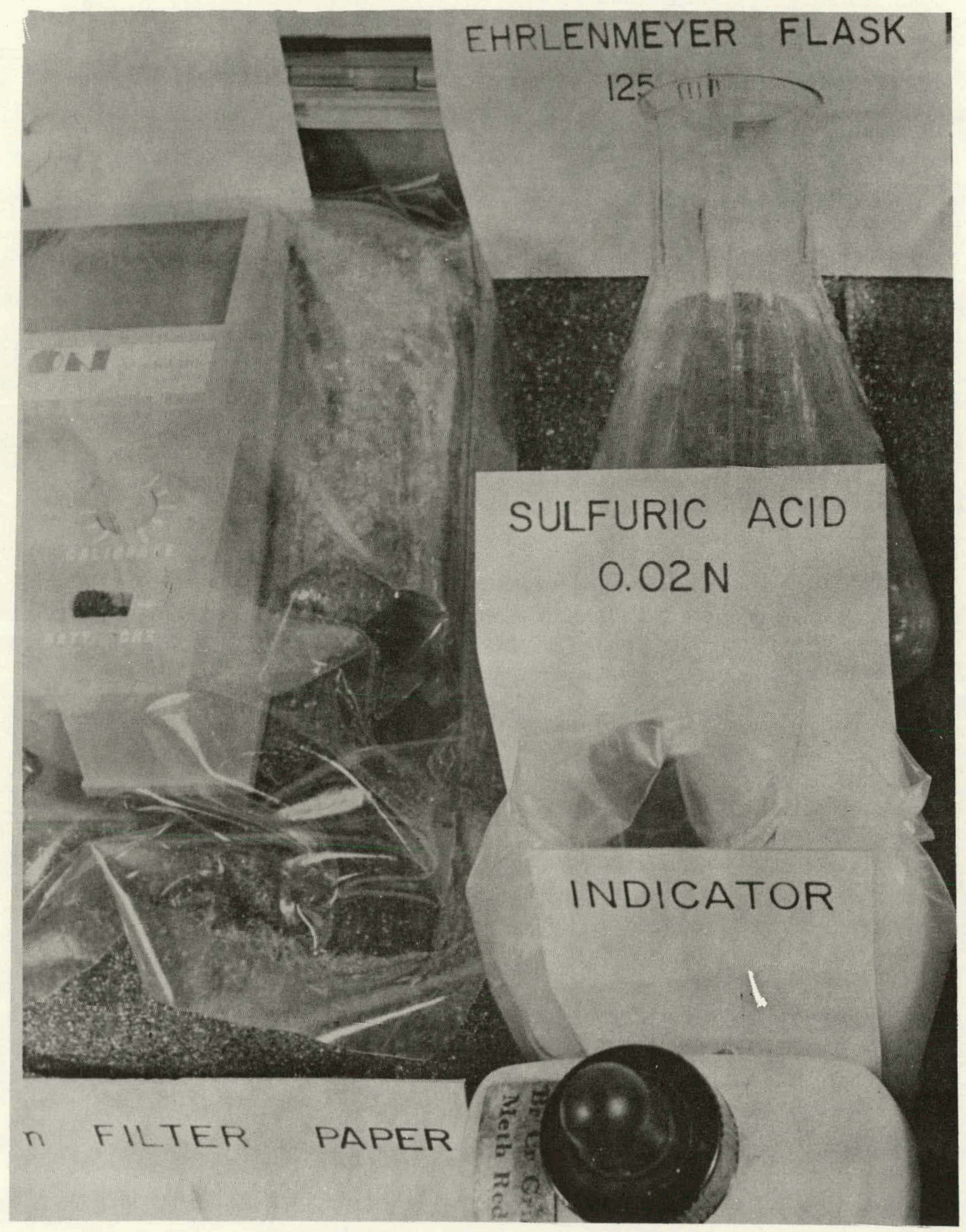

FIGURE B-6. Storage of Acid Bottle in Instrument Case 


\section{Specific Conductance}

Pure water is a poor conductor and conducts electricity in proportion to the amount of material dissolved in it. The unit of electrical conductance is called the mho because of its converse relation to resistance, for which the unit is ohm.

Specific conductance, also called conductivity, is the conductance measured between opposing faces of a 1-centimeter cube of sample at $25^{\circ} \mathrm{C}$. In practice, conductance measurements are made at various temperatures with clectrodes of various sizes and shapes, and are corrected by geometric and temperature factors to obtain a value for the specific conductance, or conductivity, of the solution being testcd.

The conductivity meter (Figue B-7) is checked for proper uperation by setting the switch to the "RED LINE" position and adjusting the small knob until the meter needle points to the red line on the scale. If the needle cannot be adjusted to the red line, the batteries in the meter must be replaced. Immerse the probe in the sample being careful that it is away from container walls and free of any obstructions. At least an inch of sample should surround the probe on all sides. Set the switch to the "TEMPERATURE" position and record the temperature reading in degrees Celsius $\left({ }^{\circ} \mathrm{C}\right)$. (Note the temperature scale reads from right to left.) Now set the $"{ }^{\circ} \mathrm{C} "$ knnb to the measured temperature.

To measure conductivity, rotate the switch slowly through the positions "SAIINITY", X100, X10, and X1 until a significant meter doflcetiun ts obtaincd. Depress the "CELL TEST" button; the reading should remain nearly constant. The meter reading multiplied by the scale factor is the conductivity in micro-mhos (umhos). All necessary correction factors are built in to the meter's electronic circuits.

A dilute solution of potassium chloride in distilled water is supplied for the daily instrument rheck. The conductivity of the $0.001 \mathrm{M} \mathrm{KC} 1$ solution is approximately $150 \mu \mathrm{mhos}$ at $25^{\circ} \mathrm{C}$. If the value obtained is significantly different at a given temperature from that shown in Figure B-7b obtain a new nrobe ur instrument from your ficld supervisor. Do not sample without a properly operating conductivity meter.

\section{pH}

$\mathrm{pH}$ is a measure of the hydrogen ion (acid) concentration in the water. A pH meter similar to the one shown in Figure B-8 will be in each sampling kit (a DEPRESS-TO-READ switch is not visible in this photograph). The $\mathrm{pH}$ meter must be calibrated at the beginning of each day's work and should be checked at frequent intervals. 


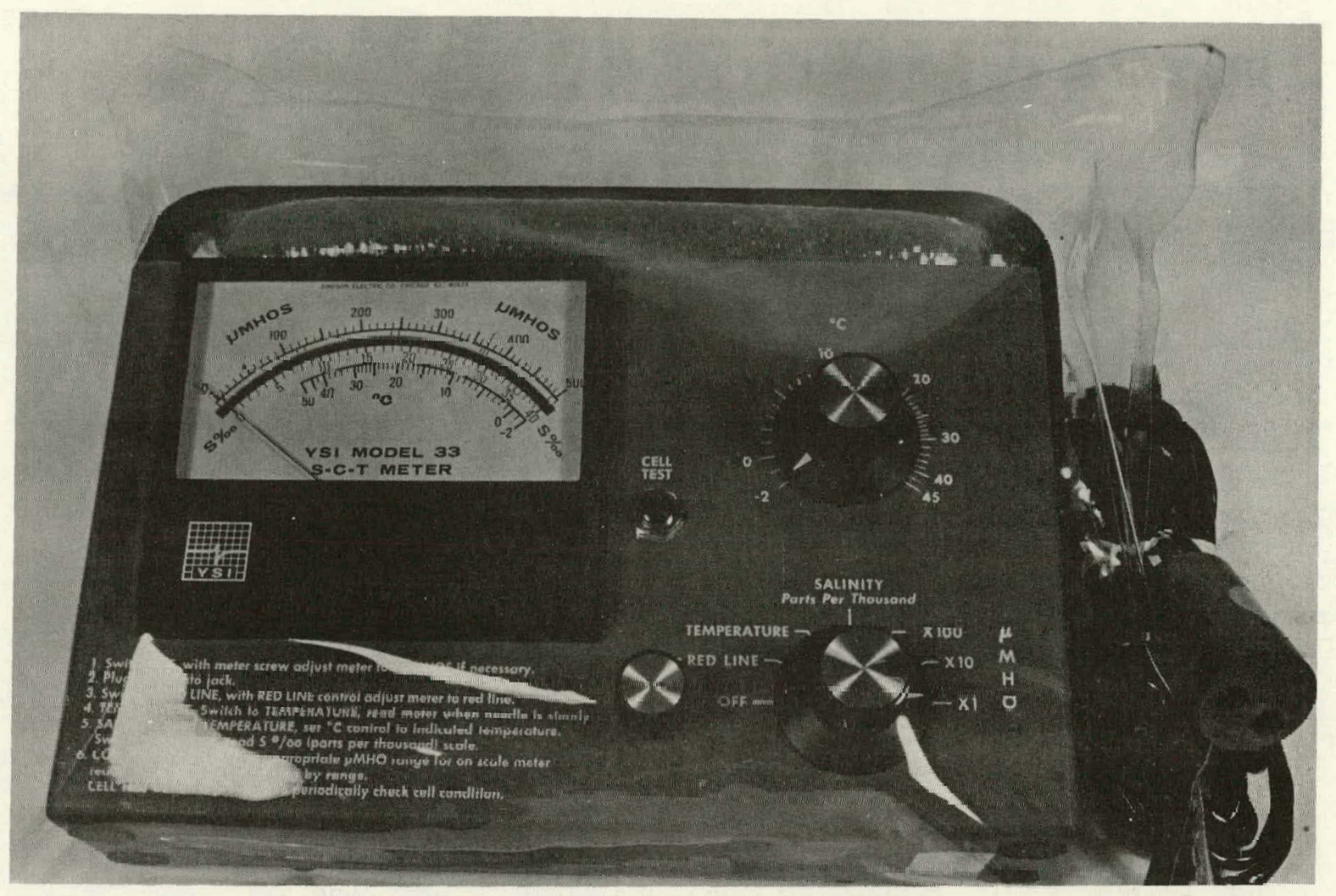

a. Conductivity Meter

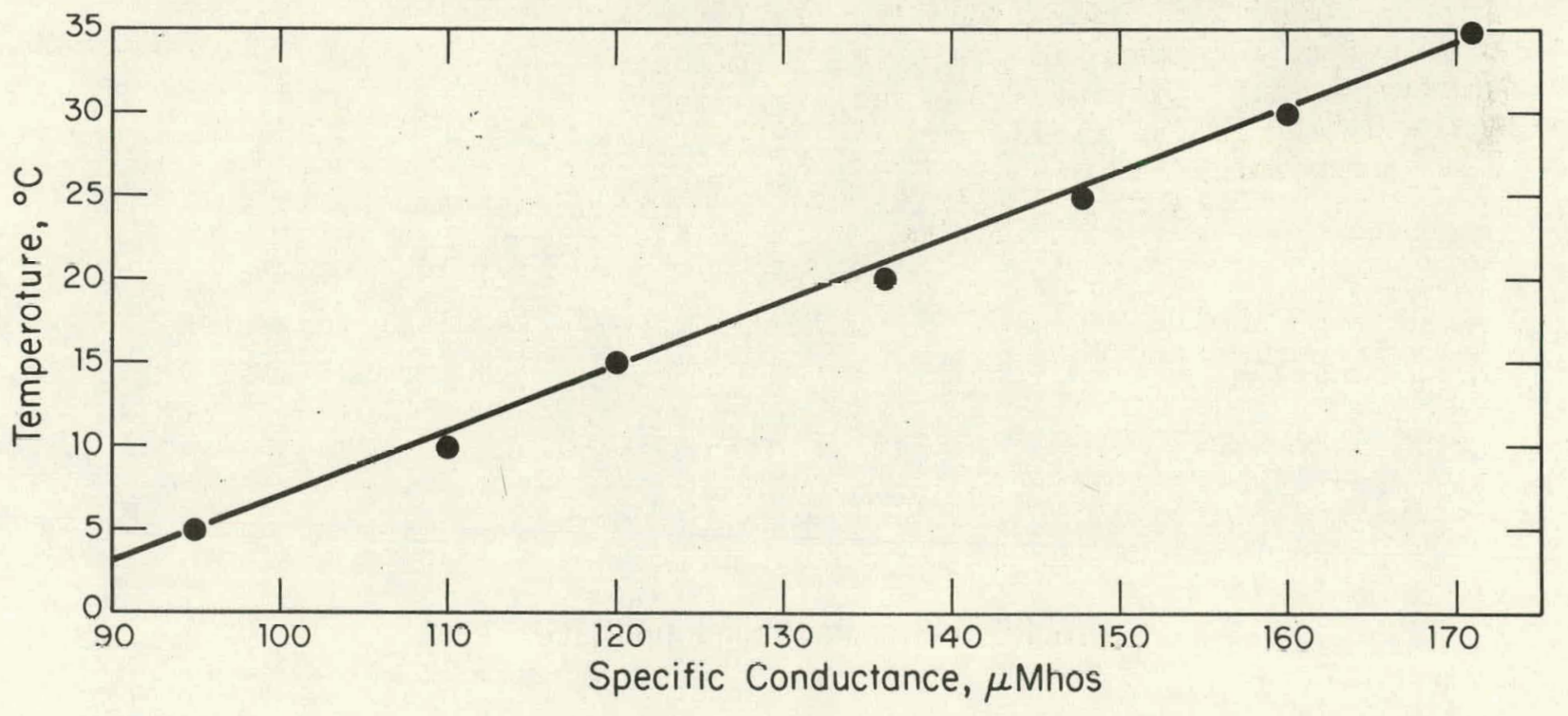

b. Plot of Conductivity vs Temperature for 0.001M KCl Solution

FIGURE B-7. Conductivity Meter 


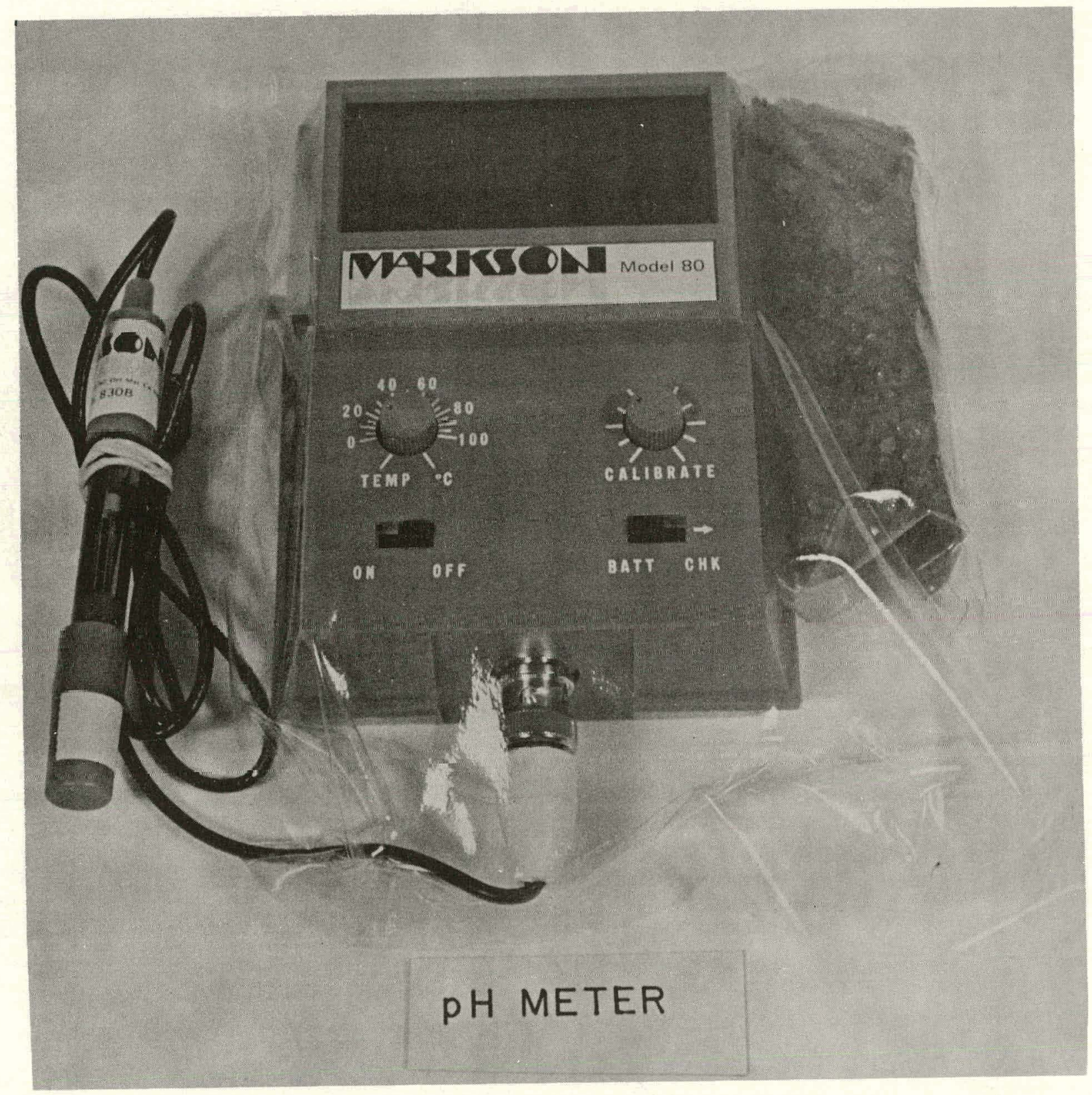

FIGURE B-8. Packaged pH Meter 
The procedure for $\mathrm{pH}$ meter calibration is as follows:

Connect the probe to the meter. Remove the plastic boot and immerse the probe in $\mathrm{pH} 7$ buffer.* Turn the meter on, check the battery by pressing the "BATTERY CHECK" switch to right - a red dot will appear in the display. If this dot is very dim or goes out when the "READ" switch is depressed, batteries may need replacement.

Adjust the "CALIBRATE" control for a reading of 7.0 (note the "READ" button must be depressed). Rinse the probe in distilled water and place it in $\mathrm{pH} 4$ buffer; adjust the "TEMP" knob for a reading of 4.0. Rinse probe again and check in $\mathrm{pH} 10$ buffer. Reading in $\mathrm{pH} 10$ buffer should be within $\pm 0.1 \mathrm{pH}$ unit of 10.0. If not, then adjust the meter using the "CALIBRATE" knob for a reading of 10.0 , rinse and check at $\mathrm{pH} 4$ and readjust "TEMP" knob for 4.0 if necessary. Rinse and recheck at 7.0.

A properly operating meter should give readings correct within $\pm 0.1 \mathrm{pH}$ unit at 4,7 , and 10 . If your meter is not within $\pm 0.2 \mathrm{pH}$ units in all three buffers, you need a new probe, new batteries, or a new meter. Do not sample without a properly operating $\mathrm{pH}$ meter.

Field $\mathrm{pH}$ measurements are made by placing the probe in the sample and taking a reading after allowing a few seconds for equilibration. If a reading $<4$ or $>9.5$ is obtained, the meter calibration should be rechecked using the 4 or 10 buffer. Recalibration may be necessary. Between uses, the probe is left wet and covered by the plastic boot.

Note that the $\mathrm{pH}$ and conductivity meters are wrapped securely in plastic together with a small bag of silica gel desiccant. This protection may be necessary in humid areas to prevent condensation of moisture within the instrument and consequent erratic operation. Desiccant, plastic bags, and tape will be furnished to field supervisors.

A daily log should be kept of the results of all meter calibrations. This log may provide early warning of instrument malfunction. Logs should be examined weekly by the field supervisor. Any instruments returned to SRL for replacement or repair should be accompanied by $\log$ sheets.

* New probes should be soaked overnight or for a minimum of one hour in $\mathrm{pH} 4$ buffer before use. The same treatment should be given to any probe which is allowed to dry. Older probes may sometimes be rejuvenated by soaking in a degreasing solution such as a commercial non-abrasive tub and tile cleaner. 


\section{Ion Exchange Equipment}

Severa1 items of equipment and supplies necessary for ion exchange removal of dissolved material from water samples are discussed below.

\section{Ion Exchange Resin}

A special high-purity, mixed, ion exchange resin (100 to 200 mesh) is packaged in 2-ounce polyethylene bottles. This resin is packaged in special clean areas. DO NOT OPEN a bottle until just before using. Special care should be taken to prevent lust from getting into the resin or into the filtered water. If contamination is suspected, discard the contaminated resin or water.

\section{Interchange cap}

A special interchange cap has been designed to enable the 1iter bottle of sample water to be coupled to the 2-ounce bottle of ion exchange resin. The interchange cap allows resin to be added to the water sample without dust getting into the sample. The interchange cap is also used to transfer the resin back into the 2-ounce bottle (Figure B-9).

\section{Sliprer}

A 6-volt, direct current slirrer and hattery (Figure B-10) are pluvided to stir the ion exchange resin in the filtered water sample. The resin is stirred a minimum of 10 minutes. A special 6-volt battery charger is provided to recharge the battery each evening. A spare battery is also provided. A fully charged battery will provide more than 20 hours of stirring. In an emergency, a standard 6-volt lantern battery can be used.

\section{Ion Exchange Resin Recovery Case}

An $\Lambda$ BS plaslic case is provided to carry 28 one-liter hottles. After the water samples are collected, filtered, and treated with the ion exchange resin ("ion exchanged"), the bottles are inverted in the carrying case to recover the resin. This is pictured in Figure B-11. Most resin will settle through the interchange cap into the 2-ounce bottles by the end of the day. 


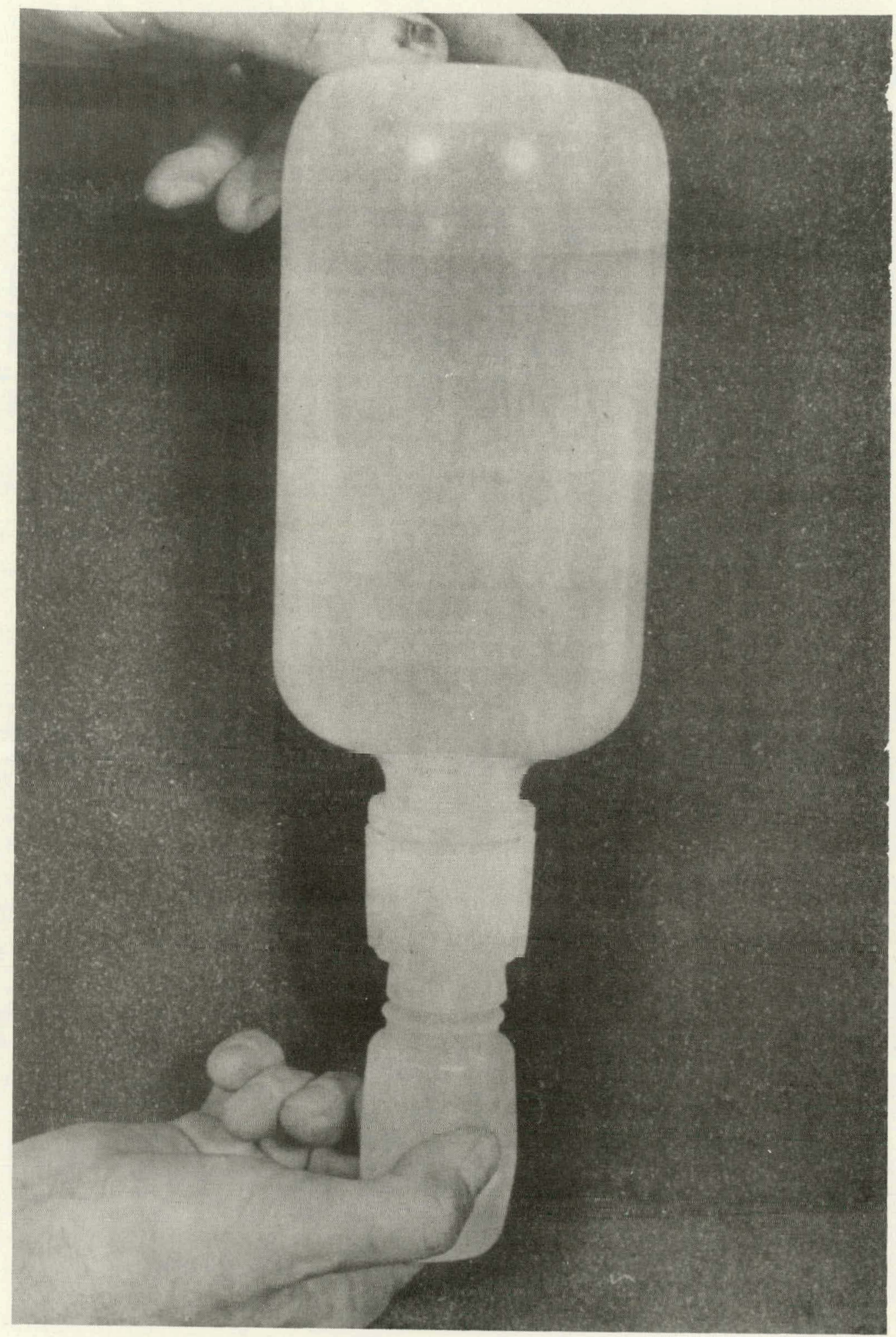

FIGURE B-9. Transfer of Ion Exchange Resin between Bottles 


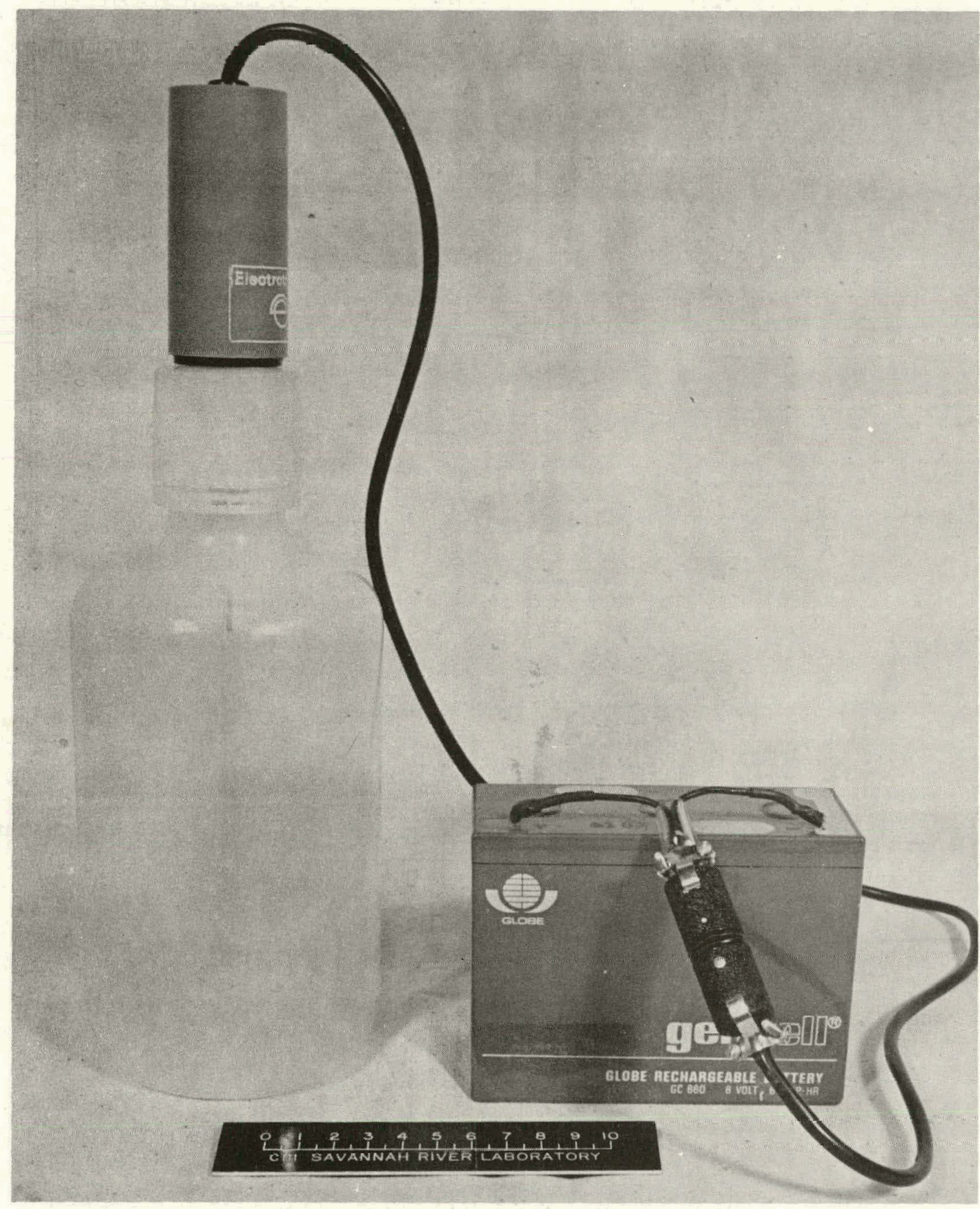

FIGURE B-10. Stirring Assembly for Ion Exchange Bottle 


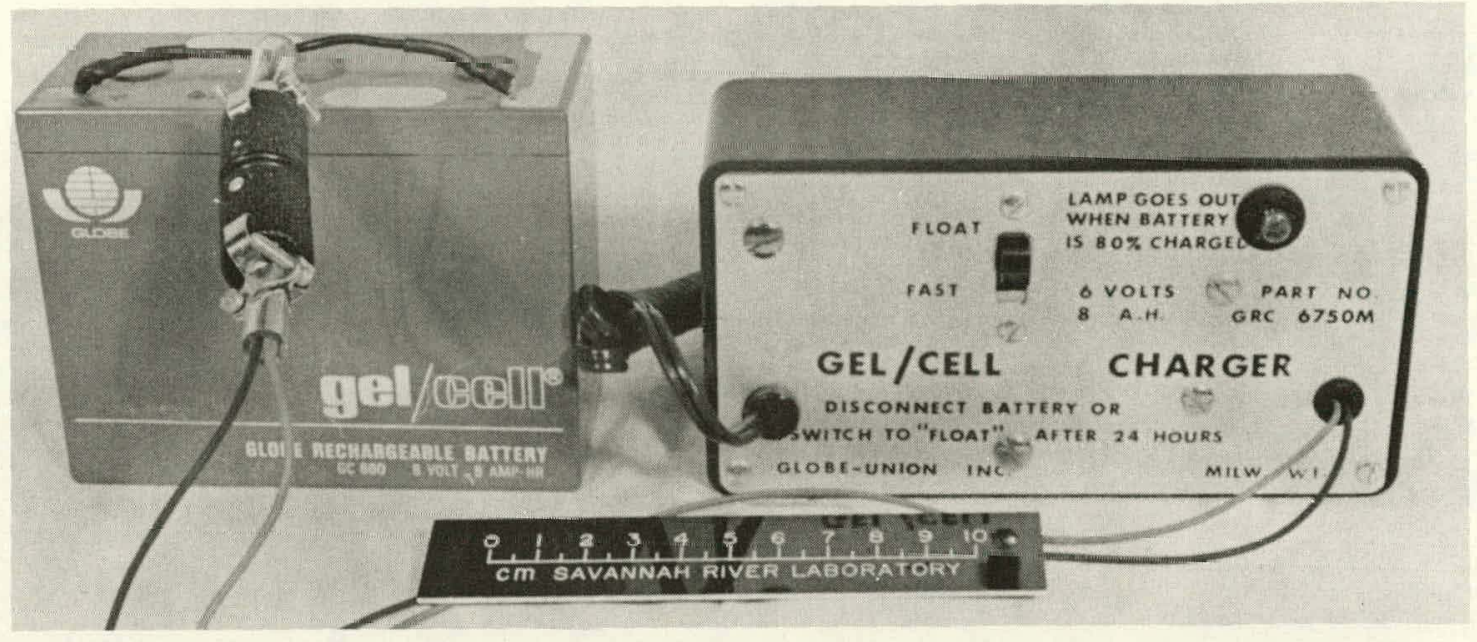

b. Stirrer

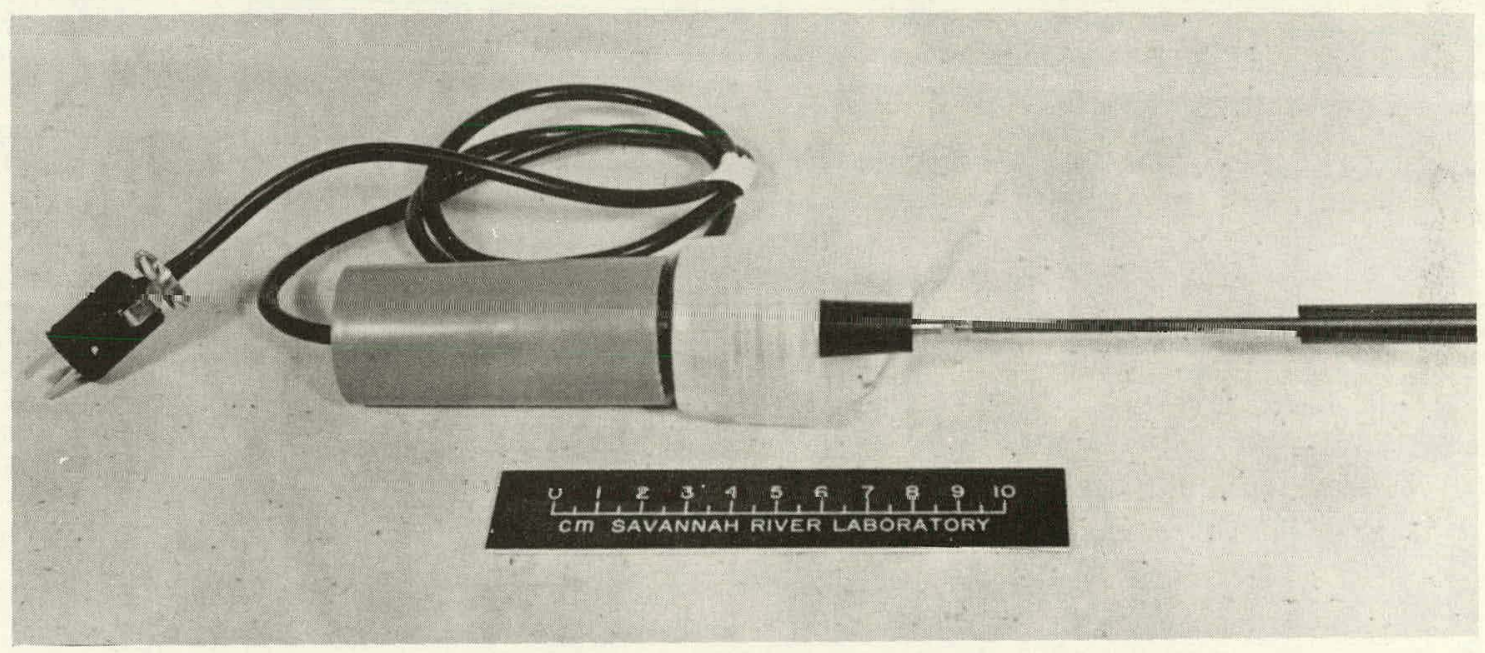

c. Battery and Battery Charger

FIGURE B-10. Continued 


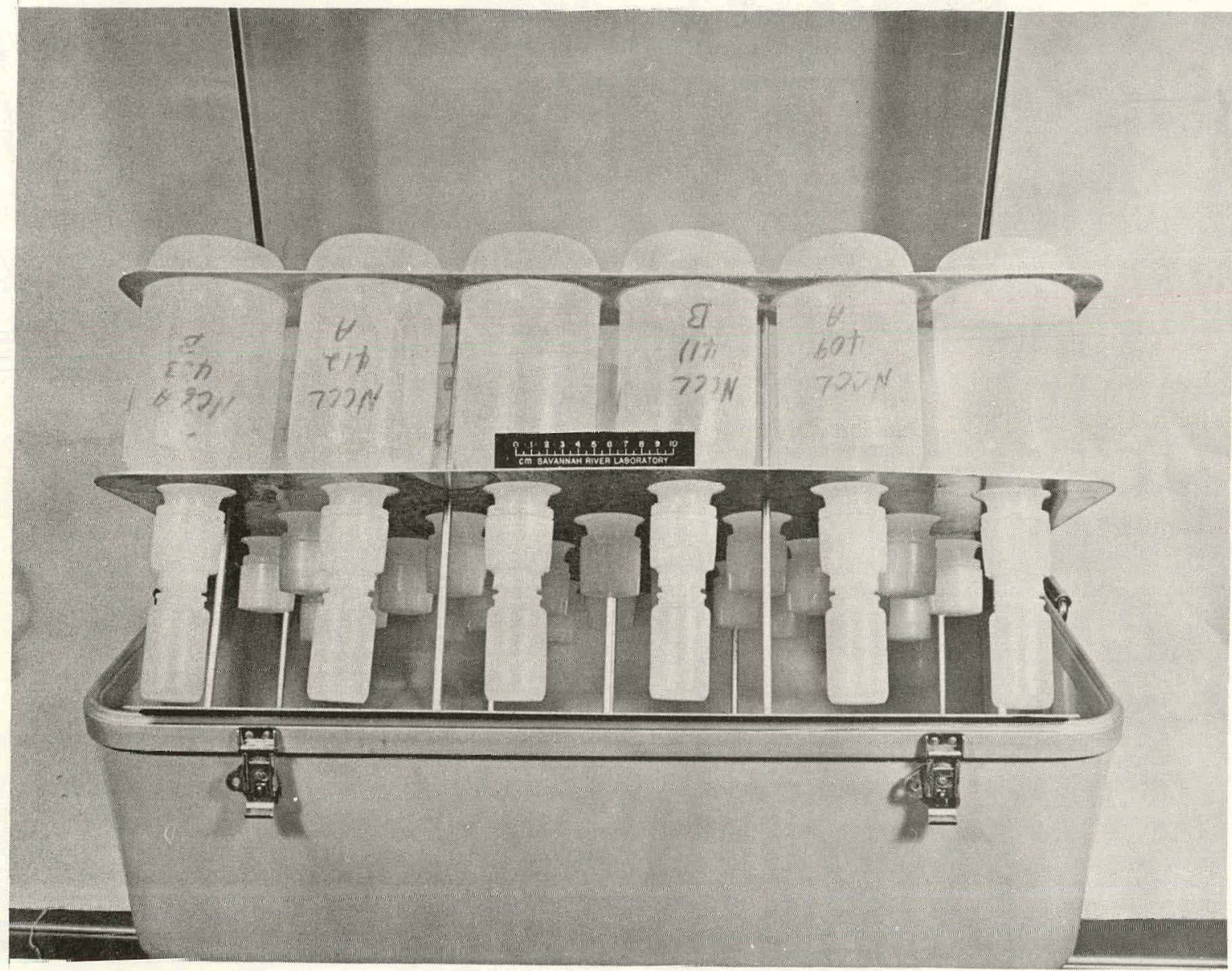

FIGURE B-11. Ion Exchange Bottles in Carrier Ready for Transporting 
The procedure for ion exchange of water samples is as follows:

Enter the Site Code on a gummed label in pencil and attach that label to a 2-ounce bottle of fresh ion exchange resin. Cover the label with transparent tape. Using the ion exchange interchange cap, transfer the resin from the labeled 2-ounce bottle of resin into the filtered water sample. Remove the interchange cap and 2-ounce bottle (keep it clean by placing on an unused liter bottle). Place the 6-volt stirrer into the water-resin mixture and stir until the next site is reached (at least ten minutes). When the stirrer is removed, rinse and insert the stirrer in a fresh 1-liter bottle to make sure that it remains clean until used again. Replace the labeled 2-ounce bottle and interchange cap on the sample, invert, and place in the resin recovery case.

The amount of filtered water which is allowed to react with ion exchange resin will normally be exactly one liter. It is possible for one liter of water to contain more dissolved solids than can be removed by the resin. Conductivity gives a measure of the concentration of dissolved material and is used to estimate the amount of water to be ion exchanged. For samples with a conductivity of less than $500 \mu \mathrm{mhos} / \mathrm{cm}$, a full liter can be used. If the conductivity is between 500 and $1000 \mu \mathrm{mhos} / \mathrm{cm}$, then $1 / 2$ liter $(500 \mathrm{~mL})$ is used. If the conductivity is between 1000 and $2000 \mu \mathrm{mhos} / \mathrm{cm}, 200 \mathrm{~mL}$ of the filtered water are used. If the conductivity exceeds $2000 \mu \mathrm{mhos} / \mathrm{cm}$, on 1 y $50 \mathrm{~mL}$ of the filtered water are used. The volume used must be recorded on the field form. If the sample volume is only $50 \mathrm{~mL}$, you may pour it directly into the 2 -ounce bottle of resin without use of the stirrer.

At the end of the field-day, resin is recovered into the labeled 2-ounce bottles which are securely capped for shipment. Caps may be stured in the clean plastic bag in which resin is issued.

\section{Water Deionizer Colums}

A water deionizer, consisting of three columns, is provided to obtain deionized water for rinsing. The first column contains activated charcoal to remove organics and chlorine. The second and third columns contain mixed-bed, ion exchange resin to remove dissolved ions. Use drinking water as supply water for the columns. When the color changes on $\sim 1 / 2$ the length of the second column (indicating it is exhausted), replace the first and second columns. The deionized water supply is used for rinsing the filter apparatus between samples. 


\section{Acidified Water Samples}

Two-ounce plastic bottles containing $1 \mathrm{~mL}$ of dilute ultrapure nitric acid have been prepared under clean conditions. At each sampling site where water is filtered, one of these bottles should be labeled with the SITE ID and nearly (but not quite) filled with filtered water. Water level should be about half-way up the threads. Tops and labels should be securely taped.

\section{Sampling for Helium Analys is of Ground Water}

\section{Materiatia Needed}

1. 10-ounce soft-drink bottles

2. Caps

3. Capper

4. Syringe

5. Shipping Box

\section{Procedure}

After running the tap for several minutes to flush out all pipes, a 10-ounce soft-drink bottle is carefully filled to overflowing. Since helium will escape very quickly from water to air, any splashing or bubbling must be held to an absolute minimum during filling. If the tap has a screw-on aerator, it must be removed before sampling.

A small syringe is used to withdraw $2 \mathrm{~cm}^{3}$ of water from the bottle, creating a $2 \mathrm{~cm}^{3}$ air volume above the water sample.

As soon as possible, a cap is placed on the bottle and firmly seated using the capper.

THE TIME BETWEEN SAMPLE COLLECTION AND SECURE SEALING OF THE BOTTLE SHOULD BE KEPT UNDER FIFTEEN SECONDS.

After sealing, the hottle is inverted, labeled, and stored in the shipping case furnished by SRI. Much of thr helium will exsulve into the air gap, which is now against the thick base of the bottle. It is especially important to invert the bottle since helium can diffuse fairly quickly through the metal cap.

Labels should indicate the SITE ID (e.g., STC $\varnothing$ 567) and should be securely taped. 


\section{Sediment Sampling}

Two devices are supplied specifically for obtaining samples of stream sediment.

\section{Scoop sampler}

A jaw scoop sampler is provided for reaching sediment in small inaccessible areas (Figure B-12). This sampler is springloaded and should be used with care. The sampler attaches to a fiberglass staff. The attachment angle of the scoop can be varied from $90^{\circ}$ to $180^{\circ}$ for use under conditions ranging from clay through silt and sand to rocky bottoms.

\section{Bag Sampler}

The bag sampler consists of a stainless steel tube with an attached bail, band clamp, and removable drill bag (Figure B-13). The attachment point of the bail was carefully selected to force the sampling element down into the sediment as the bail rope is pulled. The bag sampler was designed primarily for sampling sand or silt sediments. It is thrown slightly across- and downstream and then dragged UPSTREAM against the flow. This technique keeps even very fine silt in the bag and effectively samples the midchannel of the stream. Make certain the knot holding the sampler is strong and the other end of the rope is secure before throwing the sampler. Use a new cloth bag for each NEW site. The bag should be turned inside-out (seams out) before attaching to the bag sampler.

A smal1 shovel or hand trowel is supplied for sediment sampling in arid regions.

Twelve-inch-diameter stainless steel sieves are supplied for field sieving of sediment samples. Samples are composited onto the screen before sieving. Any water in the bottom pan should be carefully decanted so that fine material is not lost. Spatulas or plastic scoops are supplied for transfer of the sieved material to paper sample bags.

Where an area is significantly contaminated by windblown sand, an 18- and 40-mesh sieve will be used and two bags of sample will be taken. The material coarser than 18 mesh (1arger than $\sim 1 \mathrm{~mm}$ diameter) is discarded. The material passing the 18-mesh sieve but retained on the 40 -mesh sieve $(0.5 \mathrm{~mm}$ to $1 \mathrm{~mm}$ diameter) is bagged and labeled with the site code and the designation "-18+40." The material passing the 40 -mesh sieve (smaller than $0.5 \mathrm{~mm}$ diameter) is bagged and labeled with the site code and the designation "-40." 

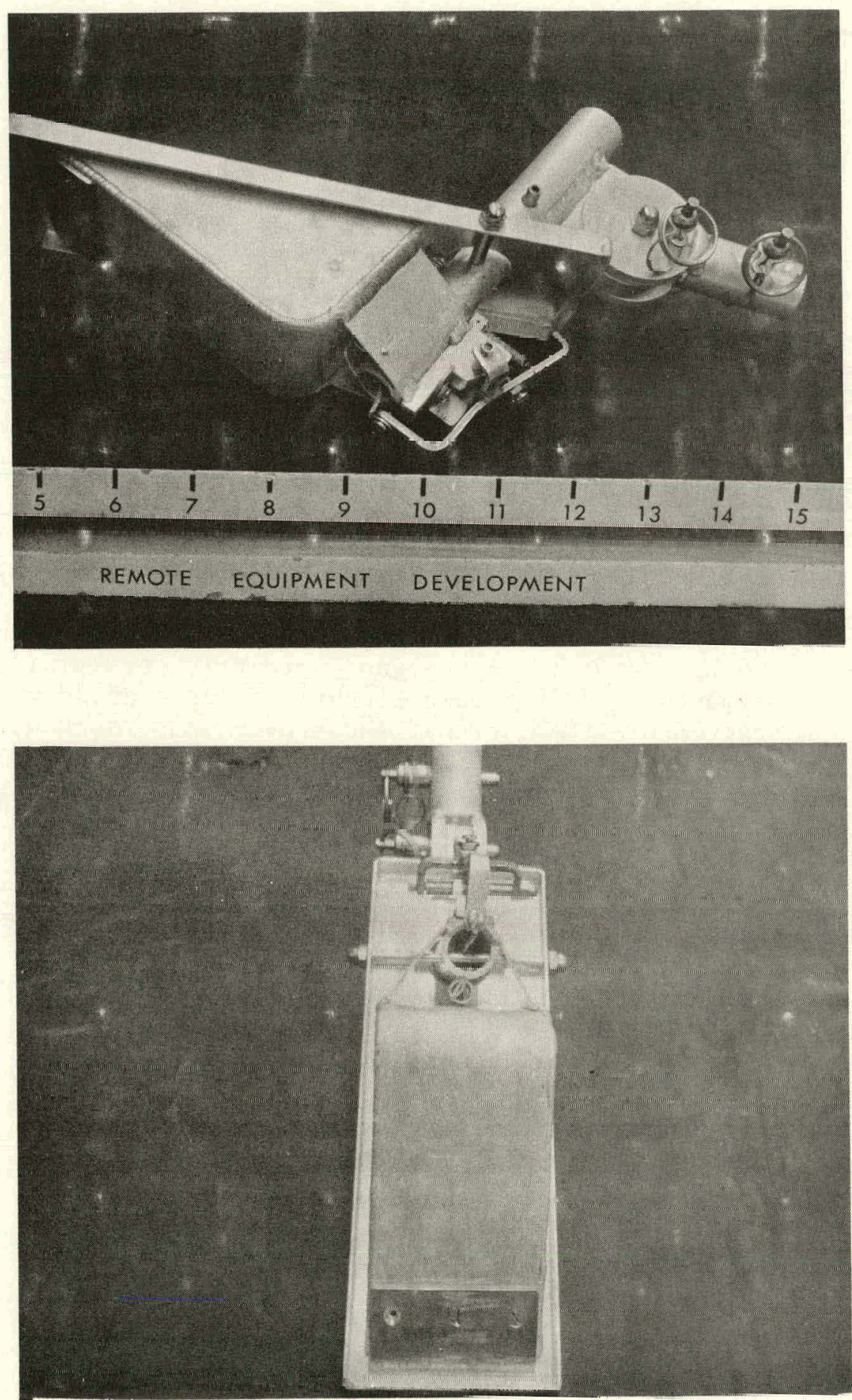

FIGURE B-12. Scoop Sampler for Collecting Confined or Coarse Bottom Sediments 


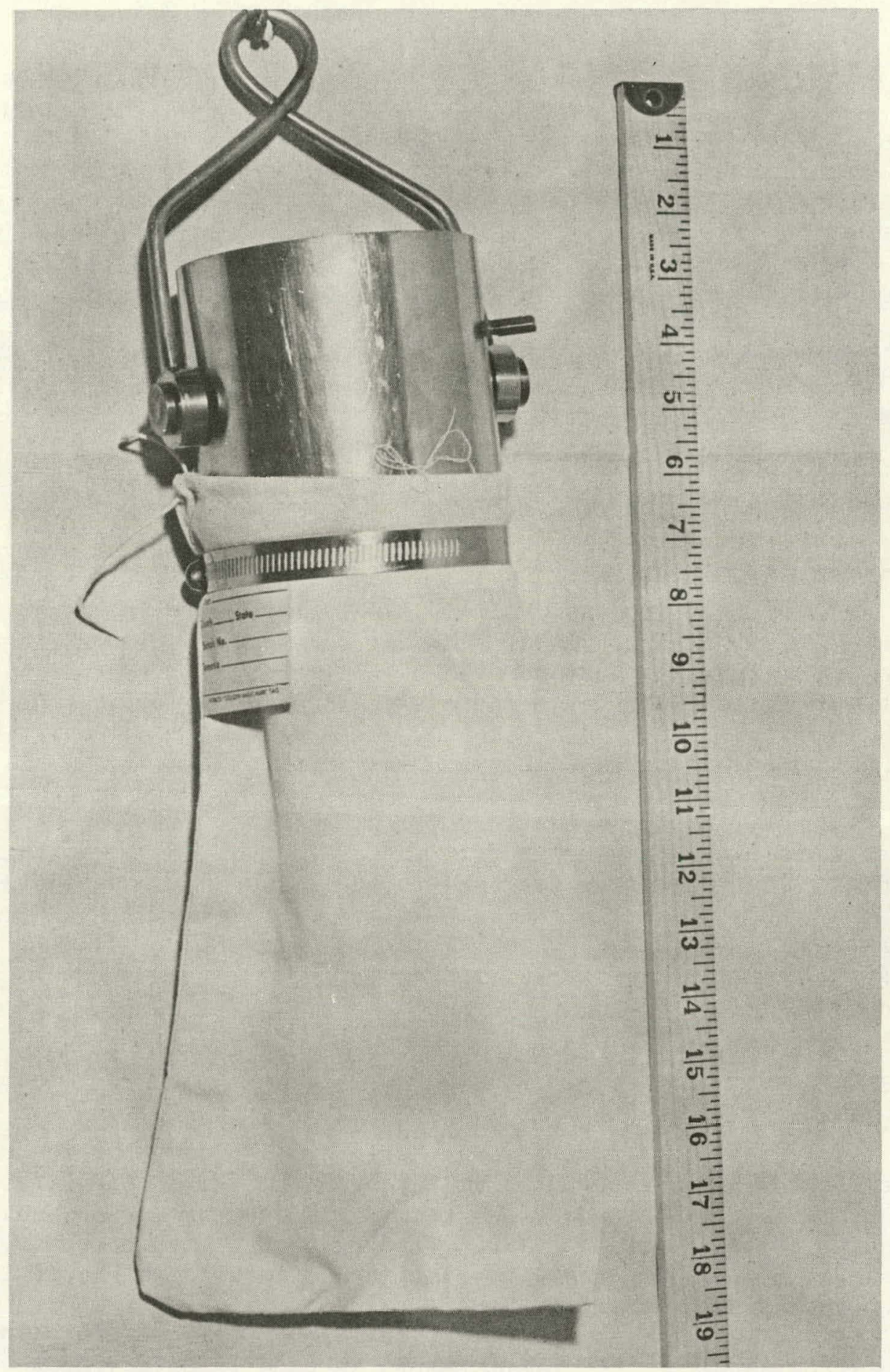

FIGURE B-13. Bag Sampler for Collecting Loose, Fine, Bottom Sediments 
The mesh designation should only be used at sites where both sizes are collected. To ensure an adequate quantity, both the 18- and 40-mesh sieves must be used at the site.

The sediment sample bag is shown in Figure B-14. A minimum of $1 / 2$ bag of sample ( $150 \mathrm{cc}$ or $\sim 1 \mathrm{~b}$ ) is required because the sample may be sieved in the laboratory into various fractions for analysis.

After testing a variety of pens, pencils, and inks, the Flowmaster ${ }^{\circledR}$ pens supplied with each kit were selected for labeling sample bays. Label the top fold of the paper sediment bag using ONLY a Floumast.p.r ${ }^{\circledR}$ pen. The sitc code is willlen un both sides of the top fold. It is suggested that the bag be labeled before the sediment is put in it.

SPFCTAL NOIE: $\Lambda 11$ writing musL ve LEGIBLE ANU L'URREC'T".

After labeling and filling, tie a piece of white cord through the folded top of the paper sediment bag. Allow the sample to air-dry. [Samples must be OVEN-DRIED ( 90 to $100^{\circ} \mathrm{C}$ ) before shipment to SRL; up to $30 \mathrm{hr}$ may be necessary to dry some samples.] Moisture from improperly dried samples may cause weakening and bursting of bags and secondary containers during shipment.

A small brush is provided for cleaning sieves between sites. Brush the sieve thoroughly from top and bottom, thon tap the rim briskly in a direction diagonal to the wires and brush thoroughly again.

\section{Scintillometers}

Scintillometers (Figure B-15) are provided for gross radioactivity measurements at each sampling site. To measure radioactivity, walk to an area free of unnatural or foreign influcnecs such as ruad pavement or gravel ur construction materials. Hold the instrument at a convenient height ( 30 in. to $50 \mathrm{in}$. above the ground), and record the count rate in counts per second (cps). Try to obtain a reading characteristic of the general area of the sampling site; don't look for highs or lows.

There are two scales, $0-100$ and $0-300$, on the scintillometer. A switch labeled "FULL SCALE RANGE" is used to determine the appropriate scale or multiplier. Settings of $0.1 \mathrm{~K}$ and $0.3 \mathrm{~K}$ are 100 and 300 cps full scale, respectively; $1 \mathrm{~K}$ and $3 \mathrm{~K}$ are 1000 and $3000 \mathrm{cps}$, and $10 \mathrm{~K}$ means $10,000 \mathrm{cps}$ full scale. On the $10 \mathrm{~K}$ setting, 30 on the $0-100$ scale (or 90 on the $0-300$ scale) means a count rate of $3000 \mathrm{cps}$ should be recorded. 


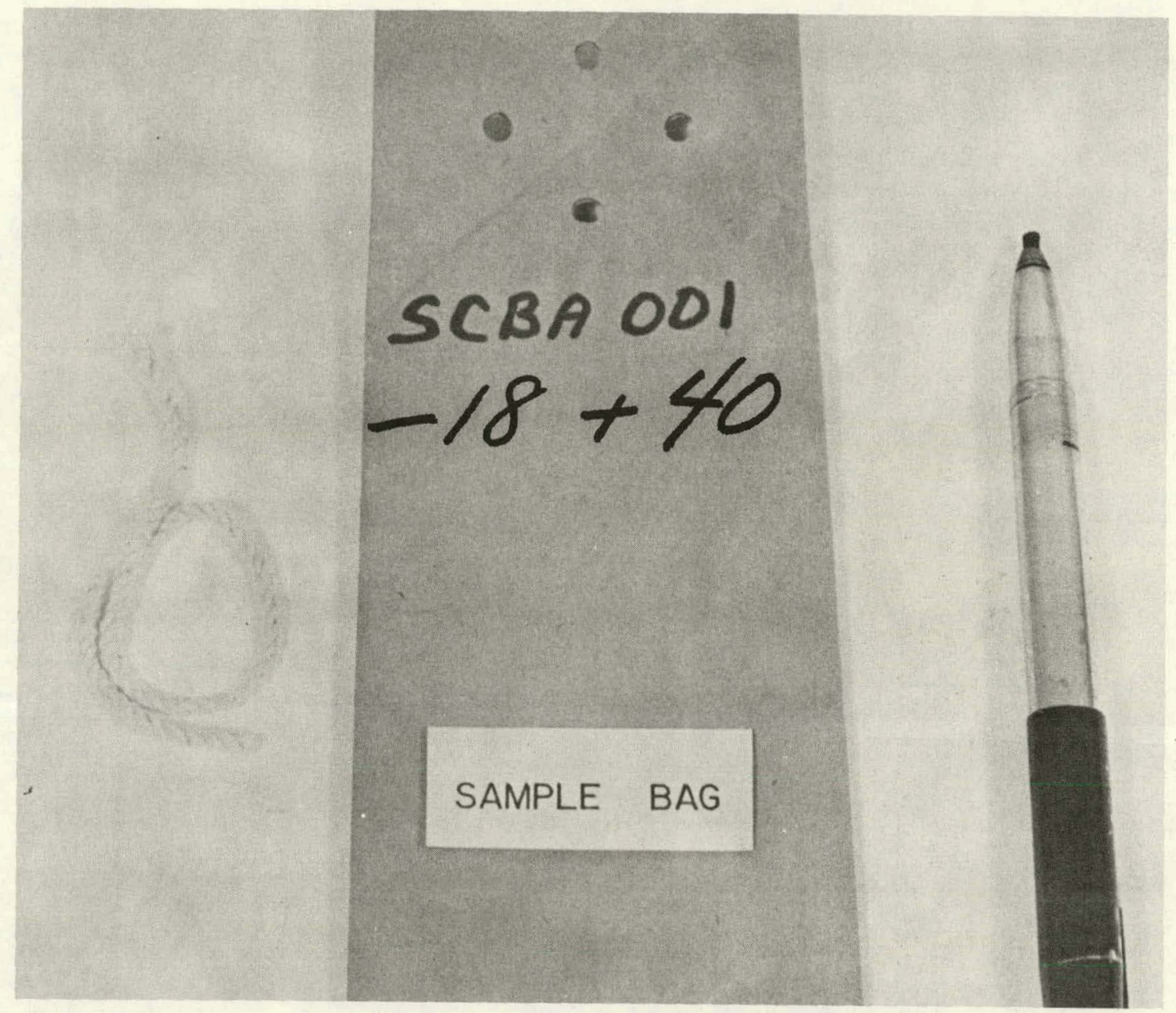

FIGURE B-14. Kraft Paper Bag for Sediment Sample 


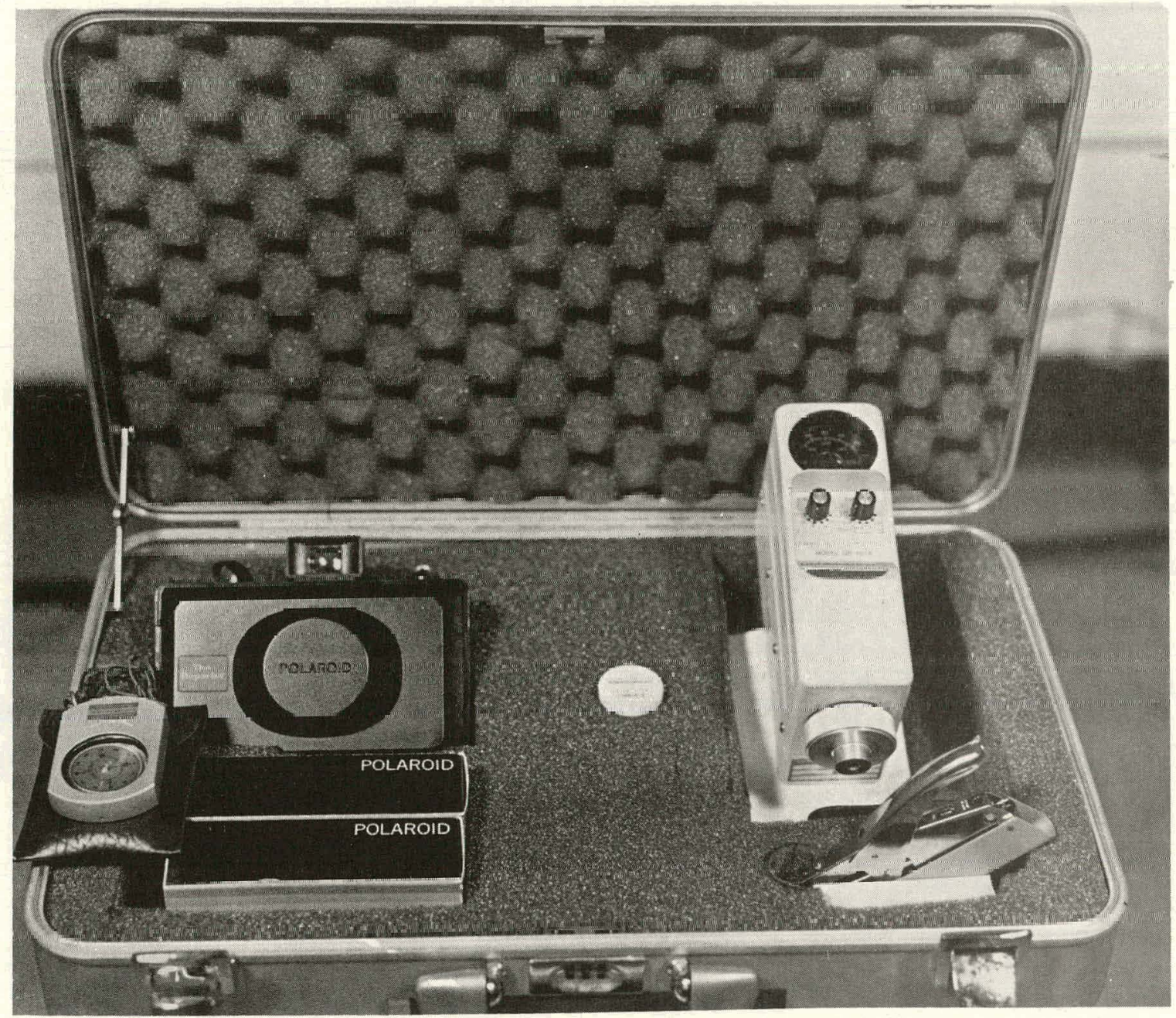

FIGURE B-15. Instrument Case B, Containing Scintillometer, Test Source, Camcra, Film, Compass, and Literature 
The "FUNCTION" switch provides positions for a battery check and meter operation with or without an audio alarm. Fresh batteries should give nearly full-scale meter deflection and batteries should be replaced if they give less than $70 \%$ of a full-scale deflection.

A plastic disc containing a small radioactive source is included for checking the scintillometer. A reading of about $450 \pm 25 \mathrm{cps}$ should be obtained with this disc. If a significantly different reading is obtained, your field supervisor will replace your scintillometer. Do not sample with an improperly operating meter. DO NOT SCRATCH OR RUB THE DISC SURFACE!

The audio alarm feature allows the meter to be carried conveniently and referred to only in areas of high radioactivity. The radioactivity measured at normal sampling sites should be an average for that site. The scintillometer, set in alarm mode, may provide some basis for selection of supplemental sampling sites.

\section{Cameras}

Land-process (Polaroid $\left.{ }^{(\mathbb{R}}\right)$ cameras are provided to capture salient features of the sampling site to facilitate quality assurance field checks. Photographs are made and stapled to the field data cards at each site.

In addition to the photograph, a description of the sampling site is written on the back of the field card. An adequate description consists of all information necessary to reach the site from a prominent landmark and all information necessary to unequivocally recognize the site once it is reached. These descriptions are used in quality assurance checking. If the site cannot be found, it is assumed to have been sampled incorrectly. Remember that failing quality assurance tests may be grounds for reduction or cancellation of sampling contracts. 


\section{B. INSTRUCTIONS FOR SAMPLING}

The following section is written assuming that the sampler is thoroughly familiar. with all methods, equipment, and supplies. A generalized procedure is outlined which can be adapted for nne- or multi-member sampling parties.

Separate instructions are given for ground water, humid area surface sampling, and arid area surface sampling. Adaptations may also be made in the event that one sampling team is collecting both ground water and surface samples in an area.

Ground Water Sampling

1. Check with Field Supervisor to assure that owners of large land tracts and public officials have been contacted.

2. Go through equipment checklist (Table B-1) and clean and inspect the equipment.

3. Plan sampling route for efficient use of available roads.

4. Locate we1l or spring and accurately lnrate site nn map.

5. Follow the sampling outline given in rable $\mathrm{B}=\mathrm{2}$.

Surface Sampling in Humid Areas

1. Check with Flcld Supervisior to assure that access clearances for any major restricted areas have been granted and that all appropriate public officials have been notified.

2. Check equipment and supplies (Table B-1). If stream water is not being collected, you should have Items 1 through 15 in Group A of Table B-1.

3. Check equipment and supplies in Table B-3.

4. Plan route.

5. Follow sampling instructions outlined in Table B-4. 


\section{Surface Sampling in Arid Areas}

1. Check with Field Supervisor for access clearance.

2. Check equipment and supplies in Table B-1. Items A- 1 through A-15 should be available.

3. Check equipment and supplies in Table B-3.

4. Plan sampling route.

5. Follow sampling instructions outlined in Table B-5.

6. Police area. 


\section{TABLE B-1}

Daily Work and Equipment Checklist

\section{A. Equipment Stored in Instrument Cases}

\begin{tabular}{|c|c|c|}
\hline $\begin{array}{l}\text { Item } \\
\text { Nomber }\end{array}$ & Equipment & Amownt and condition \\
\hline 1 & Sulfuric Acid, $0.02 \mathrm{~N}$, & One dropper-bottle, full, carefully wrapped. \\
\hline 2 & Indicator & One dropper-bottle, full, carefully wrapped. \\
\hline 3 & Erlenmeyer Flask, $125 \mathrm{~mL}$ & Clean and inspect. \\
\hline 4 & $\begin{array}{c}\text { Conductivity Meter } \\
: \quad .:-\end{array}$ & $\begin{array}{l}\text { Calibrate instrument and check batteries daily; } \\
\text { chcck plastic bag for holes; call field } \\
\text { Supervisor for any repairs. Record reading of } \\
\text { standard. }\end{array}$ \\
\hline 5 & pH Meter & $\begin{array}{l}\text { Calibrate instrument and check batteries daily; } \\
\text { check plastic bag for holes; call field } \\
\text { Sippryisnr fnr any repairs. Record inttlal } \mathrm{pH} \\
\text { and pH } 10 \text { buffer readings. }\end{array}$ \\
\hline 6 & Data Forms & Enough (plus spares); keep dry. \\
\hline 7 & Maps & Check each map individually. \\
\hline 8 & Identification Cards & Keep handy at all times. \\
\hline 9 & $\begin{array}{l}\text { Wooden or Mechanical } \\
\text { Pencils (No. 2B) }\end{array}$ & Enough, plus spares. \\
\hline 10 & Aluminum Case & Inspect, clean, and dry. \\
\hline 11 & Paper Towels & Enough, plus spares. \\
\hline 12 & 500-mL Plastic Beaker & Keep clean. \\
\hline 13 & Scintillometer & Check calibration and record reading. \\
\hline 14 & Camera and Film & Inspect. \\
\hline 15 & Compass & Inspect. \\
\hline 16 & $\begin{array}{l}\text { Miclepore } 0.8 \mathrm{wn}(142 \mathrm{~mm}) \\
\text { Filter Memhranes }\end{array}$ & Enough (plus spares); handle very carefully. \\
\hline 17 & Filter Membräñe lweezers & Check Lundliluı. \\
\hline 18 & Spare Filter Support & Keep clean. \\
\hline 19 & Spare Filter D-Ring & Check condition. \\
\hline 20 & Plastic Graduated Cylinder & Clean and inspect. \\
\hline
\end{tabular}

B. Equipment Stored in Pressure Filter case

$\begin{array}{lll}1 & \text { Pressure Filter } & \text { Clean; dry; check cundition very carcfully. } \\ 2 & \text { Filter Wrench } & \text { Check condition. } \\ 3 & \begin{array}{l}\text { Squeeze Bottle of } \\ \text { Deionized Water }\end{array} & \text { One full bottle; keep spare bottle in car. } \\ & \begin{array}{l}\text { Fluorocarbon Gas Pressure } \\ \text { Can }\end{array} & \text { Enough, plus spare. }\end{array}$

C. Equipment Stored in Ion Exchange Resin Recovery Case

$\begin{array}{lll}1 & \text { 1-liter Plastic Bottles } & 28 \text { bottles; clean; rinse with deionized water; } \\ \text { and Caps } & \text { shake dry; and cap. } \\ & 28 \text { caps; clean; rinse with deionized water; } \\ \text { Interchange Caps } & \text { shake dry; store in clean plastic bags. } \\ 3 & \text { Bottle Holder } & \text { Check condition. }\end{array}$

D. Equipment Stored in Ion Exchange Stirring Case

$\begin{array}{lll}1 & \begin{array}{l}\text { DC Stirrer and PTFE } \\ \text { Coated Blade }\end{array} & \text { Check condition; carry a spare. } \\ 2 & \text { 6-volt Battery } & \text { Check for full charge; carry a spare. } \\ 3 & \text { 2-liter Water Collection } & \text { Clean and cap. } \\ \text { Plastic Bottle and Cap }\end{array}$




\section{TABLE B-2}

Ground Water Sampling Procedure Checklist

\section{A. At the Sampling Site \\ 1. Stirring Ion Exchange Resin Mixture}

2. Sample Site Approach

3. Water Collection

4. Data Form Site Description

5a. Water Filtration

5b. Conductivity-Temperature Measurements ${ }^{a}$

6. Ion Exchange

7. pH Measurement

8. Alkalinity Titration

9. Scintillometer Readings

10. Data Form Completion

11. Field Map

12. Clean=up and Storage

B. At the End of the Day

1. Ion Exchange Resin Recovery

2. Master Map Preparation

3. Form Check

4. Instrument Carc
Stop stirring the ion exchange resin mixture from the previous site when arriving at new site. Cap 1-liter bottle with 2 -ounce resin recovery bottle and place upside-down in ion exchange resin recovery case.

Obtain permission for access.

Collect 2 liters of ground water in plastic bottle after letting water run for 2 to 3 minutes (flush pipes thorough(y). Collect and cap sample for helium analysis.

Obtain necessary site descriptions, and well information."

Filter 1 liter of water at vehicle."

Measure temperature of unfiltered water; measure conductivity of unfiltered water.

Add ion exchange resin to correct amount of filtered water and start stirrer.

Measure $\mathrm{pH}$ of unfiltered water.

Titrate $50 \mathrm{~mL}$ of water with $0.02 \mathrm{~N} \mathrm{H}_{2} \mathrm{SO}_{4}$ solution until pink color of indicator is reached.

Record readings obtained at each sampling site.

Complete all entries, write site description on back, attach photo, and sign..

Enter and label site accurately.

Recurn equipment to case; remove all debris; police area.

Recover the resin into the properly labeled 2-ounce bottles and package for shipment to SRL.

Transfer the sice locations from the daily working maps to a clean, unfolded, master map.

Check each furim and resin bottle for accuracy, legibility, etc.

Check condition of drying agent. Check for moisture in instrument case, lcave open in room overnight.

a. Measure temperature and conductivity on a portion of ivater while filtration is in progress. 
TABLE B-3

Sediment Sampling Supplies

$\begin{array}{lll}\begin{array}{lll}\text { Item } \\ \text { Nhmber }\end{array} & \text { Equipment } & \text { Amount and Conditiur } \\ 1 & \text { Bag Sampler and Rope } & \text { Clean, check condition } \\ 2 & \text { Cloth Bags } & \text { Enough, plus spares } \\ 3 & \text { Scoop Sampler } & \text { Clean, check condition } \\ 4 & \begin{array}{l}\text { Stainless Steel Sieve } \\ \text { Assembly }\end{array} & \begin{array}{l}\text { Check condition, clean out } \\ \text { trapped particles }\end{array} \\ 5 & \text { Stainless Steel Spatula } & \text { Check condition } \\ 6 & \text { Paper Sediment Bags } & \text { Enough, plus spares } \\ 7 & \text { White Cord } & \text { Enough, plus spares } \\ 8 & \text { Cüting Tuul } & \text { Keep sharp } \\ 9 & \text { Flowmaster Pen } & \text { Full of ink, plus spare pen } \\ 10 & \text { 2-1iter Water Collection } & \text { Clean, check condition } \\ & \begin{array}{l}\text { Plastic Beaker and Cord } \\ \text { Cradle }\end{array} & \\ 11 . & \text { Hand Spade } & \end{array}$




\section{TABLE B-4}

\section{Procedure for Sampling at Stream Sites}

1. Secure permission from owner or his agent for sampling.

2. Find site, verify location.

3. Collect water sample and begin filtration.

4. Measure alkalinity, conductivity, and $\mathrm{pH}$. Use filtered water for alkalinity titration if sample is noticeably cloudy.

5. Collect $\backsim 60 \mathrm{~mL}$ of filtered water in $2-02$. bottle containing pre-measured acid.

6. Perform ion exchange, stir while sediment is collected.

7. Collect and sieve composited sediment sample.

8. Recover resin in field if off-road. Stow in rack if near vehicle.

9. Take scintillometer reading.

10. Complete Field Data Form. Check form and map for accuracy. Check labels on samples. Sign form.

11. Photograph site. Include diagnostic features. Attach photo to the Field Data Form.

12. Clean sieve. Turn off meters. Police area.

TABLE B-5

Procedure for Arid Area Sampling

1. Secure permission from owner or agent.

2. Select area as near to center of grid unit as possible.

3 . Use hand spade to scrape away top 2 to 3 inches of ground surface. Take one spadeful of material from this depth at 10 separate locations at least 10 feet apart. Composite the 10 or more samples onto a combination 18 - and 40 -mesh screen assembly. Bag and label the 18- to 40-mesh material and the -40 mesh material (in the lower pan) separately. Be sure to put mesh size and correct site code on both bags.

4. Complete the Site Description Field Data Form and mark the map. Sign form.

5. Photograph site. Try to frame prominent topograpiic features in background. Attach photo to Field Data Form.

6. Police area. 
THIS PAGE

\section{WAS INTENTIONALLY LEFT BLANK}




\section{APPENDIX C: Standard Coding Instructions}

\section{SAVANNAH RIVER LABORATORY GEOCHEMICAL SURVEY FIELD DATA FORM}

\section{General Statements}

A copy of the data form is shown in Figure C-1. All data to be entered on the SRL Field Data Form MUST be entered CORRECTLY and RIGHT JUSTIFIED in the appropriate columns of the $\overline{80 \text {-column }}$ form. The form MUST be completed using ONLY a No. 2B soft-lead wooden or mechanical pencil. All data forms and associated samples must be CHECKED for accuracy, correct format, and legibility.

All letters and numbers will be formed ONLY as shown below and at the bottom of each form:

\section{Standard Letters and Numbers}

\section{ABCOEFGHIJKLMNQPORSTUV.WXYZ}

\section{9}

Only those choices given on the form or in this manual are acceptable. DO NOT. IMPROVISE. When checking, be sure that all blanks are properly filled. ANY error will cause the data card to be rejected by the computer.

PAYMENT TO CONTRACTORS WILL BE MADE ONLY FOR THOSE SAMPLE LOCATIONS WHERE ALL APPROPRIATE DATA ARE UNAMBIGUOUSLY PROVIDED ON THE FIELD DATA FORM AND SAMPLE SITE LOCATION MAP:

Specific Coding

Columns 1-8

Site Code

Columns 1 and 2 are coded with the twoletter designator for the $1^{\circ} \times 2^{\circ}$ NTMS quadrangle in which the sample is collected, e.g., KF for Klamath Falls, $\mathrm{CH}$ for Challis, etc. These map codes are furnished with each sampling map. Only the official codes are acceptable.

Columns 3 and 4 are coded with the twoletter designator for the $15^{\prime}$ rectangle (Figure C-2) within the $1^{\circ} \times 2^{\circ}$ NTMS area. Sites should be consecutively numbered 


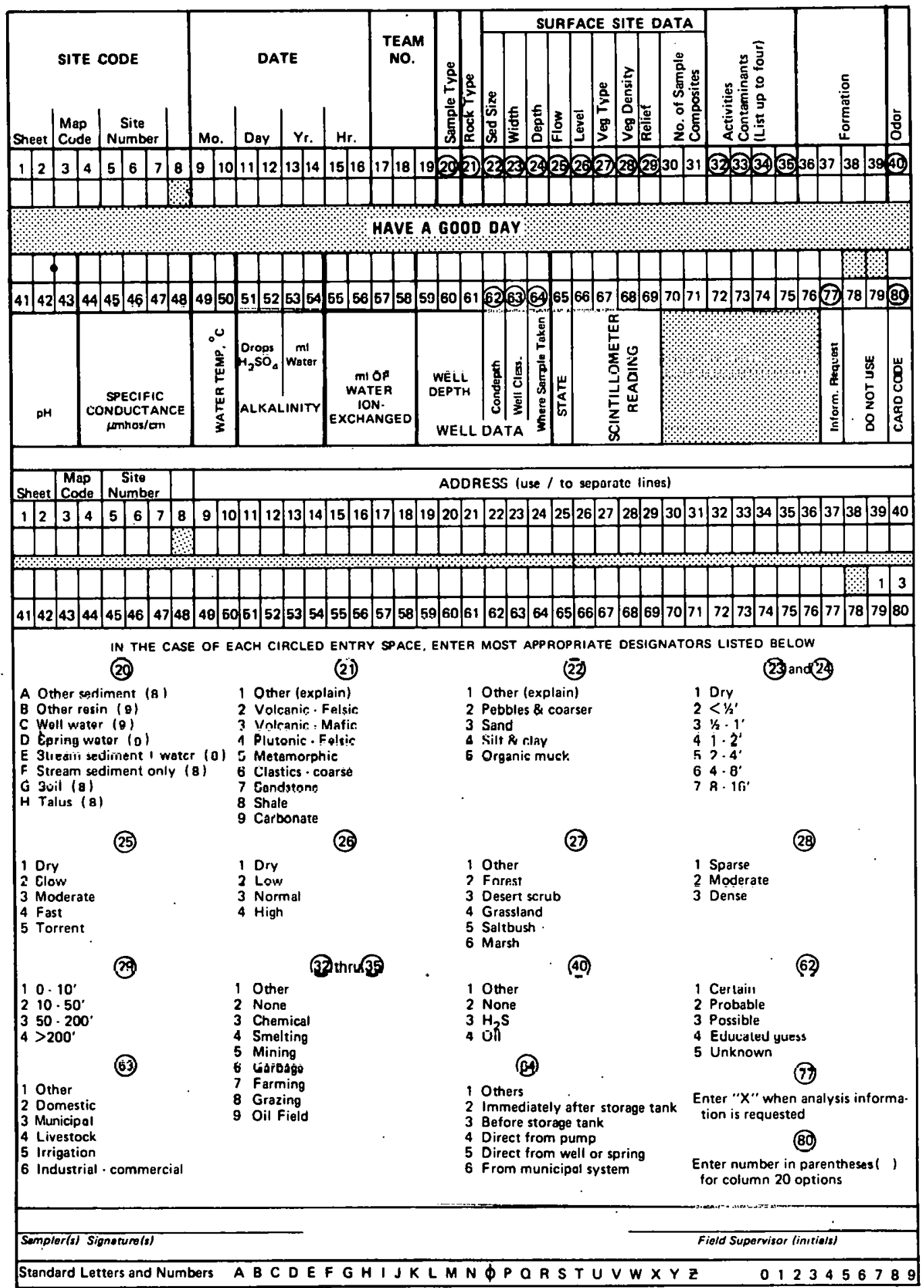

FIGURE C-1. SRL Field Data Form 


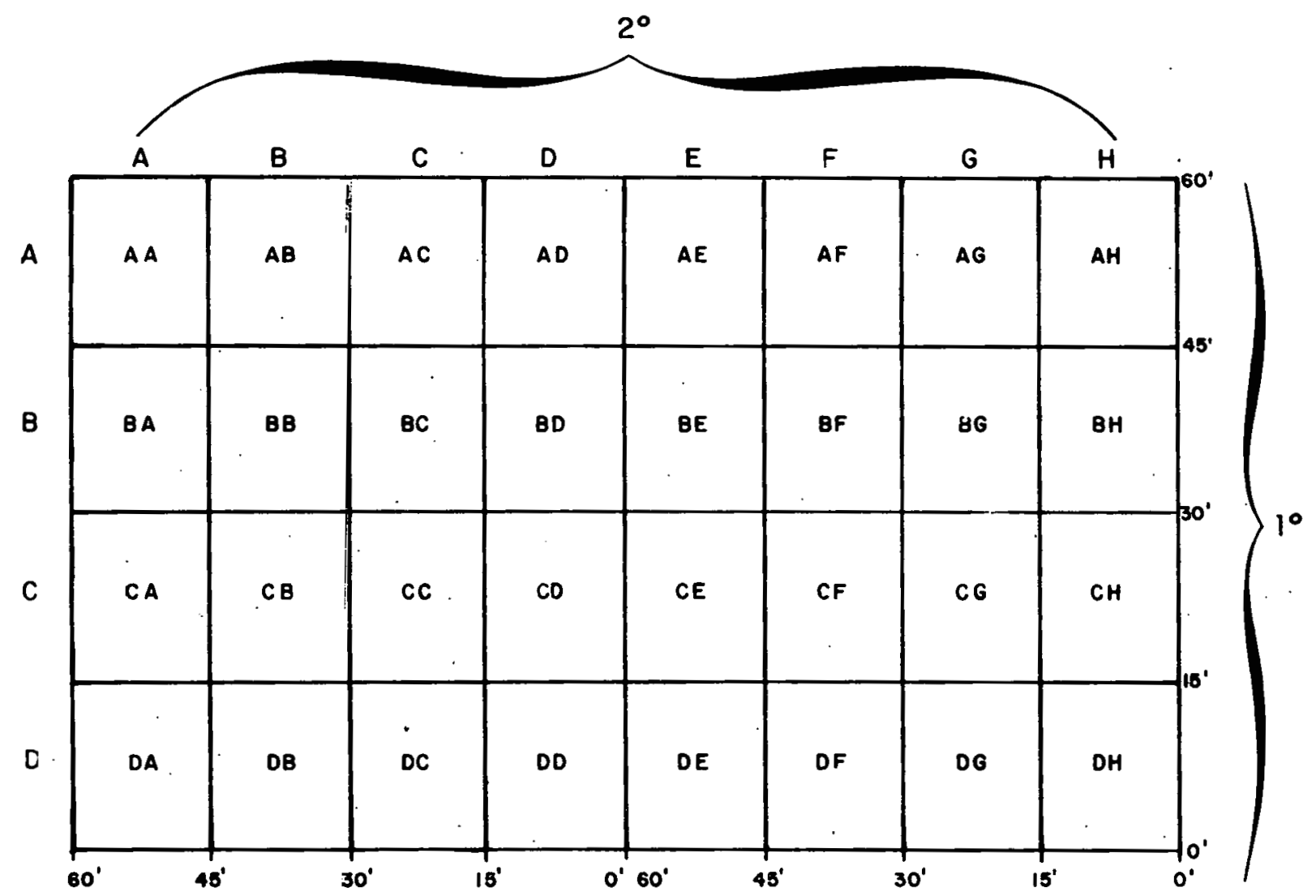

FígURE C-2. Codes for $15^{\prime}$ Rectangles Imposed on an. NTMS $1^{\circ} \times 2^{\circ}$ Quadrangle 
within each 15' map unit beginning with 001 for surface sites and 501 for ground water sites. No valid site codes should be skipped. Columns 1-7 should be filled. None should be blank. Column 8 is left BLANK.

EXAMPLE: Sample is taken from map unit $\mathrm{AA}, \mathrm{Klamath}$ Falls quadrangle; site is marked and numbered on the map with code AA: the site has been numbered as 14:

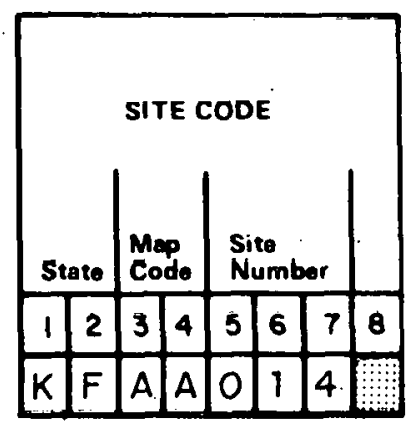

Columns 9-16

Date

The month, day, and year are to be coded in Columns 9-14 using one or two digits (right justified) as necessary, so that any unused columns are left blank.

The time (hour) will be coded in Columns 15-16 using the 24-hour clock, and rounding to the nearest whole hour (local timel. The hour entry will also he right. justified so that. Column 15 will remain blank when only one digit is appropriate.

EXAMPLE: Samplè taken on June 17, 1979, at 9:27 a.m.

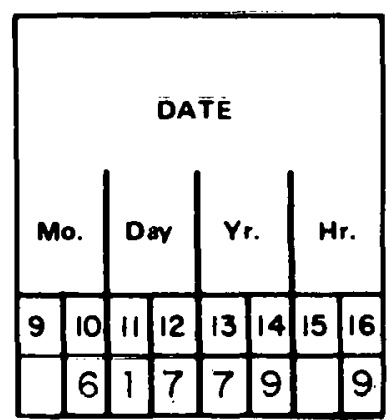


Sample taken on June 5, 1979, at $3: 35$ p.m.

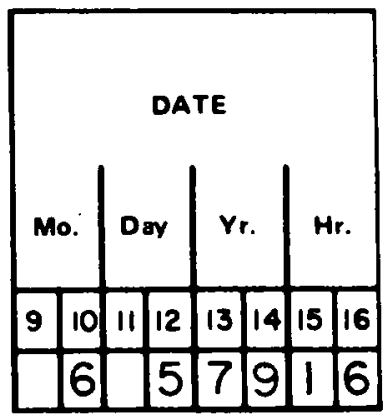

Columns 17-19

Team Number

The assigned team number is coded in Columns 17-19.

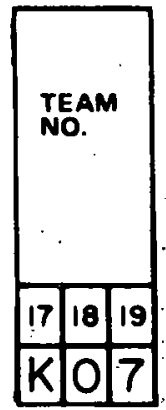

Column 20

Sample Type

A Other sediment (8)

B Other resin (9)

C Well water (9)

D Spring water (9)

E Stream sediment + water (8)

F Stream sediment oniy (8)

G Soil (8)

H Talus (8)

I Volcanic neck (8)

J Playa sediment (8)

$K$ Lake sediment (8)

L. Hot springs - sinter (8)

The column labeled "sample type" will be coded with the most appropriate description of the sample taken. The most common types of samples are listed on the field form. However, in some areas, supplementary samples may be taken and will be coded with the options listed in this manual but not on the field form. These extra samples are not intended to take the place of reconnaissance samples taken on a grid network.

The number in parentheses after each option is to be entered in Column 80 . A water sample exchanged with resin will require a "g" in Column 80 . Any sediment or soil sample, whether or not accompanied by resin, will require an "8" in Column 80 . 
EXAMPLE: Sample type is dry stream sediment.

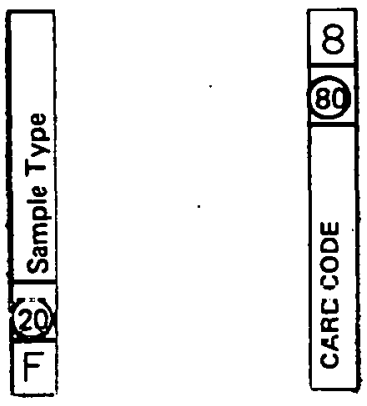

Columns 21-35

Surface Site Data

The surface site data columns are to be coded using only the most appropriate indicator descriptor listed on the form. Good judgment is important for these evaluations. Columns 22-31 will be blank only when the sample taken is a ground water sample.

\begin{tabular}{|c|c|c|c|c|c|c|c|c|c|c|c|c|}
\hline & \multicolumn{10}{|c|}{ SURFACE SITE DATA } & \multirow{2}{*}{\multicolumn{2}{|c|}{ 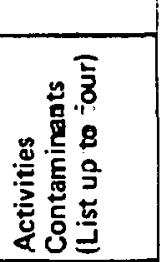 }} \\
\hline$\frac{j}{2}$ & 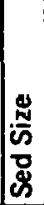 & $\frac{5}{\frac{5}{2}}$ & $\begin{array}{l}\text { 点 } \\
\text { 另 } \\
\text { ه }\end{array}$ & $\frac{3}{14}$ & 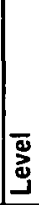 & 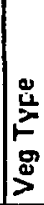 & 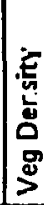 & 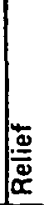 & & 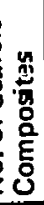 & & \\
\hline & 14 & (3) & 84 & 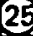 & 4 & 20 & 160 & $4<9$ & 30 & 31 & & \\
\hline 1 & 3 & 3 & 2 & 3 & 3 & 2 & 2 & 2 & & 7 & & \\
\hline
\end{tabular}

\section{Column 21}

Rock Type

(21)

1 Other (explain)

2 Volcanic - Felsic

3 Volcanic-Mafic

:4 Plutonic-Felsic

5 Metamorphic

- G Clastics - coarse

7 Sandstone

8 Shale

9 Carbonate

o Unconsolidated

valley fill
The rock type entry should reflect the predominant rock type present in the immediate vicinity of the sample site. Note that if Option 1 (other) is used, an explanation must be given at the bottom or on the back of the field form. Column 21 will be coded for surface samples and ground water samples. 
Sed Size

(22)

1 Other (explain)

2 Pebbles \& coarser

3 Sand

4 Silt \& clay

5 Organic muck

Columns 23-24

Width, Depth

(23) and (24)

1 Dry

$2<1 / 2$ '

$3 \frac{1}{2}-1^{\prime}$

$41 \cdot 2^{\prime}$

$52-4^{\prime}$

$64-8^{\prime}$

$78 \cdot 16^{\prime}$

Columns 25-26

Flow, Level

(25)

1 Dry

2 Slow

3 Moderate

4 Fast

5 Torrent

(26)

1 Dry

2 Low

3 Normal

4 High
The sed size entry should reflect the nature of. the loose sediment material sampled at the site. In cases where the sample material differs markedly from the surrounding sediment, this fact" should be noted in a comment.

If the sample is taken from a stream site, estimate the average width and depth of the stream over the approximately 100 feet of stream length where the sample is taken.

NOTE: Option 1 (Dry) will apply to dry streams and other types of surface samples such as soil and will be verified by the photograph of the site.

These columns should provide an indication of the general condition of stream water at the time of sampling. Column 25 is used to indicate the rate of flow at the sampling location. Column 26 describes the water level relative to its apparent normal level.

NOTE: Option 1 (Dry) will be used when sampling dry streams or other surface material such as soil. 
Veg Type

(27)

1 Other

2 Forest

3 Desert scrub

4 Grassland

5 Saltbush

6 Marsh

Veg Density

(28)

1 Gporse

2 Moderate

3 Detise

Column 29

Relief

(29)

$10 \cdot 10^{\prime}$

$210.50^{\circ}$

$350-200^{\circ}$

$4>2 \mathrm{na}^{\prime}$
These columns are used to describe the type and amount of plant growth in the immediate vicinity of the sample location. Column 27 should reflect the dominant plant type near the sample location. If Option 1 (other) is used, please explain your answer on the field form.

Density (Column 28) is a subjective observation made in relation to visibility, ease of access, etc. A key factor to consider is percentage of ground cover. A thickly forested area may be moderate if thcrc is 1ittlc undergrowth. $\overline{\Lambda \text { grassy }}$ area may be dense if there is virtually complete ground cover.

Relief is an indicator of local surface expression. The area to be included around a sampled location will usually not exceed a few liundred yards in mountainous terrains, but may exceed up to "ul/2 mile in relatively rlat areas. Where il appeais noleworthy to includc an area much larger or smaller than implied in the general guidelines above, a note should be included in the comments.

Columns $30-31$

Number of Samplc Composites

In Columns 30 and 31 , record the number of subsamples taken at each site that are composited together to give the sieved samples for that site. There should be a minimum of 5 subsamples (or composites) at wet sites, and 10 at dry sites. If Column 30 is not needed, it should be left blank. 


\section{Columns 32-35}

Activities;

Contaminants

(32) thru(35)

1 Other

2 None

3 Chemical

4 Smelting

5 Mining

6 Garbage

7 Farming

8 Grazing

9 Oil Field
Columns 32 through 35 will apply to surface site and ground water sites. The activities/contaminants column is to indicate those nearby activities which may influence the analytical results. It is a very important entry, and should be carefully chosen from the list of numerical designators provided on the data form. In addition to the numerical entry, details such as proximity to the sample site, type and status of mine (i.e., gold, silver, lead-zinc, coal, etc.) or power plant (i.e., hydroelectric, coal-fired, nuclear, etc.) should be indicated in the comments. The major activity and/or contamination is always listed in Column 35. A second activity, if you consider it important, is listed in Column 34. A third activity, if necessary, in Column 33, etc. Columns 32,33 , and 34 if not used are to be left biank.

Columns 36-39

Formation

Columns 36 through 39 should be used to indicate the geologic formation surrounding the sampling site. The first letter of the formation name is entered in Column 36 . The next three consonants in the formation name are entered in Columns 37,38 , and 39 . If the formation name is unknown, but the age of surrounding material. is known, the age may be entered in Columns 36-39. If neither formation nor age are known, "UNKN" is entered in Columns 36-39. For ground water sites, note under comments whether the formation is at the surface or in a deeper aquifer.

EXAMPLE: Formation surrounding sampling site is Dakota Sandstone.

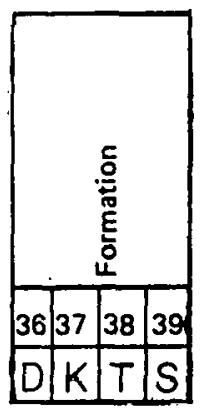


EXAMPLE: Formation is not known, but age is Cambrian.

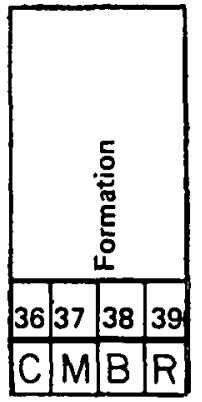

Columns 40-64 may he 1eft hlank at dry sites.

Column 40

Odor

(40)

1 Other

2 None

$3 \mathrm{H}_{3} \mathrm{~S}$

4 Oil
Code the appropriate descriptor of well or stream water odor in Column 40. If Option 1 (other) is used, please explain with comments.

Columns $41-4.3$

$\mathrm{pH}$

The $\mathrm{pH}$ of the sampled water is to be measured using the $\mathrm{pH}$ meter provided, and will be recorded to the nearest tenth $(0.1)$ of a $\mathrm{pH}$ unit.

If the $\mathrm{pH}$ is less than 10, only Columns 42 and 43 will be coded, and Column 41 will be left blank (only rarely will. the pll be greater thai 10, thus Columi 41 will normally romain blank). $\Lambda$ docimal point occurs hetween Columns 42 and 43 ,

EXAMPLES :
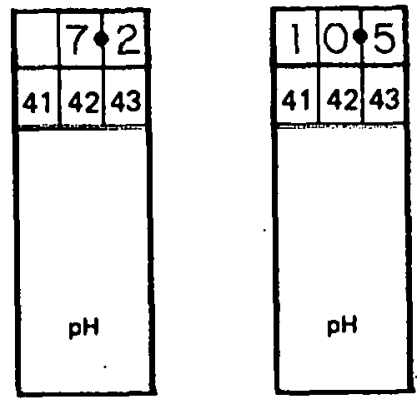
Specific Conductance, $\mu \mathrm{mhos} / \mathrm{cm}$

The conductivity measurement is recorded in Columns $44-48$ as read on the meter, or as some multiple of the meter reading which is determined by the scale range setting used. The conductivity reading must always be right justified so that any of the appropriately designated (but unused) columns will be left blank.

EXAMPLES:

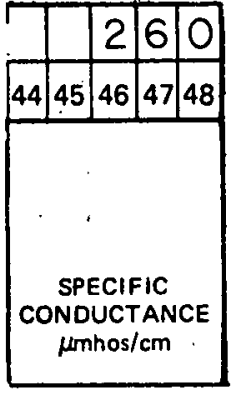

Meter reads 260 with scale Xl, record 260

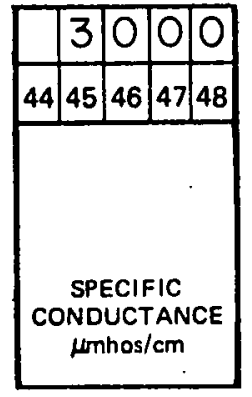

Meter reads 300 with scale $\mathrm{X} 10$, record 3000
Columns 49-50

Water Temperature, ${ }^{\circ} \mathrm{C}$
The water temperature, taken at the time of sampling, will be coded in Columns 49-50. The, water temperature will be recorded in degrees Celsius $\left({ }^{\circ} \mathrm{C}\right)$ to the nearest whole degree $\left(1.0^{\circ} \mathrm{C}\right)$. If the water temperature is between $0^{\circ} \mathrm{C}$ and $9^{\circ} \mathrm{C}$, the temperature will be coded in Column 50 , and Column 49 will remain blank.

\section{EXAMPLES :}


Columns 51-52

Alkalinity, drops of acid solution

Record in Columns 51-52 the number of drops of $0.02 \mathrm{~N}$ sulfuric acid solution necessary to reach the end point of the alkalinity titration. If 9 or fewer drops are used, then Column 51 is left blank.

\section{EXAMPLE :}

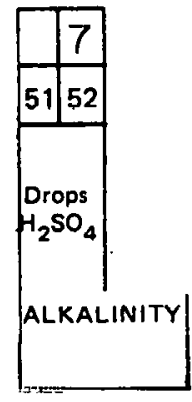

\section{Columns 53-54}

Alkalinitiy, $\mathrm{mI}$. of water

Enter in Columns 53 and 54 the actual number of milliliters of water used in the alkalinity titration. This amount is normally about $50 \mathrm{~mL}$, but may be as few as 5 to $10 \mathrm{~mL}$ in limestone areas. If less than $10 \mathrm{~mL}$ are used, enter a "0" (zero). in Column 53.

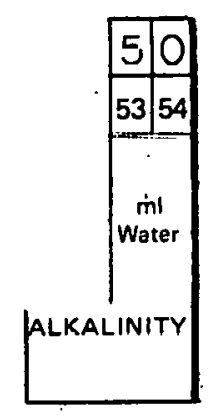


Columns 55-58

$\mathrm{mL}$ of Water Ion Exchanged

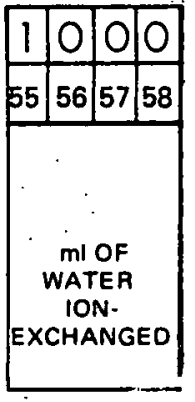

Columns 59-64

We11 Data

Columns 59-61

We11 Depth, ft

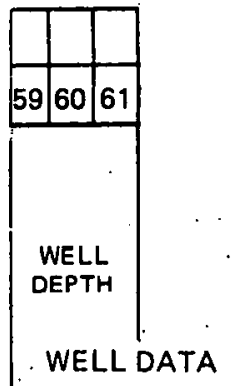

Column 62

Condepth

1 Certain

2 Probable

3 Possible

4 Educated guess

5 Unknown
:Record (to the nearest $10 \mathrm{~mL}$ ) the volume of water which is mixed with the ion exchange resin. Normally, this will be $1000 \mathrm{~mL}$ unless the specific conductance is too large. If less than $1000 \mathrm{~mL}$ is used, then Column 55 is left blank.
The wel1-data columns are to be coded using the most appropriate entries when the sample taken is a ground water sample.

Record the depth of the well to the nearest whole foot, using one to four digits (right-justified) as necessary, so that any unused columns are left blank. Free-flowing springs should have "zero" foot depth. If depth of well is totally unknown, code a slash (/) in Column 61:. An educated guess is strongly preferred over "unknown."

The degree of confidence with which the we11 depth is known is coded in Column 62 . If Column 61 is coded with a slash (/), then Column 62 must be coded with a " 5 " (unknown). 
EXAMPLE: Sample is taken from a well which the owner knows is 123 feet deep.

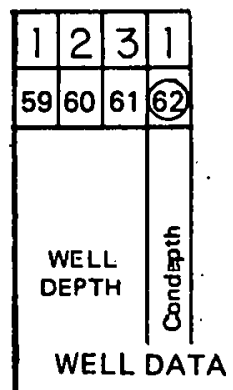

EXAMPLE: Sample taken from a spring.

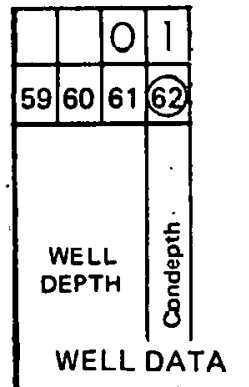

Column 63

Wel1 Classification

(63)

1 Other

2 Domestic

3 Municipal

4 I ivestork

5 Irrigation

6 Industrial - commerclal

Column 64

Where Sample Taken

(64)

1 Others

2 Immediately after storage tank

3 Before storage tank

4 Direct from pump

5 Direct from well or spring

6 From municipal system
The classification of the well sampled is coded in Column 63 using the most appropriate descriptor.

NOTE: A sample from an undeveloped spring would normally reyuire a "l" to be coded in. Column 63 .

The sampling location is coded in Column 64. Note that it is important to collect the sample as near the well head as possible. 
Column 65 is coded with the first letter of the state in which the sample is taken.

EXAMPLE: Sample is taken in Oregon.

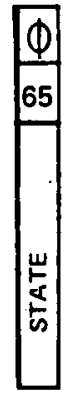

Columns 66-69

Scintillometer

The scintillometer reading in "counts per Reading second is recorded in Columns 66-69.

EXAMPLE: The scintillometer reads 80 on the 100 scale with full-scale. (F.S.) range set at $0.1 \mathrm{~K}$. Actual reading is $80 \mathrm{cps}$.

\begin{tabular}{|c|c|}
\hline & 1810 \\
\hline \begin{tabular}{l|l}
66 & 67 \\
\end{tabular} & \begin{tabular}{ll|l}
7 & 68 & 69
\end{tabular} \\
\hline & ס \\
\hline
\end{tabular}

EXAMPLE: The scintillometer reads 200 on the 300 scale with F.S. range set at $3 \mathrm{~K}$. Actual reading is $2000 \mathrm{cps}$.

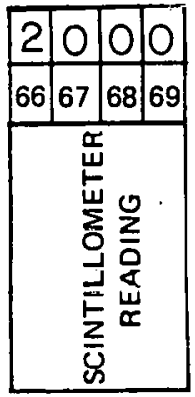


Columns $70-76$

Blank

Column 70 is coded with an $X$ when the sample is from a supplemental site. Columns 71-76 are not used and are to be left blank.

Column 77

Information Request

If you have had to agree to send analytical

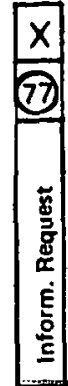
information to a person to gain access to his property, enter an $X$ in Column 77 . Remember to record the person's name and address in the spaces provided.

(77)

Enter " $X$ " when analysis information is requested.

Columns $78-79$

Blank

Columins 78 and 79 must be left blank.

Column 80

Card Code

Column 80 is coded with the appropriate number found in parenthesis for the Column 20 option used. This information is used to set up flles fur storagc of analytical data in the SRL computer.

(80)

Enter number in parentheses( ) for column 20 options 
General

This card is used to record the mailing address for owners of ground water sampling sites. If possible, give the name of the person who allowed the sample to be taken. The information on this card will be used to verify that the sample submitted to SRL was actually collected at the address given and to supply analytical information.

Specific Coding

Columns 1-8

Site Code

Sheet - Map Code Site Number

The Site Code must be coded exactly the same as the Site Code in Columns I-8 on Card above. Column 8 is always left blank.

Columns 9-77

Address

Code the mailing address from every site at which a ground water sample is taken. If an address cannot be given, then code slashes ( $/$ ) in Columns 9 and 10 and explain the reason in the "Comments" section. Slashes (/) are used to separate each line of the address. (Remember to include the Zip Code for each address.)

Columns 79-80

Card Code

The number 13 activates coding to store this address information properly.

Autuiliated data checking is performed on all cards received. All fields must be completed except where blanks are specifically allowed in the foregoing instructions. 
Site Description

A complete site description must be written on the back of every field form. You must include all information necessary to reach the site from a prominent landmark (such as a road intersection) and sufficient detail so that someone unfamiliar with the area can locate and unequivocally recognize the site once it is reached. A photograph of the sampling site and its surroundings must be stapled to the back of the field card.

FXAMPLE; From Death Valley Junction, site is $0.5 \mathrm{mi}$. north on CA Route $190 ; 0.3 \mathrm{mi}$. west of road, turn west off Rt. 190 onto dirt road at sign "Smith's Airport ahead." Stock well, concrete pond $\dot{b}$ f 1 ln diantelei. Trail lcads downhill to west. Radio towers visible on hilltop to southwest.

Automated data checking is performed on all cards received. All fields must be completed except where blanks are specifically allowed in the foregoing instructions.

CERTIFICATION: Sign the form where designated to certify that the sample(s) was (were) taken and treated as described, and that the information shown is as true and complete as possible. ALL members of the sampling party will sign the form. The field supervisor will also sign or initial the form to show that he has checked the form AND ASSOCIATED SAMPLE for accuracy, correct format, and legibility. All forms and samples should be checked by at least two diftèrènt people.

I certify that the above sample was taken by SAL procedures ot the indicated site and the information listed is correci ot time of amoling.

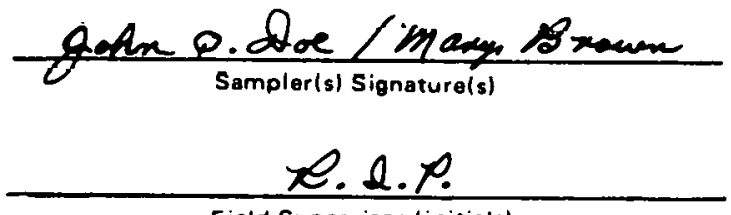

I hove checked this form and associated samples for accuracy. correct format, and legibility.

Field Supervisor (initials) 
APPENDIX D: Sampling Kit Inventory Forms

Form A. SRL/NURE Field Supervisor's Kit Inventory

Form B. SRL/NURE Sampling Kit Inventory 


Vendor
Date Issued _ _ ${ }^{\mathrm{BX}}$
Date Returned _ Checked By__

SRL/NURE FIELD SUPERVISOR'S KIT INVENTORY

NUMBER

\begin{tabular}{|c|c|c|c|}
\hline SHIPPED & RETURNED & & SERIML \# \\
\hline . & & $\begin{array}{l}\text { COMPLETE SAMPLING KIT CONSISTING OF } \\
\text { FOUR (4) CASES AND CONTENTS PER "NURE } \\
\text { SAMPLING KIT INVENTORY" (ATTACHED) }\end{array}$ & \\
\hline & & Adaptor, gas can to filter unit & \\
\hline & & Back-packs & \\
\hline & & Bag, Cloth, for bag sampler & \\
\hline & & Bag, Paper, for sieved samples & \\
\hline & & Bag, Plastic, for enclosing instrument & \\
\hline & & Batteries, AA & \\
\hline & & Batteries, D & \\
\hline & . & Batteries, 6 volt, rechargeable & \\
\hline & & Battery Charger & \\
\hline & & Bottle, dropping, plastic & \\
\hline & & Bottle, dropplng, plaslic & \\
\hline & & Bottle, soft drink & \\
\hline & & Brochure, public relations handout & \\
\hline & & Cappers, bottle & \\
\hline & & Caps, bottle & \\
\hline & & Column, charcoal & \\
\hline & & Column, ion exchange resin & \\
\hline & & Cülumn, universal & \\
\hline & & Caps, interchange, for 1 -1iter bottles & \\
\hline & & Caps, interchange, for $\frac{1}{2}-11$ ter bollles & \\
\hline & & Uroppers, Medicine, for alkalintty lesl & \\
\hline & & Dessicant, Silica-Gel, with indicator & \\
\hline & & Film, Polaroid $d^{(8)}$ Type 667 & \\
\hline & & Filters, Plastic Membrane, $0.8 \mu \mathrm{m}$ Pore & \\
\hline & & Filter Support, fritted plastic disc & \\
\hline & & Forms, Field Data (green) & \\
\hline & & Freon, 12- or 14-ounce canisters & \\
\hline & & 0 -rings, assorted spares for Filter Unit & \\
\hline
\end{tabular}


NUMBER

\begin{tabular}{|c|c|c|c|}
\hline SHIPPED & RETURNED & & SERIAL \# \\
\hline & & \begin{tabular}{|l} 
Pen set, Rapidometric \\
(1 pen, 1 template, ink) \\
\end{tabular} & \\
\hline & . & Probe, conductivity & \\
\hline & & Probe, $\mathrm{pH}$ & \\
\hline & & Solution, alkalinity test $\left(0.02 \mathrm{~N} \mathrm{H}_{2} \mathrm{SO}_{4}\right)$ & \\
\hline & & $\begin{array}{l}\text { Solution, conductivity standard } \\
(0.001 \mathrm{M} \mathrm{KCl})\end{array}$ & \\
\hline & & Solution, indicator & \\
\hline & & Solution, pH 4 standard & \\
\hline & & Solution, pH 7 standard & \\
\hline & & Solution, pH 10 standard & \\
\hline & & Staples & \\
\hline & & Stirrer Motors & \\
\hline & & Stirrer Shafts, long & \\
\hline & & Stirrer Shafts, short & . \\
\hline & & Syringe, $5 \mathrm{~mL}$ & \\
\hline & & Syringe with filter, $50 \mathrm{~mL}$ & \\
\hline & & Tape, plastic, white & \\
\hline & & Tubinq, plastic, $\frac{1}{3}-i n$. diameter & \\
\hline
\end{tabular}


MATERIAL ISSUED/RETURNED

SRL-NURE PROGRAM

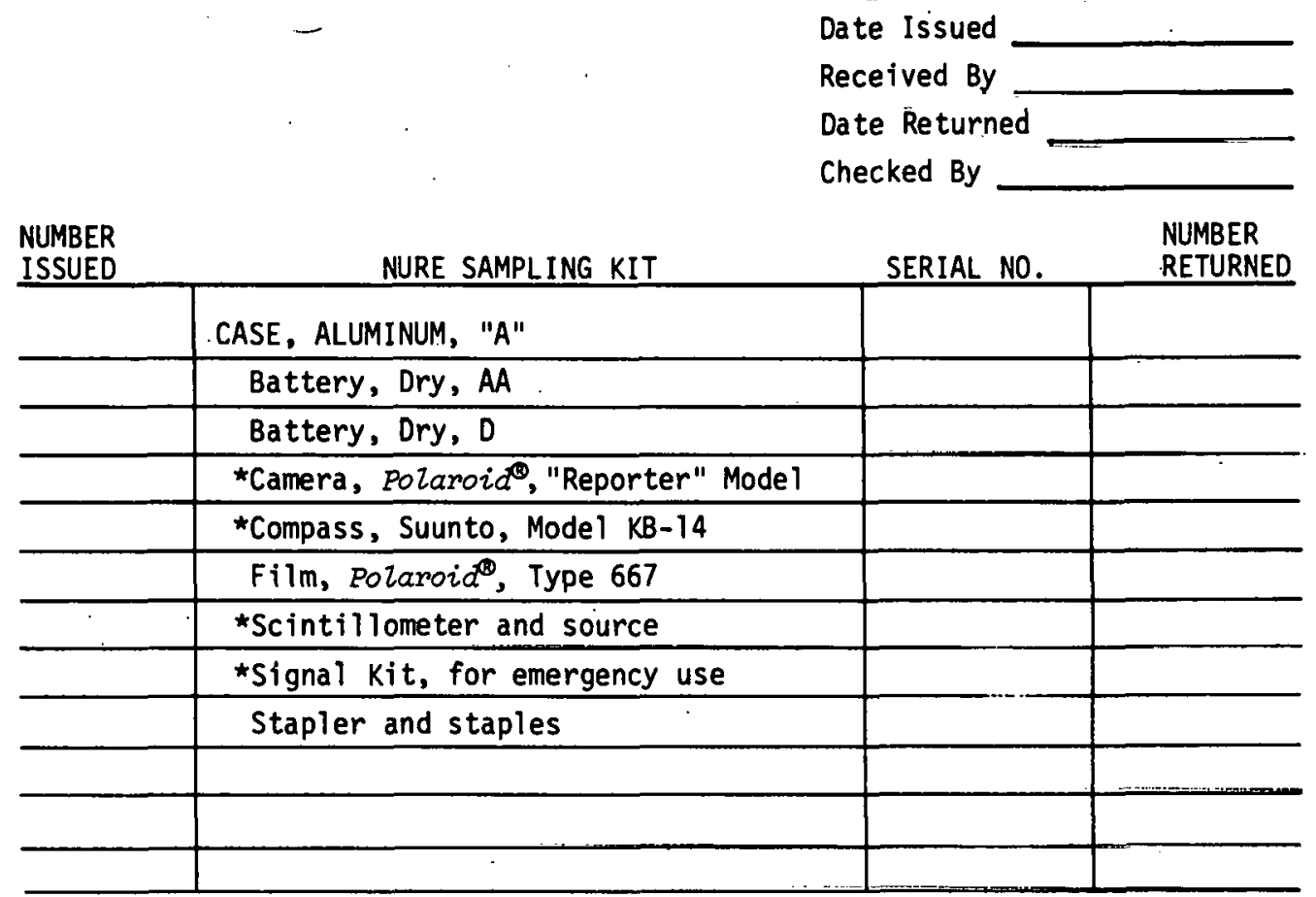

* Items to be returned to SRL in original cases. 
MATERIAL ISSUED/RETURNED

SRL-NURE PROGRAM
Vendor

AX

Date Issued

Received $B y$ Date Returned

Checked By

\begin{tabular}{|c|c|c|c|}
\hline $\begin{array}{l}\text { NUMBER } \\
\text { ISSUED } \\
\end{array}$ & NURE SAMPLING KIT (Cont'd) & SERIAL NO. & $\begin{array}{l}\text { NUMBER } \\
\text { RETURNED } \\
\end{array}$ \\
\hline & CASE, ALUMINUM, "B" & - & \\
\hline & *Beaker, $600 \mathrm{~mL}$, plastic & & \\
\hline & *Bottle, dropping, plastic & & \\
\hline & $\star C y l$ inder, graduated, $50 \mathrm{~mL}$ & & \\
\hline & «Flask, Erlenmeyer, $125 \mathrm{~mL}$ & & \\
\hline & * Meter, Conductivity, with probe & & \\
\hline & *Meter, pH, with probe & & \\
\hline & *Scoop, plastic, small & & \\
\hline & Solutions, standard, $\mathrm{pH} 4,7$, and 10 & . & \\
\hline & 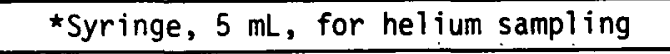 & $\therefore$ & \\
\hline & *Syringe, $50 \mathrm{~mL}$, with filter & & \\
\hline & *Tweezers & . & \\
\hline & & $\cdot$ & \\
\hline & & & \\
\hline & & $\therefore$ & \\
\hline
\end{tabular}

* Items to be returned to SRL in original cases. 
MATERIAL ISSUED/RETURNED

SRL-NURE PROGRAM
Vendor

I.

Ax

Date Issued

Received By

Date Returned

Checked By

NUMBER

NURE SAMPLING KIT (Cont'd)

SERIAL NO.

NUMBER

RETURNED

CASE; GREY PLASTIC, "C"

*0-rings, assorted spares for

filter unit

*Pen set, Flowmaster ${ }^{\circledR}$ (1 pen, ink, and spare tips)

*Pip Pins, for scoop sampler

*Sampler, Bag, with rope and Z-clamps

* Sampler, Scoop, with handle and cord

* Sieve (18 mesh)

*Sieve (40 mesh)

*șieve Pan (bottom)

*Sieve Top

Solution, conductivity standard

$(0.001 \mathrm{M} \mathrm{KC1})$

Sulution, $\mathrm{PH} 4$ standard

Solution, $\mathrm{pH} 7$ standard

Solution, $\mathrm{pH} 10$ standard

*Stirrer, long shaft

*Stirrer, short shaft

*Syringe, plastic, $50 \mathrm{~mL}$

Tape, plastic, white, 1-in. wide

Tape, plastic, white, 2-in. wide

*Thermometer

Tubing, plastic, 1/2-in. diam. $x$ 6 -in. long

* Items to be returned to SRL in original cases. 
MATERIAL ISSUED/RETURNED

SRL-NURE PROGRAM
Vendor

AX

Date Issued

Received By

Date Returned

Checked By

NUMBER

NURE SAMPLING KIT (Cont'd)

NUMBER

ISSUED

CASE, GREY PLASTIC, "C"

*Adaptor, gas can to filter unit

Bag, Cloth, for bag sampler

Bag, Paper, for sieved samples

Bag, Plastic, $7 \times 12$ inches

Bag, Plastic, $12 \times 1.4$ inches

*Batteries, 6 Volt, rechargeable

*Battery Charger, 6 Volt

*Bottle, $500 \mathrm{~mL}$ wash

*Brush, sieve

*Capper, Bottle

*Case, Grey, small

*Cl ip Board

*Column, Charcoal

*Column, Ion Exchange Resin

${ }^{\star}$ Column, Universal

*Desiccant, Silica Gel, with indicator

*Filter, Unit and Case

*F1lter Support, fritted plastic disc

*Filter Wrench

*Garden Trowe 1

*Graduated Cylinder, $1000 \mathrm{~mL}$

*Items to be returned to SRL in original cases. 
MATERIAL ISSUED/RETURNED

SRL-NURE PROGRAM
Vendor

Ax

Date Issued

Received By

Date Returned

Checked By

\begin{tabular}{|c|c|c|c|}
\hline $\begin{array}{l}\text { NUMBER } \\
\text { ISSUED } \\
\end{array}$ & NURE SAMPLING KIT (Cont'd) & SERIAL NO. & $\begin{array}{l}\text { NUMBER } \\
\text { RETURNED } \\
\end{array}$ \\
\hline & CASE, GREY PLASTIC, "D" & & \\
\hline & *Bottle Rack & & \\
\hline & *Bottles, 1 liter, polyethylene & & \\
\hline & *Bottles, 2 liter, polyethylene & & \\
\hline & *Bottles, $500 \mathrm{~mL}$, polyethylene & & \\
\hline & $\begin{array}{l}\text { *Caps, interchange, for 1-liter } \\
\text { bottles }\end{array}$ & & \\
\hline & $\begin{array}{l}\text { *Caps, interchange, for } 1 / 2-1 \text { iter } \\
\text { bottles }\end{array}$ & & \\
\hline & & & \\
\hline & & & \\
\hline & & & \\
\hline
\end{tabular}

* Items to be returned to SRL in original cases. 